FINAL TECHNICAL REPORT

\title{
DEVELOPMENT OF THE INSTRUMENTATION AND MODELING FOR HEAT TRANSFER CHARACTERISTICS IN CFBC
}

TO

U.S. DEPARTMENT OF ENERGY

NATIONAL ENERGY TECHNOLOGY LABORATORY

P.O. BOX 10940, MS 921-118

PITTSBURGH, PA 15236-0940

FOR

PROJECT NO.: DE-FG22-95MT95013

BY

DR. SEONG W. LEE, PRINCIPAL INVESTIGATOR

MORGAN STATE UNIVERSITY

SCHOOL OF ENGINEERING

BALTIMORE, MD 21239

(Phone) 443-885-3106 


\section{TABLE OF CONTENTS}

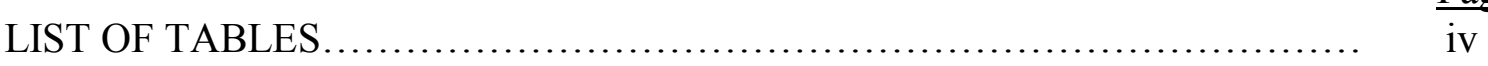

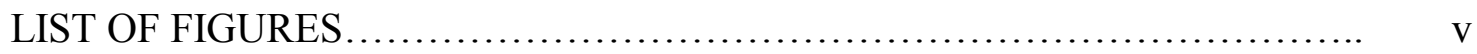

\section{CHAPTER}

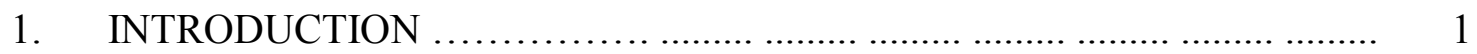

2. BENCH-SCALE CIRCULATING FLUIDIZED BED (CFB) TEST

FACILITIES …....................................................................... 5

2.1 Design and Fabrication of the Bench-Scale CFB System ..................... 5

2.2 Auxiliary Subsystems for the Bench-Scale CFB Model ....................... 14

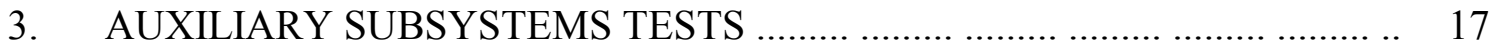

3.1 The Characteristics of a Regenerative Blower........................ 17

3.2 The Characteristics of Gas Distributor and Cyclone..................... 19

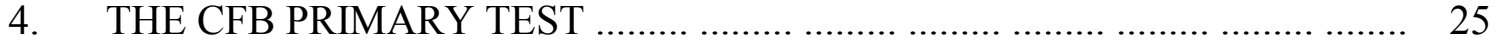

4.1 Characteristics of Bed Materials ................................................ 25

4.2 Test No.1 with Glass Bead ...................................................... 25

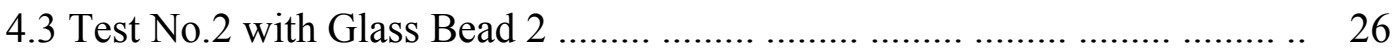

4.4 Test No.3 with Glass Bead 4 .................................................... 27

5. DATA ACQUISITION SYSTEM …............................................ 29

5.1 Development of Pressure Sensor Data Acquisition System ................... 29

6. DEVELOPMENT OF THE INSTRUMENTATION FOR PRESSURE

MEASUREMENT .................................................................... 32

6.1 Pressure Measurement System for the CFB Riser ............................. 32

6.2 Pressure Transducer Calibration .................................................. 32

6.3 Test Results and Discussion ................................................ 35

7. SYSTEM TEST OF CFB COLD FLOW MODEL ................................. 40

7.1 Experimental Apparatus and Procedures ....................................... 40

7.2 Results and Discussion ........................................................... 41

8. MEASUREMENTS OF THE GAS AND PARTICLE FLOW FIELDS ......... . 48

8.1 Test Conditions ..................................................................... 48

8.2 Results and Discussion ............................................................ 48

8.2.1 Test with Lower Gas Superficial Velocity ................................ 48

8.2.2 Test with Higher Gas Superficial Velocity .............................. . 53

9. DESIGN AND ARRANGEMENT OF THE HEAT TRANSFER PROBE..... 61

9.1 Heat Transfer Mechanisms and Theory............................. 63 
9.2 Experimental Results of Heat Transfer Rate and Characteristics

10. NUMERICAL SIMULATION FOR THE CFB COLD MODEL WITHOUT

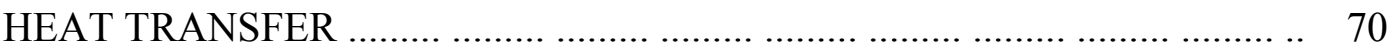

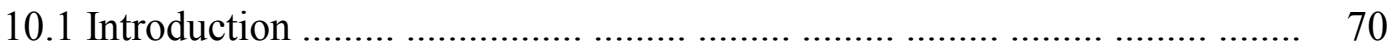

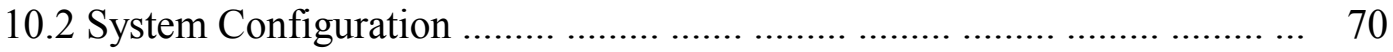

10.3 Basic Physical Modeling ............................................................... 71

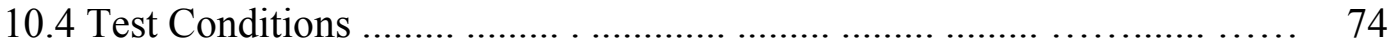

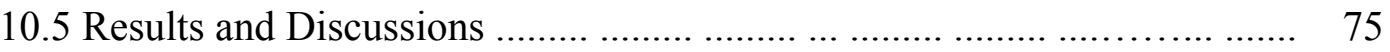

10.5.1 The Effect of Air Pressure ……......................................... $\quad 75$

10.5.2 The Effect of Air Velocity ……............................................. 84

11. NUMERICAL SIMULATION FOR THE CFB COLD MODEL WITH

HEAT TRANSFER ...................................................... 90

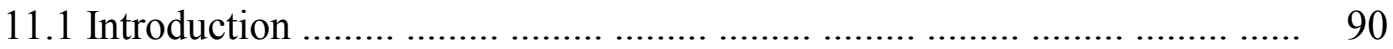

11.2 System Configuration ............................................................ 90

11.3 Basic Physical Modeling for Flow and Heat Transfer ............................ 91

11.4 Calculations Conditions for Isothermal Gas Flow ........................... 93

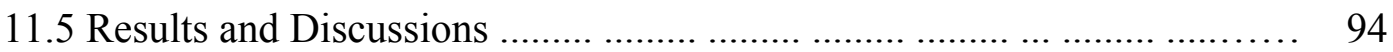

11.5.1 The Effect of Air Velocity ................................................... 94

10.5.2 The Effect of Air Pressure …................................................... 99

10.5.3 The Effect of Temperature ….............................................. 102

10.6 Heat Transfer Characteristics ...................................................... 106

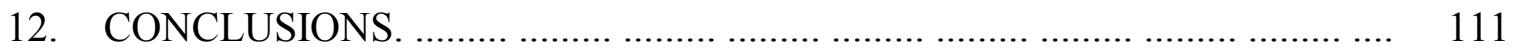

REFERENCES ............................................................. 114 


\section{LIST OF TABLES}

1. Page

1. Glass Bead Particle Properties .......................................................... 25

2. $\quad$ Planned Test Matrix..................................................................... 48

3. Test Conditions for Simulation ........................................... 74

4. Calculation Conditions for Numerical ........................................ 93 


\section{LIST OF FIGURES}

1. Schematic Diagram of the Gas Distributor (Flat Perforated Plate)............ $\frac{\text { Page }}{6}$

2. Schematic Diagram of the Cyclone System............................... 8

3 Schematic Diagram of the Wind Box ................................. 10

$4 \quad$ Schematic Diagram of the Surge Tank ................................... 11

$5 \quad$ Schematic Diagram of the Solid Control Valve............................ 13

$6 \quad$ Schematic Diagram of the Bench-scale CFB System....................... 16

7 The Regenerative Blower Pressure Characteristics at Standard Condition...... 18

8 The Regenerative Blower Pressure Characteristics at Open bypass Valve Conditions.............................. 20

$9 \quad$ Chamber Pressure and Riser Pressure Drop............................. 23

10 Gas Distributor and Cyclone Characteristics.............................. 24

11 Solid Recirculation Rate vs. Aeration Valve Opening...................... 28

12 Arrangement of Pressure Measurement in the Bench-Scale Circulating Fluidized Bed System.............................................. 33

13 Instrumentation for Pressure Transducer Calibration System................ 34

14 Differential Pressure vs. Column Height.................................... 37

15 Differential Pressure vs. Column Height................................ 38

16 Differential Pressure vs. Column Height................................. 39

17 Gas Flow Rate vs. Pressure Drop of Pitot Probe............................ 42

18 Air Flow Rate vs. Primary Air Temperature.............................. 43

19 Solid Feed Rate vs. Aeration Air Flow Rate.................................. 45

20 Pressure Change of Riser Column vs. Solid Feed Rate........................ 46

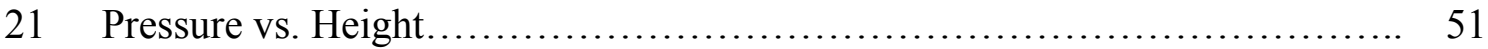


$22 \quad$ Pressure vs. Height .................................................. 52

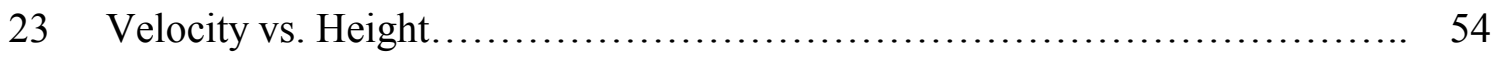

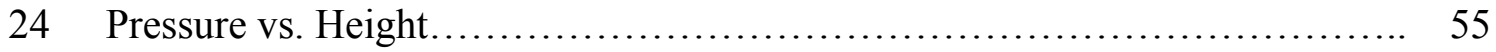

$25 \quad$ Pressure vs. Height .................................................. 58

26 Void Fract. Vs. Height................................................ 59

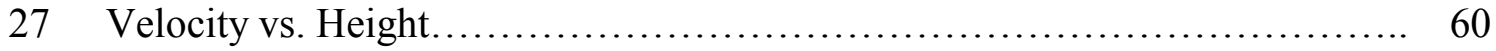

28 Schematic Diagram of the Bench-scale CFD System With the Heat Transfer Probe............................................................. 62

29 Heat Transfer Coefficient Changes with the Probe Height.................... 67

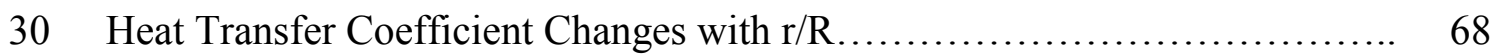

31 Flow System and Velocity Component in CFB Riser...................... 72

32 Velocity Vector along the CFB Riser................................... 76

33 Velocity Profiles in the Vertical Direction of CFB Riser..................... 77

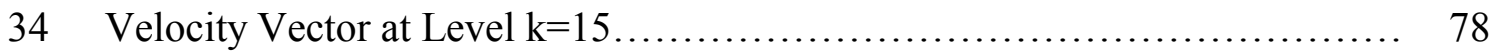

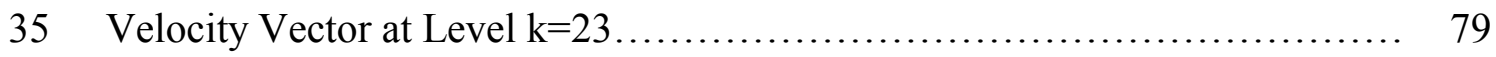

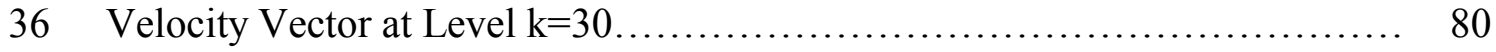

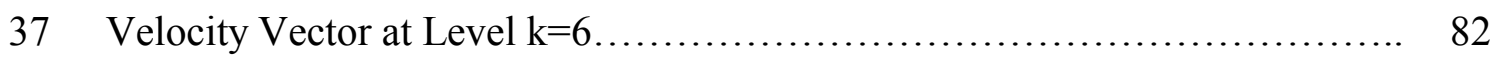

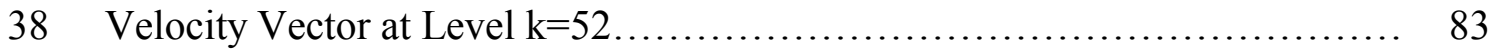

39 Pressure Profiles along the CFB Riser................................. 85

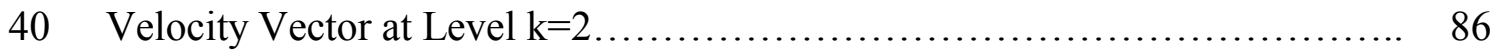

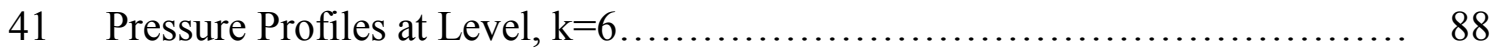

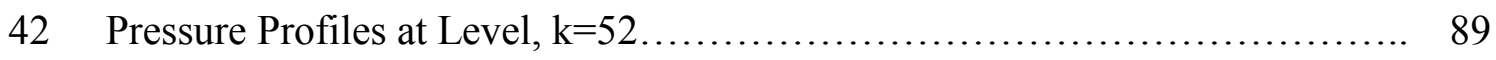

43 Velocity Profiles along the CFB Riser.................................. 95 
44 Velocity Profiles in the CFB Riser with a Heat Transfer Probe............... 96

45 Velocity Profiles at Level, $\mathrm{k}=23$ (Heat Transfer Probe Inlet Location)........ 98

46 Static Pressure Profiles along the CFB Riser.......................... 100

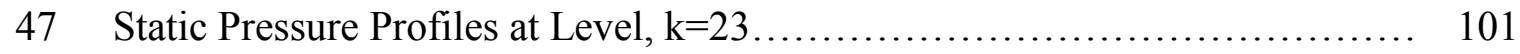

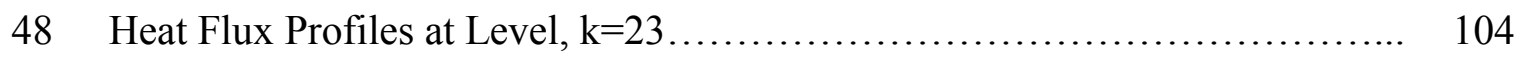

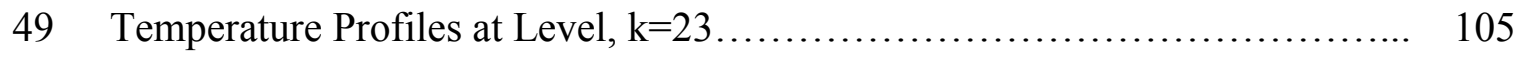

50 Temperature Change along the CFB Riser............................ 108

51 Heat Flux Profiles along the CFB Riser.............................. 109 


\section{INTRODUCTION}

Fluidized bed combustion (FBC) has grown in recent years because it can burn high-sulfur coal in an environmentally acceptable manner without the use of flue-gas scrubbers. In FBC, there are lower levels of nitrogen oxides compared to other combustion methods. Additionally, low bed temperatures of $\mathrm{FBC}$ systems help eliminate the potential for slag formation on the waste-cooled walls of the boiler, while high heat transfer in the fluidized bed permits a more economical boiler design.

Despite of these advantages, several undesirable features $[1,2]$ were

found to be inherent with this first generation FBC boiler systems; Problems with solids feeding, relatively low combustion efficiency due to unburned coal particles from the existing freeboard, low calcium utilization of sorbents for sulfur retention, which might affect the emission of pollutants and elutriations of fines, erosion of in-bed tubes [3], and poor load following capability. As well, conventional FBC designs produce large variations in heat transfer rate from the fluidized bed. Generally, these changes in heat transfer rate are modest, but are accompanied by degradation in combustion. So, the innovative concepts in bed design are required to control heat transfer independently.

To remedy the problems found in conventional FBCs, a system employing the concept of a circulation fluidized bed boiler (CFB) was then developed to improve the performance of bubbling FBC boilers. In this system, as shown in Figure 1, coal and lifestone delivered from the storage piles are pulverized, and conveyed to separate storage bins. From there, the pulverized coal and limestone are gravimetrically fed to the solid inductor, injects them into the boiler near the bottom. At the same time, primary 
combustion air from the FD fan discharge is preheated conventionally, using flue gas and fed into the CFB through a bottom air plenum chamber.

The bottom portion of the boiler is refractory lined to eliminate high heat losses in the primary combustion zone. The upper portion of the boiler contains evaporative waterwalls with sufficient heat removal capability to maintain $1550^{\circ} \mathrm{F}$ gas/solids average temperature with the furnace [4]. Secondary combustion air is injected into the boiler above the refractory bottom-portion of the furnace to complete combustion and improve $\mathrm{SO}_{2}$ removal and $\mathrm{NO}_{\mathrm{x}}$ removal for emission control. The solids carried from the furnace are separated from the gas by a primary cyclone. To further reduce the solids loading before entering the convective pass of the steam generator, a second high-efficiency cyclone is used. Solids discharged from the bottom of the primary cyclone pass through a solid diverted system. The major portion of the cyclone solids is diverted to a solids heatrecovery $\mathrm{FBC}$ system and the remainder is reinjected into the bottom of the CFB.

Heat extracted from the solids heat-recovery bed is used for additional evaporation and super heating. Air for fluidization of these beds comes from a separate air fan. Because no combustion occurs in the bed, this secondary air is also heated by the solids and discharged to the CFB above the refractory section.

The gas velocities are 3 to 4 times as high as in conventional bubbling fluidized beds. As a consequence, a high-density bed cannot form and all of the solid particles are carried up through the boiler. A more uniform lower-density gas/solid mixture exists throughout the entire boiler. The solids move through the boiler at much lower velocity than the gas; solids residence times are on the order of minutes. The long residence times coupled with the small particle size produce high combustion efficiency and high $\mathrm{SO}_{2}$ 
removal with much lower limestone feed. The small particle size and controlled fluidizing velocity produce in-bed tube heat transfer rates three to four times greater than in conventional bubbling fluidized bed thus minimizing the size and cost of the entire solids heat-removal subsystem. Solids are discharged from one end of the solids heatrecovery bed, after which some solids are diverted to the waste-disposal system to maintain a constant system-solids inventory.

Advantages of the CFBC system over the conventional bubbling FBC system include higher combustion efficiency (97\%-99.5\%), increased limestone use due to the greater efficiency of smaller particle sizes and long solids residence time in CFB boiler, reduced $\mathrm{NO}_{\mathrm{x}}$ formation resulting from staged combustion, a simpler control system due to the separation of combustion and heat transfer in the solids heat-recovery bed, and a high turndown ratio resulting from the large ratio between operating gas velocity and the solids suspension velocity in CFB boiler.

Although CFB boilers have today reached commercial status, there is still much to learn about the heat transfer and hydrodynamics, which take place in the combustion chamber of a CFB. The particle connective component is of key importance in these processes and is controlled by the particle flux to the heat transfer surface. No existing correlations of heat transfer characteristics in the CFB give consistent agreement with the available data.

The objective of this research is to measure the heat transfer and processes of hydrodynamics to the walls of the combustion chamber of CFB and to analyze the data by means of a computer simulation. The instrumentation will be developed for measuring the local heat transfer rate effectively in CFB. Furthermore, a comparison will be made 
with available heat transfer data found in the literature. Finally, this work is expected to provide design guidelines of the heat transfer surfaces in CFB and an innovative concept to maintain constant, optimum combustion temperature over the complete operating load range of the CFB system.

\section{BENCH-SCALE CIRCILATING FLUIDIZED BED (CFB) TEST FACILITIES}

\subsection{Design and Fabrication of the Bench-Scale CFB System}

The bench-scale circulating fluidized bed (CFB) system was carefully designed/fabricated to better understand the fluid dynamics of gas/particle flow and to study the bed-surface heat transfer phenomena on the wall of the CFB riser. Design of the major components in the bench-scale CFB system is summarized as follows;

Gas Distributor:

The design of the gas distributor is an important factor in determining the overall performance of fluidized bed process. The quality of bubbling fluidization, the system pressure drop, and the degree of solid-gas contact are strongly influenced by the type of gas distributor [5].

A simple flat perforated plate, as shown in Figure 1 was chosen for this study. This type of gas distributor is widely used for industrial and laboratory-scale operations because it retains the advantages of the single plate such as ease of design and construction, and is combined with good gas distribution.

An actual hole size of the distributor is 0.0625 inches. The opening rate is 3.03 $\%$ with total 152 holes. The pressure drop from the gas distributor is 3.94 inches of water which is about $10 \%$ of the total riser pressure drop. 


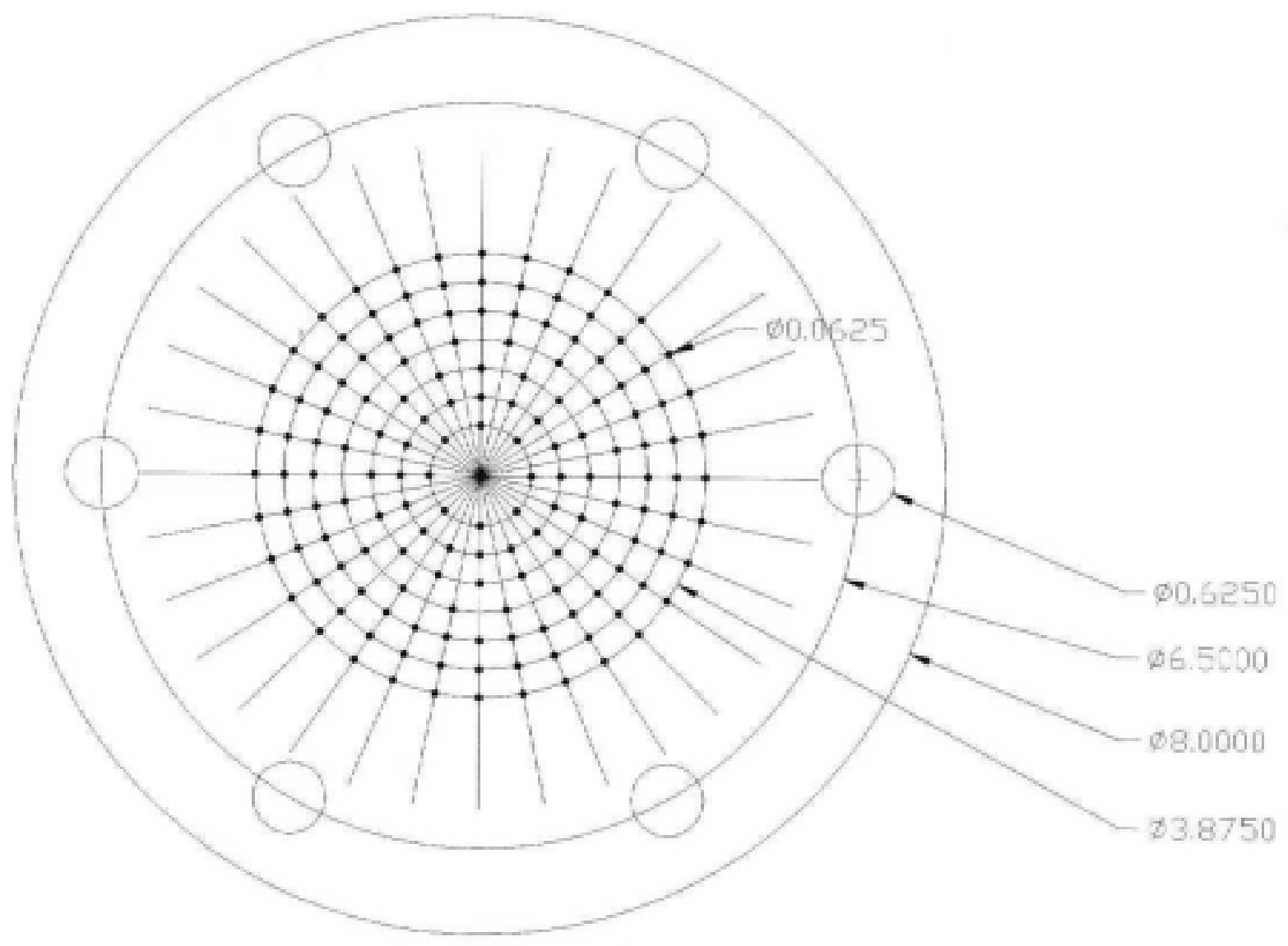

Figure 1 Schematic Diagram of the Gas Distributor (Flat Perforated P1ate) (A11 dimensions are inches) 
Cyclone:

The cyclone system achieves particulate removal by centrifugal, inertial, and gravitational forces. The cyclone depends on the centrifugal separation of the particulate phase to the walls, as a result of the turn of the gas/solids stream as it enters. The efficiency is thus a function of the velocity of the stream entering the cyclone and turning angle, which is related to the diameter of the barrel section of the cyclone [6].

As shown in Figure 2, the cyclone is designed and fabricated by plexiglass. The gas flow turns downwards from the cylindrical barrel section into the lower conical section. At the bottom, the gas flow turns upwards, forming a central ascending vortex. The separation between the exit clean gas flow and the inlet dirty gas stream can sometimes be improved by a central cylindrical tube, which forms a downward extension of the exit duct.

The design of cyclone was referred to the ASME standard design criteria and other reference [7]. The gas inlet velocity is an important design factor in deciding the cyclone inlet diameter $D_{1}$. The gas inlet velocity is determined by the solid load/density and particle mean size. The cyclone inlet diameter was determined by the gas inlet flow rate $\mathrm{Q}$ and gas inlet velocity $\mathrm{u}$ to the cyclone. In our design case, solid load is $20-50$ $\mathrm{lb} / \mathrm{h}$ of glass beads with $2.5 \mathrm{~g} / \mathrm{cc}$ of density. The mean particle diameter is $0.04 \mathrm{~mm}$. The inlet gas flow rate $\mathrm{Q}$ to the cyclone is $250 \mathrm{~m} / \mathrm{h}$. The cyclone inlet diameter $\mathrm{D}_{1}$ is given by $D_{1}=\sqrt{4 Q / \pi \mu_{g}}$ 


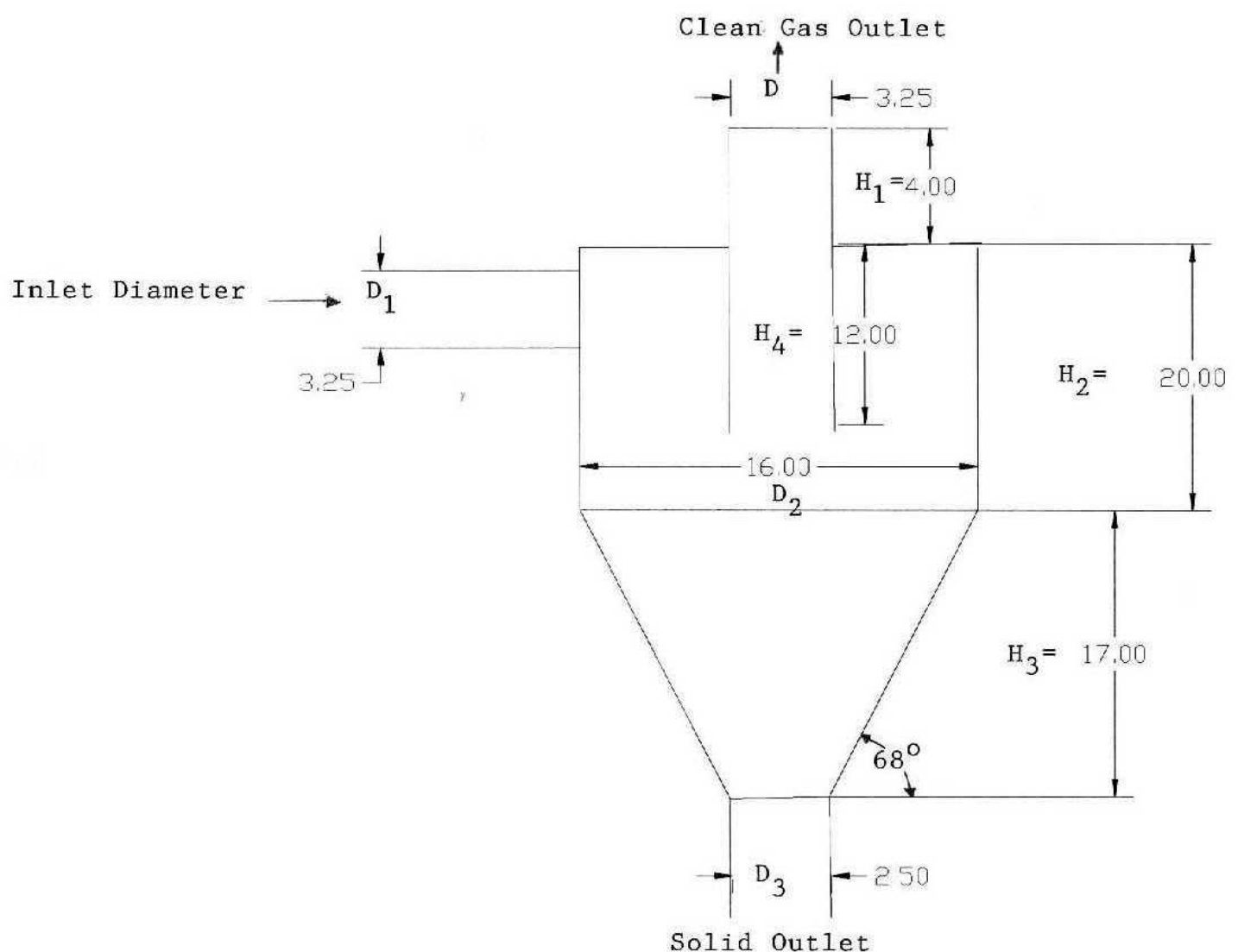

Figure 2 Schematic Diagram of the Cyclone System (Al1 dimensions are inches.) 
The clean gas outlet diameter $\mathrm{D}$ was employed as the same dimension of $\mathrm{D}_{1}$. This dimension was used to find to other dimensions of the cyclone components such as upper pipe length $\mathrm{H}_{1}$, lower pipe length of clean gas outlet $\mathrm{H}_{4}$, cyclone chamber diameter $\mathrm{D}_{2}$, chamber height $\mathrm{H}_{2}$, and solid outlet diameter $\mathrm{D}_{3}$.

Wind Box:

The wind box is an important part of the CFB system. Fluidizing air from high pressure blower at desired pressure and flow rate be delivered to the wind box through a PVC pipe. The gas kinetic energy is transferred into the potential energy.

The wind box is designed to damp out the small flow of unsteady fluidizing air and to provide a uniform air for the distributor and the riser. The gas velocity at the top of wind box is reduced to $1 / 4$ of the velocity at the wind box inlet. The pressure is increased four times because the diameter of the wind box is increased from 2 inches to 4 inches as shown Figure 3. The increased pressure provided uniform gas velocity through the small holes of the gas distributor plate. The maximum pressure of the wind box is 200 inches of water, which could match with the high pressure blower. The wind box is made of 1/16" thick stainless steel plate with a top bolted flange to the distributor as shown Figure 3. 


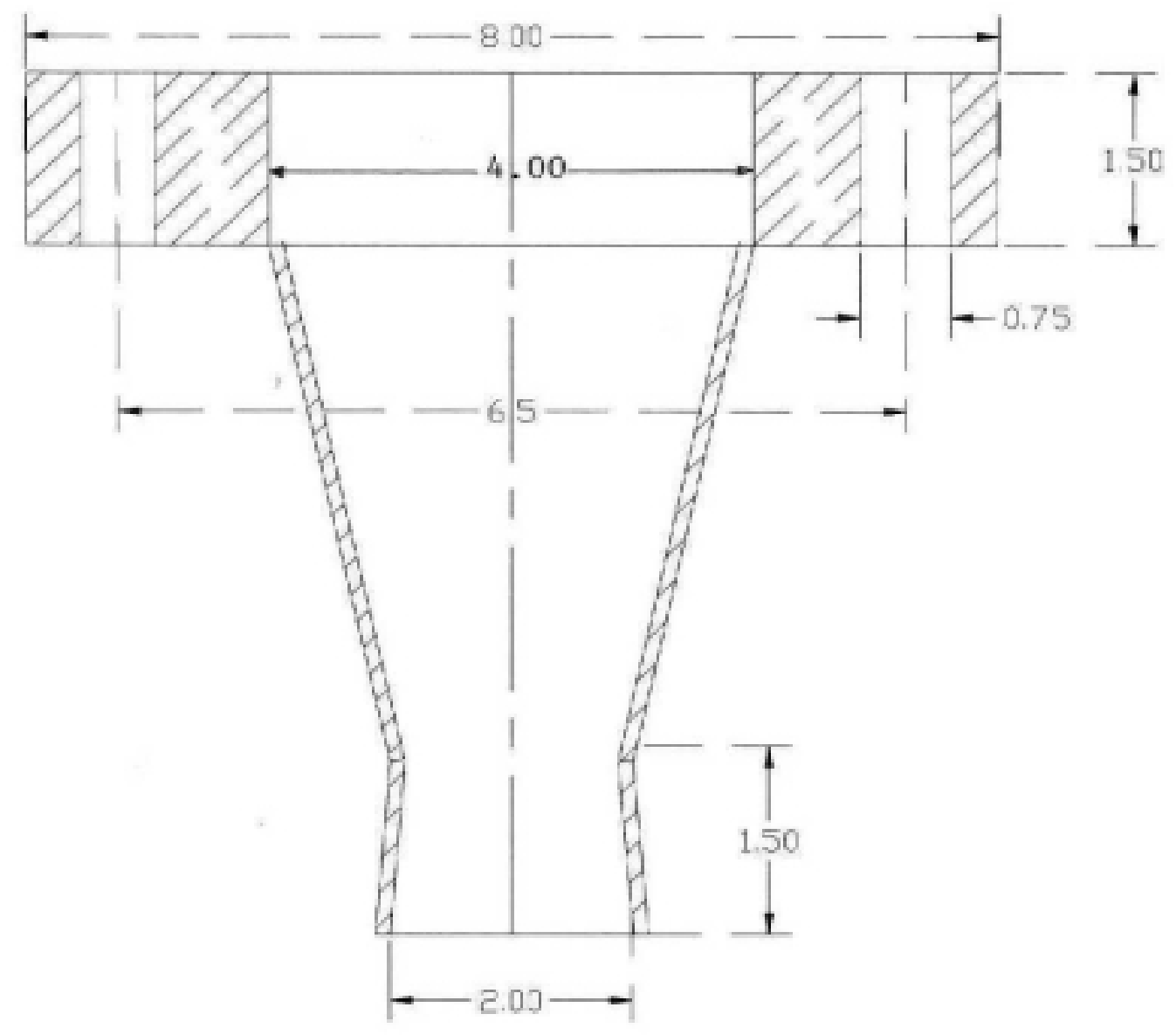

Figure 3 Schematic Diagram of the Wind Box (All dimensions are inches.) 


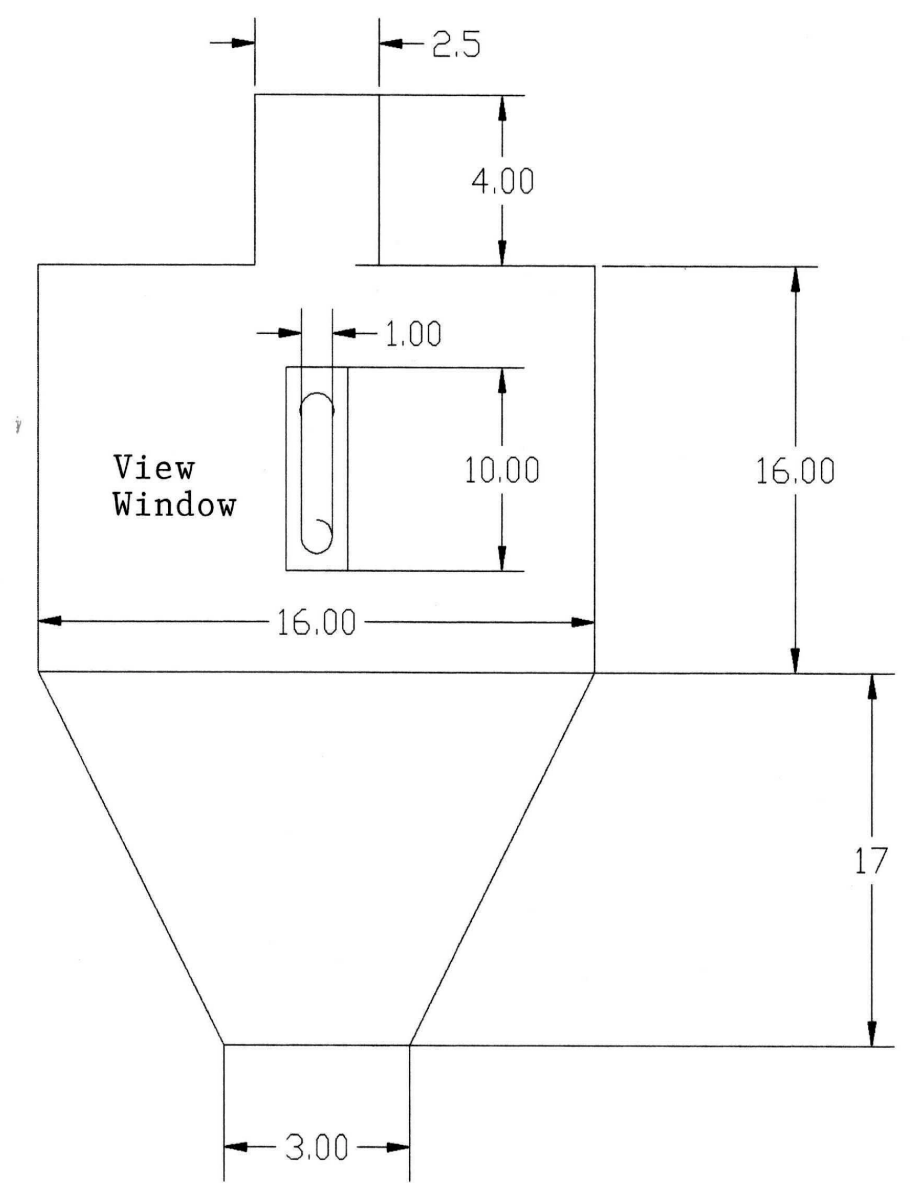

Figure 4 Schematic Diagram of the Surge Tank (All dimensions are inches) 
Surge Tank:

The surge tank achieves the solid particle storage and feeding of solid particles into the riser. In addition, the surge tank also stores enough solids in the system to ensure smooth operation of the system. The schematic diagram of the surge tank, which is made of 1/16 inches carbon steel plate, as shown in Figure 4. The total volume of the surge tank is about $2.7 \mathrm{ft}$, can store $80 \mathrm{~kg}$ of solid particles. The solid level in the tank can be measured through the attached glass view window.

\section{Solid Control Valve:}

The solid control valve is used to measure the solid flow rate through the system, which is installed to the pipe between the cyclone and the surge tank. The solid control valve as the butterfly valve is designed and fabricated as shown in Figure 5. The solid particles are accumulated in the pipe when the valve is closed. The solid circulation rate $\mathrm{C}$ can be calculated by solid bulk density, accumulating time $\mathrm{t}$, and volume of the measuring vessel $\mathrm{V}$, as expressed below:

$$
C=\frac{\rho_{s} V}{t}
$$

Riser:

The riser is the fast fluidized bed regime of CFB combustion chamber where all chemical reactions take place. Solid particles are entrained by the primary gas the riser tube. The riser tube is made of 4 inches ID plexiglass. Under normal operating conditions, the superficial 


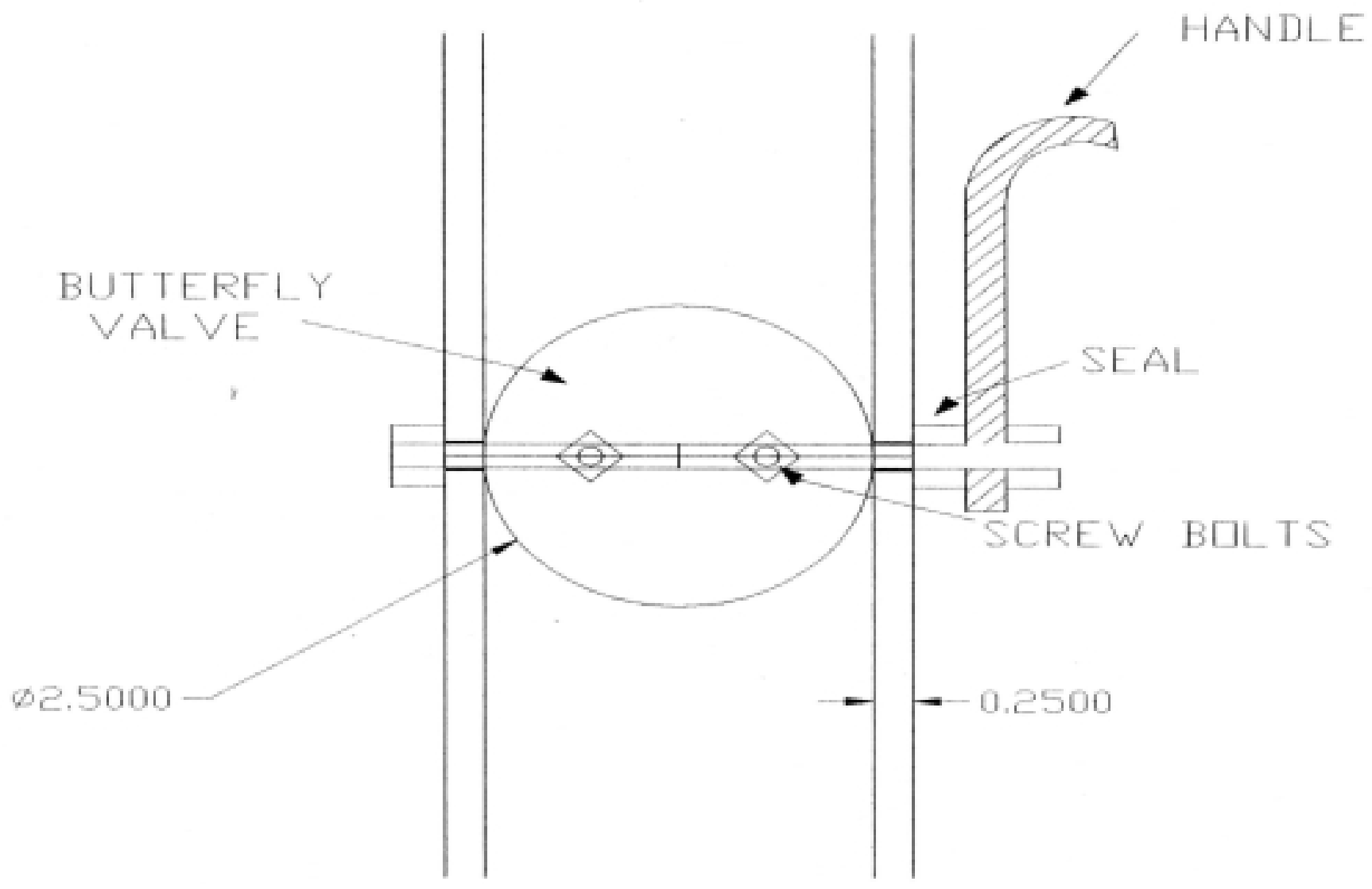

Figure 5 Schematic Diagram of the Solid Control Valve 
gas velocity is 5 to 10 times of the particle terminal velocity [8]. The total pressure drop in the riser tube is about 39.4 inches of water. The optimizing operating condition will be determined by further experiments.

\subsection{Auxiliary Subsystems for the Bench-Scale CFB Model}

The bench-scale CFB model and supporting auxiliary subsystems are schematically shown in Figure 6, which included air supply system, instrumented riser, gas-solid separation system, solid return/storage tank.

The air supply subsystem consists of blower, control valves, PVC piping, and flow measuring devices as shown in Figure 6. Primary air is supplied by a $7.5 \mathrm{hp}$ ROTRON Model DR808AY72MX, regenerative blower of 116-in. of water and 345 scfm. Two 1-hp, two-speed centrifugal blowers will be used to supply secondary air separately during the test. Primary air is controlled by the primary inlet valve and the bypass valve. Secondary air is controlled by the aeration valve.

Pressure transducer with a data acquisition system will be used to measure the pressure change along the different height of the riser. A five-point, 3-dimensional probe with pressure transducer will be used to measure gas axial, tangential, and radial velocities. The heat transfer probe will be developed to measure the bed-surface heat transfer coefficient on the wall of the CFB riser. The probe will be consisted of two major components, heating component and heat flux sensing unit. The output of the thermocouples will be recorded on a computerized data acquisition system consisting of a direct-current amplifier, an $\mathrm{A} / \mathrm{D}$ converter, and a personal computer 
In order to determine the local mass flux of the solid particles, the electrostatic probe will be designed and fabricated along with a signal processing system. 


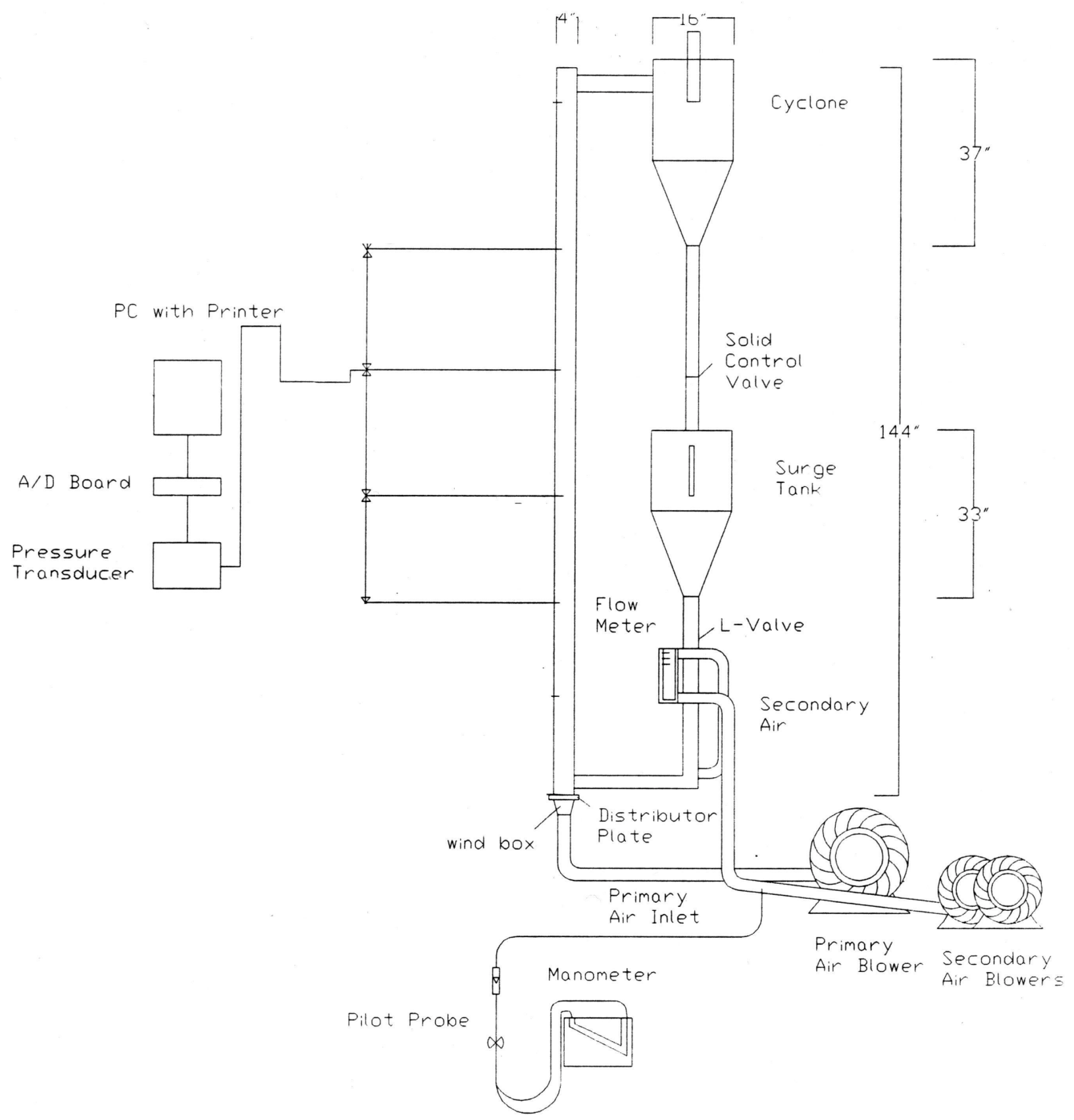

Figure 6 Schematic Diagram of the Bench-scale CFB System 


\section{Auxiliary Subsystems Tests}

\subsection{The Characteristics of a Regenerative Blower}

The blower used for the circulating fluidized bed is a high pressure regenerative blower, model DR823 from EG\&E Rotron Inc., with an external muffler, a filter, a three-phase, 220 voltage driving motor, a $60 \mathrm{~Hz}$ frequency, and a 7.5 horsepower. The blower, made of cast aluminum, has maximum pressure of 250 inches water and a maximum gas flow rate of 184 SCFM. The blower outlet is connected to the CFB wind box by 2 inches of PVC pipe. The primary gas flow rate is measured by a pitot probe which is set in the 2 inches PVC pipe.

The pressure in the wind box is measured by a 10 -foot manometer. The gas flow rate is adjusted by the bypass controlling valve. When the bypass valve is fully closed, the blower works in its standard condition. The blower's standard condition is provided by the manufacturer. The starting conditions, which include the air flow rate of $5 \mathrm{~m} / \mathrm{min}$ and 42 inches water pressure were tested by an experimental measurement. Under the standard conditions, the generative blower pressure is almost a linear function of the airflow rate.

The results are shown in Figure 7. When the air flow rate increases, the pressure at the blower outlet is decreased. The minimum airflow rate is $4 \mathrm{~m} / \mathrm{min}$ which corresponds to the maximum pressure 


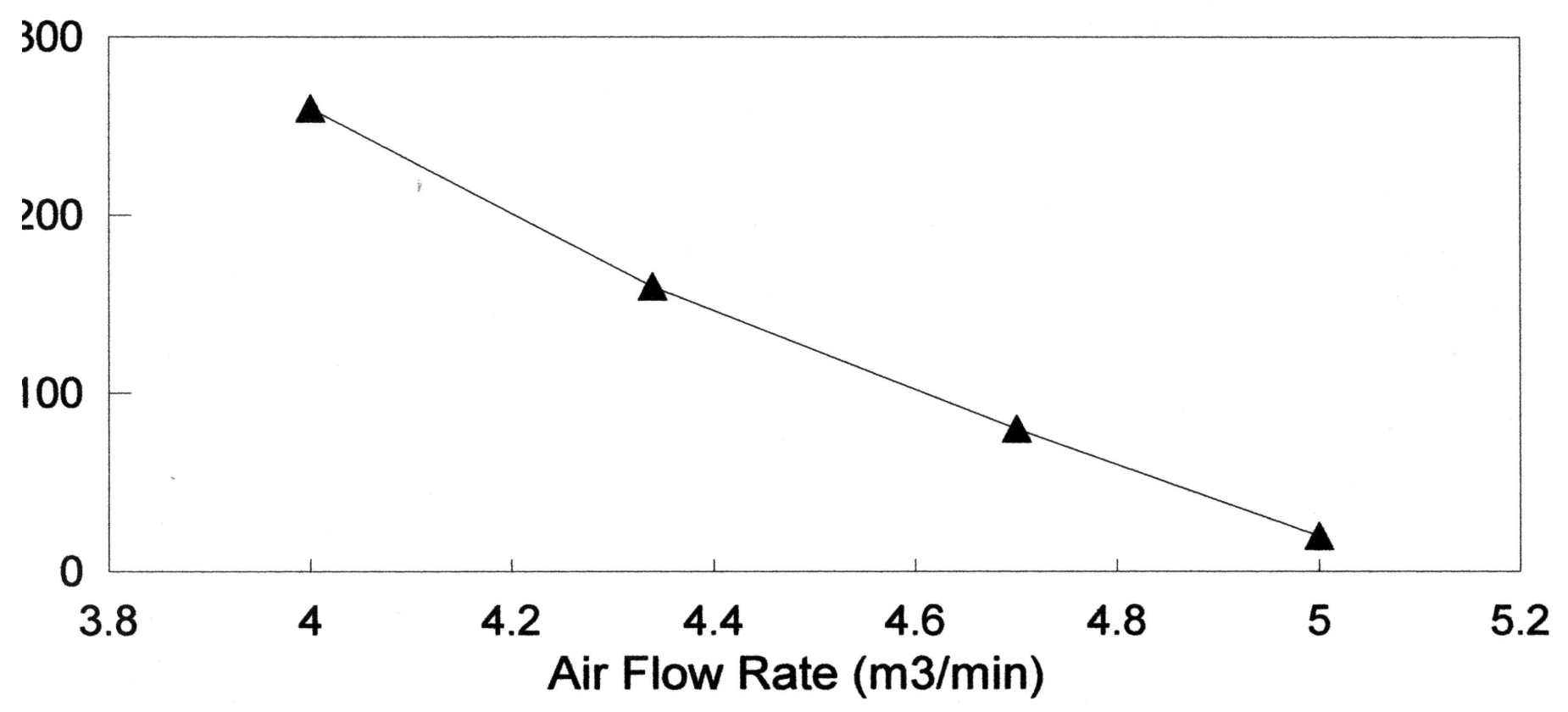

Figure 7 The Regenerative Blower Pressure Characteristics at Standard Condition 
drop of 280 inches water. As a test case, the bypass valve was opened to adjust the pressure in the wind box and the airflow rate in the riser tube.

The pressure characteristics at the open bypass valve conditions are shown in Figure 8. The airflow rate in the riser is a function of the pressure in the wind box. When the pressure in the wind box increases, the airflow rate through the riser is increased. Since there are no solids in the circulating fluidized bed (CFB) riser, the pressure drop also can be used to estimate the gas distributor pressure drop.

\subsection{The Characteristics of Gas Distributor and Cyclone}

The gas distributor and cyclone, with design details were introduced in previous report [1]. The gas distributor was modified by inserting a piece of filter cloth into the gas distributor plate to prevent solids particles from leaking into the wind box. The filter cloth caused a pressure drop increase for the gas distributor plate.

In order to determine the hydrodynamic characteristics of the gas distributor and cyclone, two pressure taps were installed on both sides of the distributor. Two pressure taps were also installed on the inlet and outlet of the cyclone. A pressure tap was installed on the cyclone top to measure the chamber pressure. The pressure drop of the riser column was also measured from the bottom to the top. The gas distributor pressure drop was measured by a mercury manometer in inch units. The riser pressure drops were measured by a water manometer in $\mathrm{cm}$ units. Those 


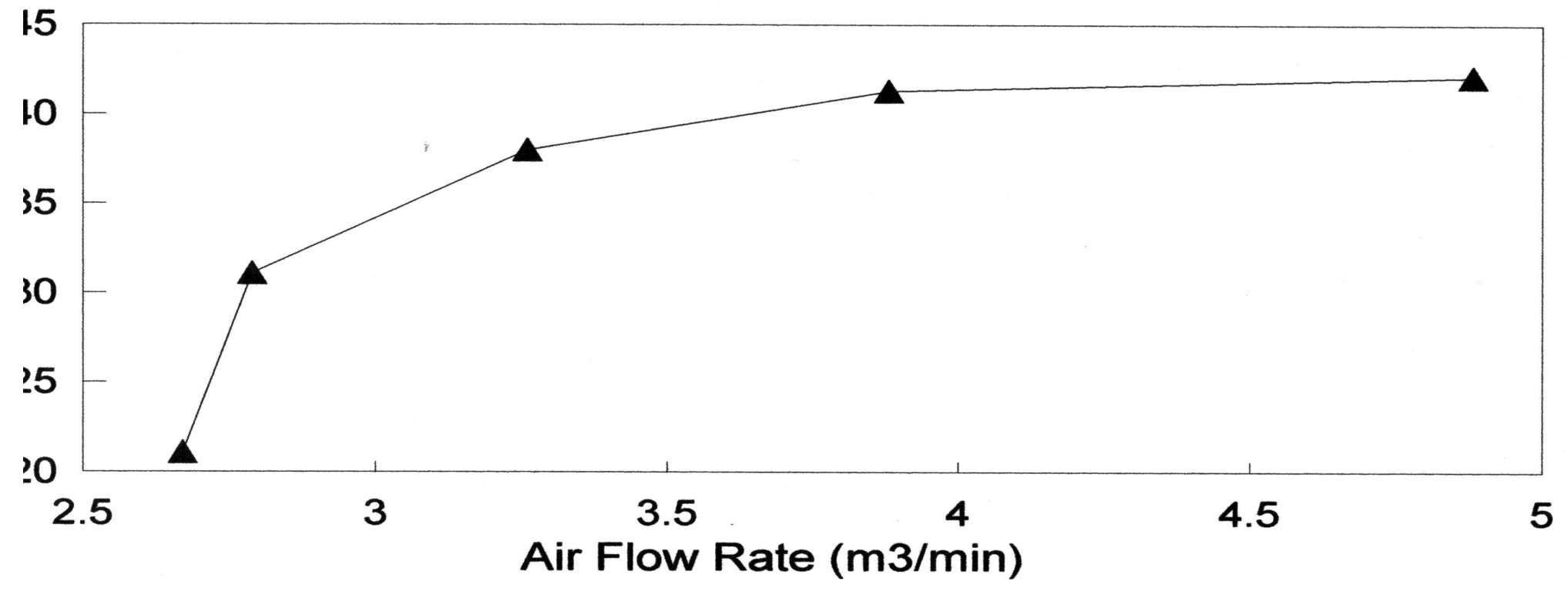

Figure 8 The Regenerative Blower Pressure Characteristics at Open bypass Valve Conditions 
pressure drops are a function of the primary gas flow rate. The gas flow rate is measured by a designed pitot probe which was described in the previous report [9].

The probe was installed in the primary air supply from the high pressure blower with a high pressure and raising temperature. Therefore, it was necessary to the correct the flow rate into standard flow rate which is set at standard conditions: 1 atmosphere pressure and $20 \mathrm{C}$ temperature. The primary gas flow rate is controlled by adjusting the bypass and primary air inlet valves.

The test results show that the pressure and pressure drops increase as the primary airflow rate increases. Figure 9 indicates the pressure drop in the riser column to be lower than $0.6 \mathrm{~cm}$ water, and it can be ignored for our test case. The chamber pressure increased from $4 \mathrm{~cm}$ water to $8.2 \mathrm{~cm}$ water when the air flow rate changed from $0.049 \mathrm{~m} / \mathrm{min}$ to $0.171 \mathrm{~m} / \mathrm{min}$. The chamber pressure can be used as an indication for the dust filter work conditions. When the dust filter fills up with dust, its pressure drop will increase. Empirically, the filter pressure drop should not be larger than 20 $\mathrm{cm}$ water. When the filter chamber pressure reaches this value, the filter bag should be cleaned.

The cyclone pressure drop and gas distributor pressure drop are functions of primary air flow rate input, as shown in Figure 10. The maximum pressure drop of the gas distributor is about 8 inches mercury $(3.93 \mathrm{psi})$ when the air flow rate is set at $0.17 \mathrm{~m}$ /min. The higher gas pressure drop indicates primary air in the riser column with a 
uniform superficial velocity. The maximum pressure drop from the cyclone is about $2.2 \mathrm{~cm}$ water, which indicates the cyclone was designed successfully for the fine particle separation. 


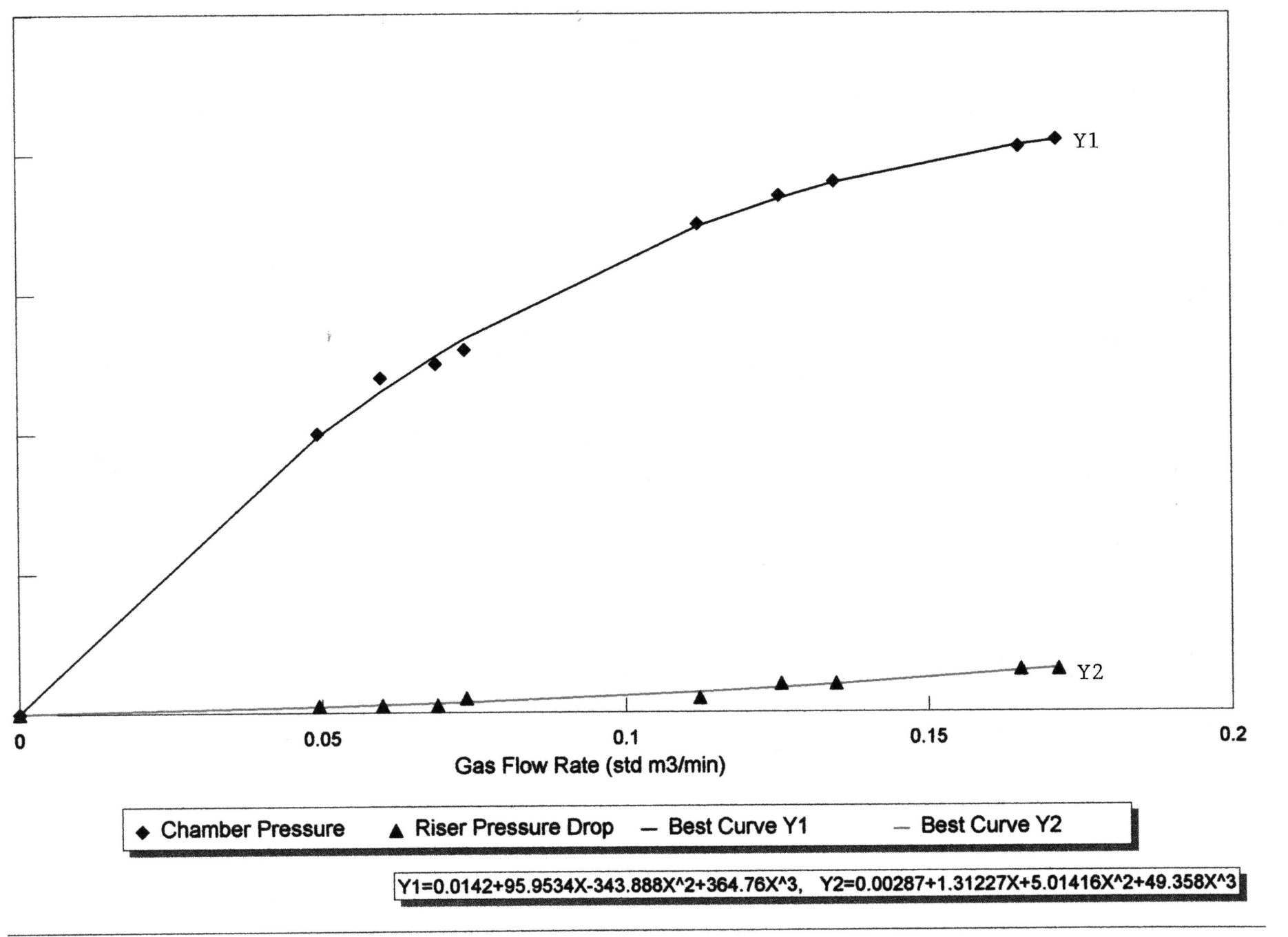

Figure 9 Chamber Pressure and Riser Pressure Drop 


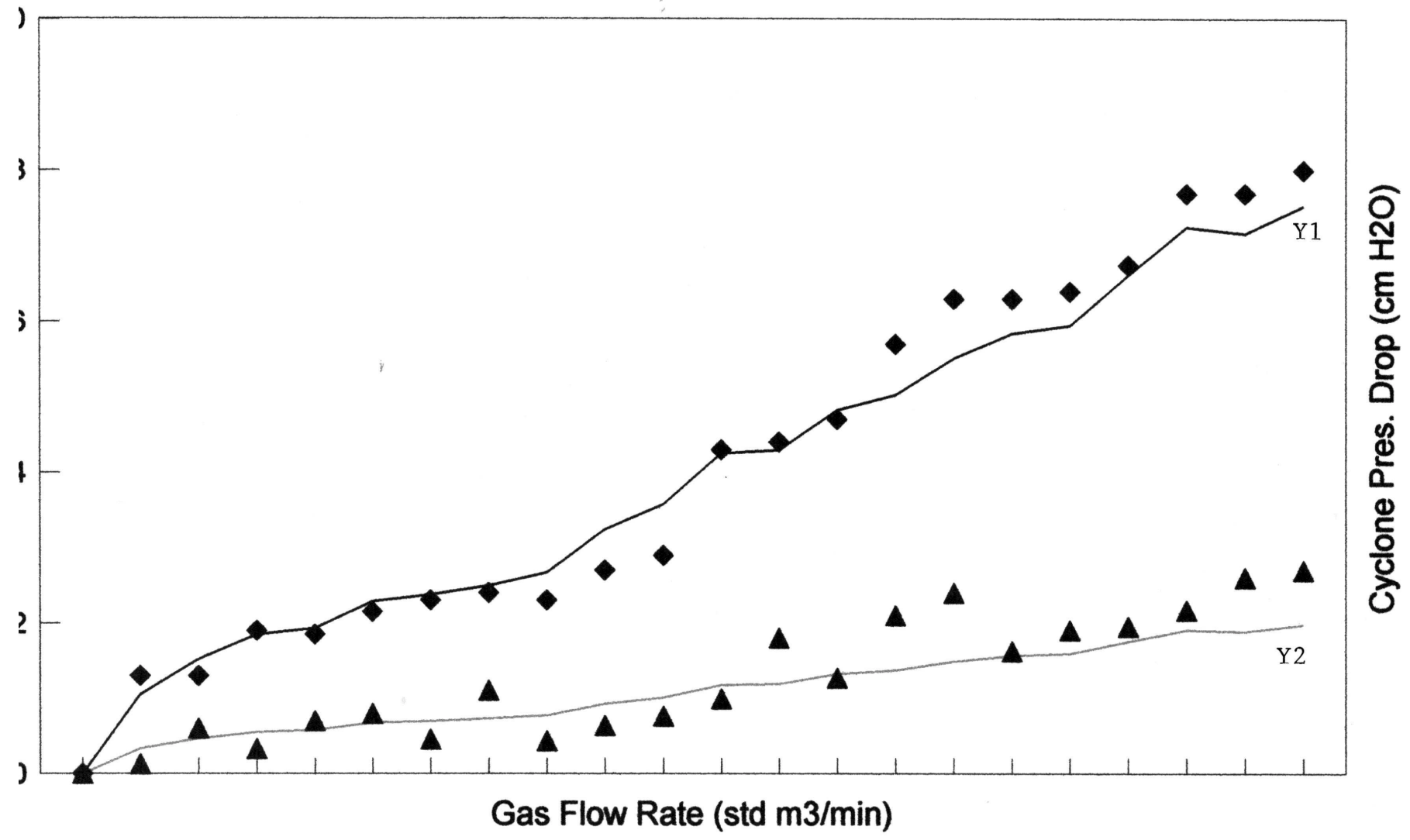

- Gas Distributor \ Cyclone - Best Curve Y1 - Best Curve Y2

$Y 1=51.379 X^{\wedge} 1.145, Y 2=11.182 X^{\wedge} 1.033$

Figure 10 Gas Distributor and Cyclone Characteristics 


\section{The CFB Primary Test}

\subsection{Characteristics of Bed Materials}

The glass beads are selected as one of the CFB bed materials for primary system test. The glass bead particle properties are shown in Table 1 .

Table 1. Glass Bead Particle Properties

\begin{tabular}{|l|c|c|c|c|}
\hline Glass Bead No. & Bead 1 & Bead 2 & Bead3 & Bead 4 \\
\hline Batch No. & 90203 & 90604 & 42501 & Mixture \\
\hline Size No. & 304 & 710 & 812 & $50 \%$ Mix. \\
\hline $\begin{array}{l}\text { Mean Size (mm) } \\
\text { Shape Factor }\end{array}$ & 0.554 & 0.179 & 0.174 & 0.168 \\
\hline Particle Density (g/cc) & 1 & 1 & 1 & 1 \\
\hline Bulk Density (g/cc) & 1.451 & 1.306 & 1.282 & 1.276 \\
\hline Fixed Bed Void Fraction & 0.431 & 0.488 & 0.497 & 0.5 \\
\hline $\begin{array}{l}\text { Minimum Fluidization Velocity } \\
\text { (MFV) (m/s) [2] }\end{array}$ & 0.228 & 0.026 & 0.025 & 0.023 \\
\hline MFV (m/s) [3] & 0.323 & 0.066 & 0.058 & 0.063 \\
\hline Particle Terminal Velocity (m/s) & 4.284 & 1.250 & 1.206 & 1.153 \\
\hline [4] & & & & \\
\hline
\end{tabular}

\subsection{Test No.1 with Glass Bead}

The test conditions for this test are as follows:
a) $25 \mathrm{lbs}$ of bead $1 \mathrm{was}$ put into the surge tank.
b) The bypass valve was fully closed.
c) The primary input air valve was fully opened. 
d) The aeration air valve was adjusted to inject the circulation solid into the riser tube.

There were no solids flowing through the riser tube. All of the solids injected into the riser settled at the bottom of the riser tube and formed a bubbling fluidized bed. This was not the desired result.

\subsection{Test No.2 with Glass Bead 2}

The test conditions for this test are as follows:

a) $25 \mathrm{lbs}$ of bead 2 was inputted into the serge tank

b) The bypass valve was fully closed.

c) The primary input air valve was fully opened.

d) The aeration air valve was adjusted to inject the circulation solid into the riser tube.

Solids flowed through the riser tube in a good fast fluidized bed regime. The 25 lbs of total solid input was not enough to maintain a stable running condition. The serge tank was empty, and the L-valve solid leg was very shorts (about 5 inches) and did not contain an adequate amount of beads. This was not the desired result. 


\subsection{Test No.3 with Glass Bead 4}

The test conditions for this test were the same as the test No.2, except an additional $25 \mathrm{lbs}$ of the bead 3 was added to the system. the solid mixture (50 lbs) contained of $50 \%$ bead 2 and $50 \%$ of bead 3 . This mixture formed "bead $4 "$

a) $50 \mathrm{lbs}$ of bead 4 (25 lbs of bead 3$)$ was inputted into the surge tank.

b) The by pass valve was fully closed, and the primary input air valve was fully opened, the primary airflow rate for the riser tube was about $2 \mathrm{~m} / \mathrm{sec}$ which responded to a superficial velocity in the riser tube of $4.1 \mathrm{~m} / \mathrm{s}$. This was about 3.2 times that of the particles terminal velocity.

c) Since the aeration airflow rate was too small for the flow rate meter measurement, the aeration air valve was adjusted to inject the circulation solid into the riser tube.

Solids flowed through the riser tube in a good fast fluidized bed regime. The solid circulation rate was a function of the aeration air valve opening. Figure 11 shows the solid recirculation rate with the change of the aeration valve opening. The solid circulation rate increases as the aeration valve increases.

The average bed voidage (or bed density) is 0.884 which was determined by weighing the bed material when the primary air immediately closed. 


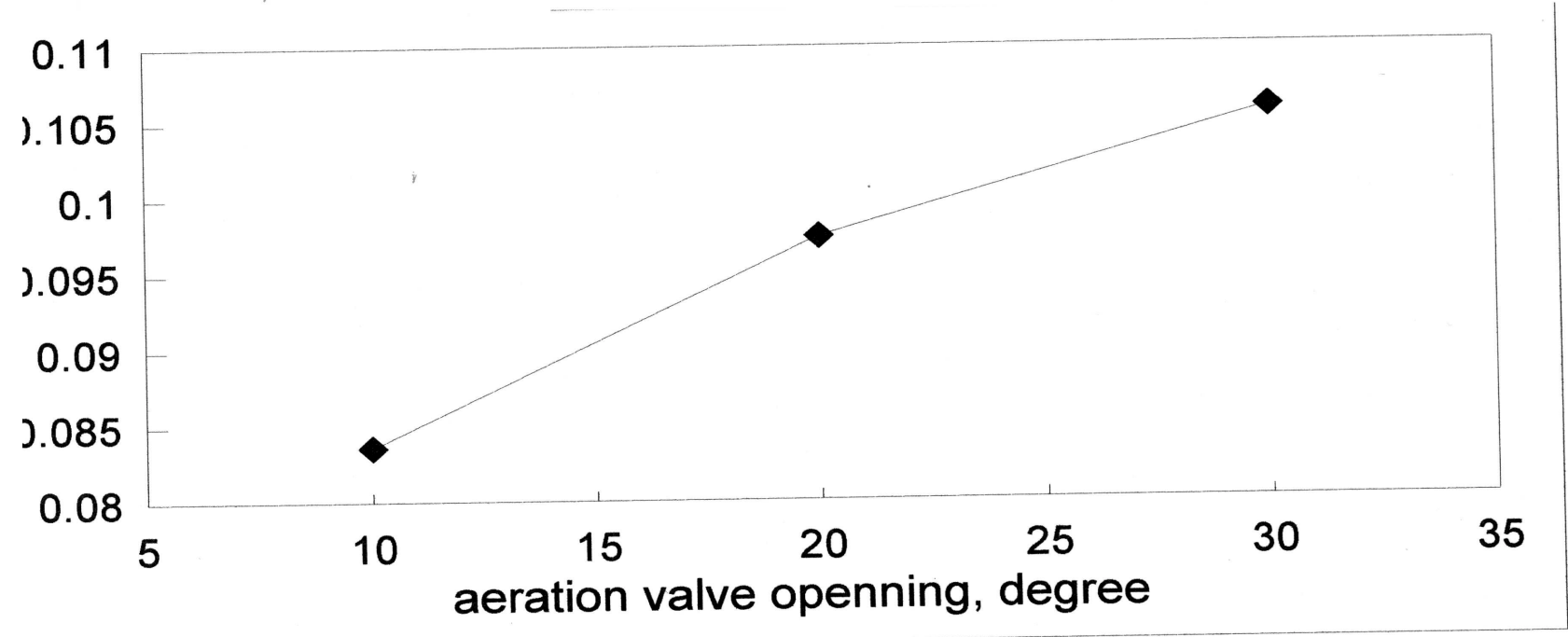

Figure 11 Solid Recirculation Rate vs. Aeration Valve Opening 


\section{Data Acquisition System}

\subsection{Development of Pressure Sensor Data Acquisition System}

A data acquisition system was developed to be used with the Honeywell pressure transducers, serial numbers 26PCBFA2G and 26 PCBFA1D. Two types of sensors were used, a single pressure sensor, and a differential pressure sensor, respectively. Each is capable of an output voltage of 0 to $+/-50 \mathrm{mV}$, which corresponds to a pressure of 0 to $+/-5$ psi.

The linear operation of these devices was verified through tests, as detailed at the end of this report. Several attempts were made to build a differential amplifier circuit and to input the signal at an analog-to-digital board, (Analog Devices Board Model RTI-800) [9]. These attempts proved to be inadequate due to a lack of circuit response pressures of less than $0.01421 . \mathrm{mV}$. We were attempting to amplify the signal 100 times and to input this signal into the single ended input of the A/D board.

By altering the $\mathrm{A} / \mathrm{D}$ board's configuration from a single ended input to a differential input, we eliminated the need for an external amplifier circuit. Based on specific jumper settings, such as a bipolar range $+/-5 \mathrm{~V}$, and a differential input, the analog-to-digital (A/D) board is capable of accepting voltages ranging from $+/-10 \mathrm{mV}$. The sensor's signal was directly inputted into the corresponding channels of the A/D board. As an example, the output on channel 0 is comprised of two inputs from connector $\mathrm{J} 2$ and from pins 3 (input O hi) and 19 (input O lo).

Based on software controls, the A/D board can have amplification (gain) of 1, 10, $100,500$. 
The software used to control the A/D board is Paragon 500. [10]. This is a powerful program capable of controlling, monitoring, and reporting the status of various devices at either a local or a remote location. We are using this software in one of its simplest forms. Paragon 500 is used to set the gain on the A/D board channels, to collect the data, to record, and to display the data. Control of the A/D board is accomplished through "function" blocks in the software. The A/D gain for each channel is specified through the A/D block. Data scanning rates are set through "EXPR" blocks. Data recording is set through the analog history or "AHIST" block.

Using this data acquisition system required calibrating the sensors through the A/D board, as displayed by the Paragon 500 software. Sensor signals were inputted to the proper $\mathrm{A} / \mathrm{D}$ inputs. The output, as shown by the Paragon 500 software, is used to determine several points. With no pressure applied (0 Pressure), the sensor's output, as displayed, was averaged.

This value then became the "zero offset". A steady pressure was applied to the sensor as read with a manometer. The pressure readings from the manometer were compared with the average displayed Paragon 500 values. A regression analysis provided an $\mathrm{Y}$ intercept and the slope of the relationship between the displayed valued and the pressure readings. These values were inputted into the expression function blocks with the following equation.

$$
\text { OUTPUT }=(((\text { Input Signal - Zero Offset }) *(\text { Slope })-\text { Y Intercept })
$$

Because the function blocks are restricted in their data descriptions, the following expression is used. 
$\left(\left((\mathrm{I} 1-\mathrm{K} 2)^{*} \mathrm{~K} 1\right)-\mathrm{I} 2\right.$

Although the expression looks quite different, it is the same.

$$
\begin{aligned}
& \text { I1 = Input Signal } \\
& \text { K2 = Zero Offset } \\
& \text { K1 = Slope } \\
& \text { I2 = Y Intercept }
\end{aligned}
$$

The following circuit represents the data acquisition system. For detailed information on either the Analog Device RTI- 800 A/D board or the Paragon 500 software refer to the user's manual. 


\section{DEVELOPMENT OF THE INSTRUMENTATION FOR PRESSURE MEASUREMENT}

\subsection{Pressure Measurement System for the CFB Riser}

In order to conduct the experimental tests with millet particles and to determine the bed average structure in the riser of CFB system, a pressure transducer system was designed to measure the pressure and differential pressure at seven points along the riser wall as shown in Figure 12. Seven pressure transducers, 26 PC series of Honeywell Micro Switch were used for this system.

The pressure transducers were connected to pressure taps by a $1 / 4$ " OD x $0.175^{\prime \prime}$ ID vinyl tube. The pressure tabs were installed on the riser wall in the vertical direction: tap \#1 (or Pt 1) at $1.27 \mathrm{~cm}$ from the bottom;(Pt2) at $40.64 \mathrm{~cm}$; tap \#3(Pt 3) at $101.6 \mathrm{~cm}$ from the bottom; tap \#4 (Pt 4) at $162.56 \mathrm{~cm}$; tap \#5 (Pt 5) at $223.52 \mathrm{~cm}$ from the bottom; tap \#6 (Pt6) at $284.48 \mathrm{~cm}$; and tap \#7 (Pt 7) at $386.84 \mathrm{~cm}$. The pressure at Pt 7 is measured by a straight style pressure transducer. The pressures are recorded by a PC with an RTI-800 ADC board from the Analog Device, and Paragon 500 software from Intec Controls Corporation.

\subsection{Pressure Transducer Calibration}

Before using the transducers for pressure measurement, each transducer was carefully calibrated with a specially designed pressure 


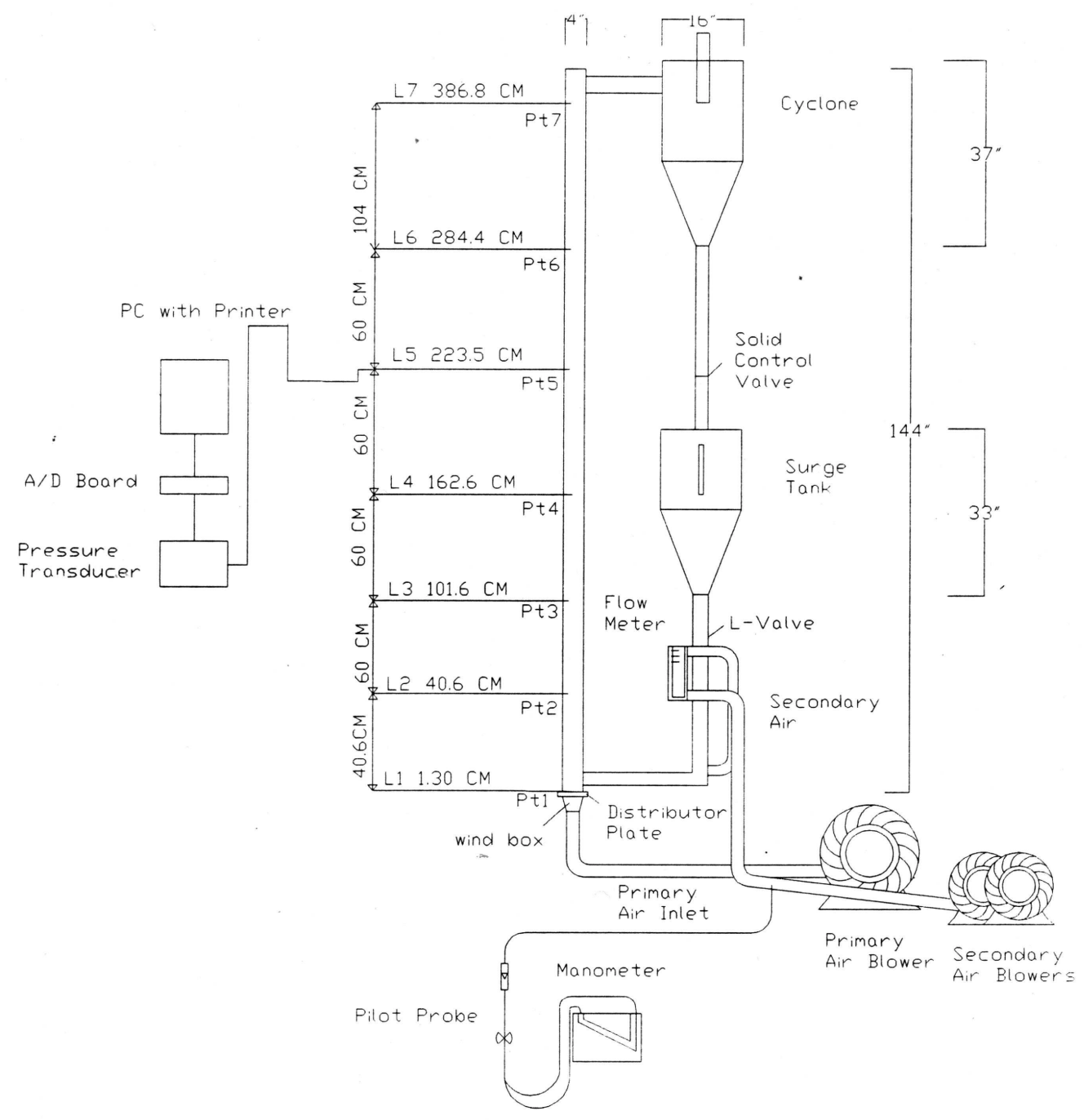

Figure 12 Arrangement of Pressure Measurement in the Bench-Scale Circulating Fluidized Bed System 


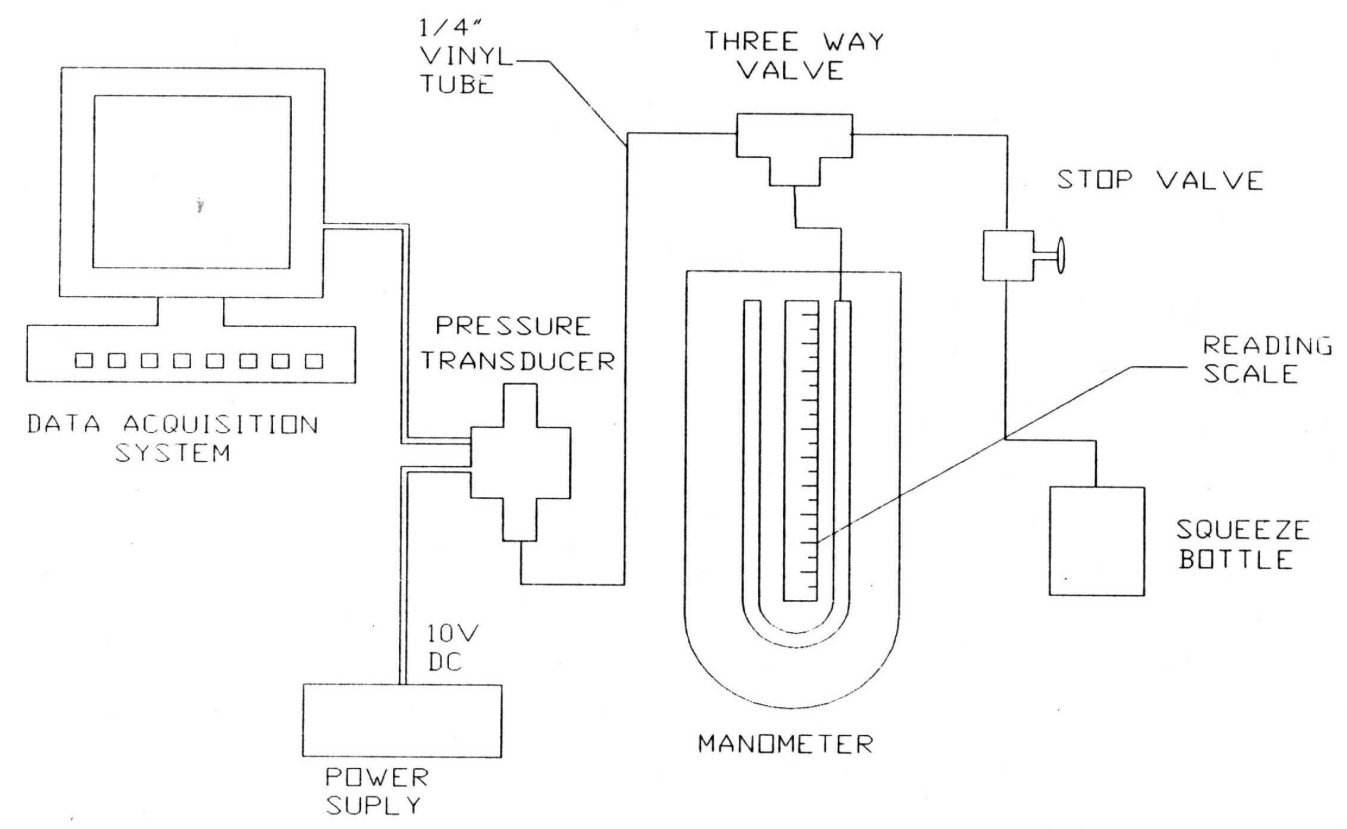

Figure 13 Instrumentation for Pressure Transducer Calibration System 
calibration system as shown in Figure 13. The pressure is generated by pressing the plastic bottle and setting a pressure valve, which is connected to the stop valve. The pressure was measured by the manometer and the PC. The results were recorded on the PC and calculated with LOTUS program. For each transducer, the pressure change was a linear function.

In order to prevent the falling millet particles into the pressure tap and plugging up the pressure measurement tube, a metal screen was placed at the inlet of the pressure tap.

\subsection{Test Results and Discussion}

After warming up about 20 minutes, the system reached the steady state. The changes of temperature and pressure at the wind box were recorded. The gas density was the function of pressure and temperature, which could be calculated by using the ideal gas law [4]. The primary air flow rate was measured by the modified pitot probe. The superficial gas velocity in the riser column was calculated from the following equation [5]:

$$
U_{g}=\frac{Q_{g}}{A_{\text {riser }}}
$$

where, $U=$ is the gas superficial velocity in the riser column, in $\mathrm{m} / \mathrm{s}$. $\mathrm{Q}$ is the primary airflow rate under operation conditions, measured in $\mathrm{m} / \mathrm{s}$. A is the crosssectional area of the riser tube in $\mathrm{m}$. The test conditions for the lower superficial velocity test case included the setting of gas superficial velocity in the riser column at 9.7 $\mathrm{m} / \mathrm{s}$. The aeration (secondary air) flow rate was adjusted to change the solid feed rate at three values for the three test cases; $3391 \mathrm{~g} / \mathrm{min}$. for case $1,2848 \mathrm{~g} / \mathrm{min}$. for case 2 , 
and $2153 \mathrm{~g} / \mathrm{min}$. for case 3 . For each of the test cases, the differential pressures were recorded by the computer-assisted data acquisition system. The pressure drop along the riser column was a function of the riser column height, as shown Figures 14 (for case 1), Figure 15 (for case 20, and Figure 16 (for case 30). The pressure drop decreased as the riser column height increased. Cases 1 and 3 showed more gradually changes. However, the change of case 3 is more linear region between Pt2 and Pt 6. 


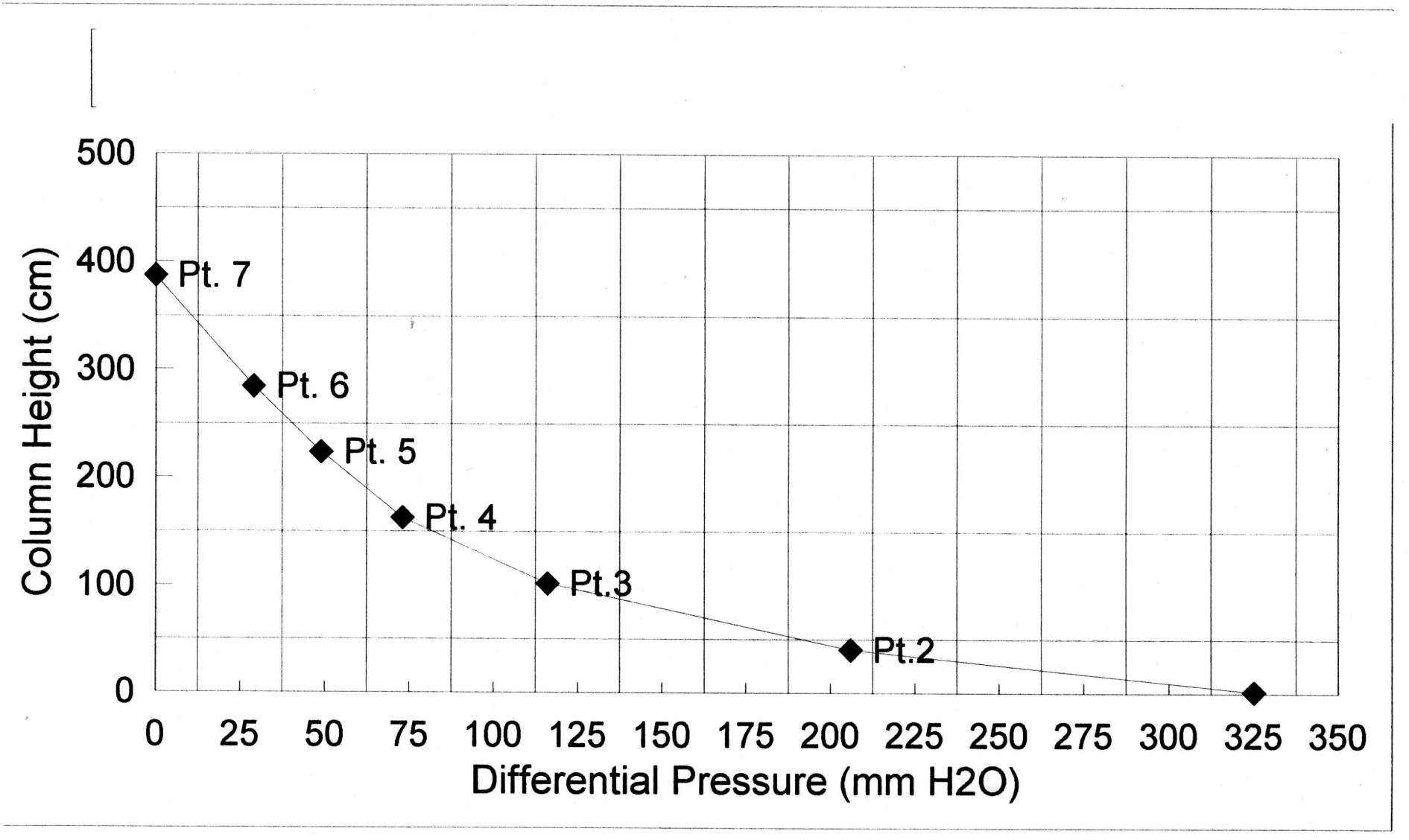

Figure 14 Differential Pressure vs. Column Height 


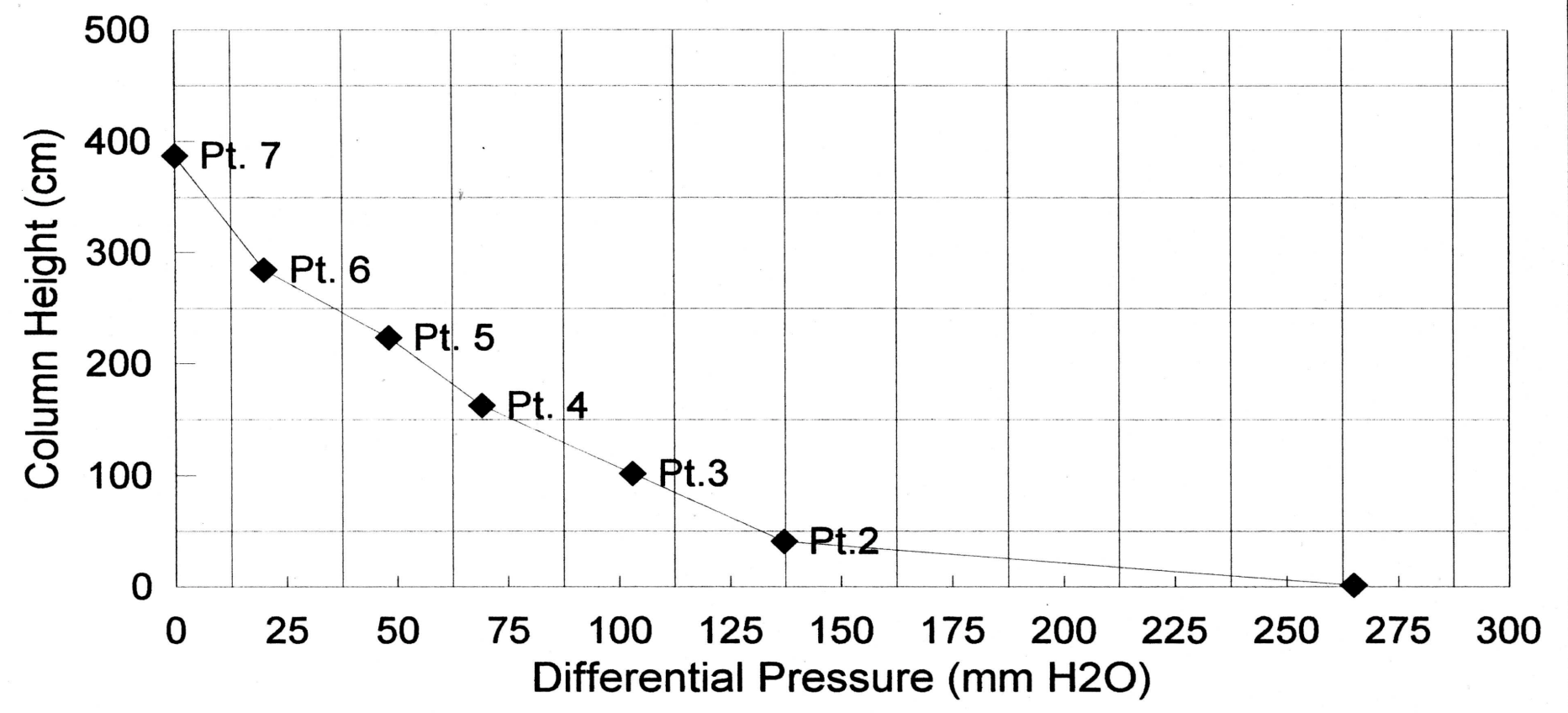

Figure 15 Differential Pressure vs. Column Height 


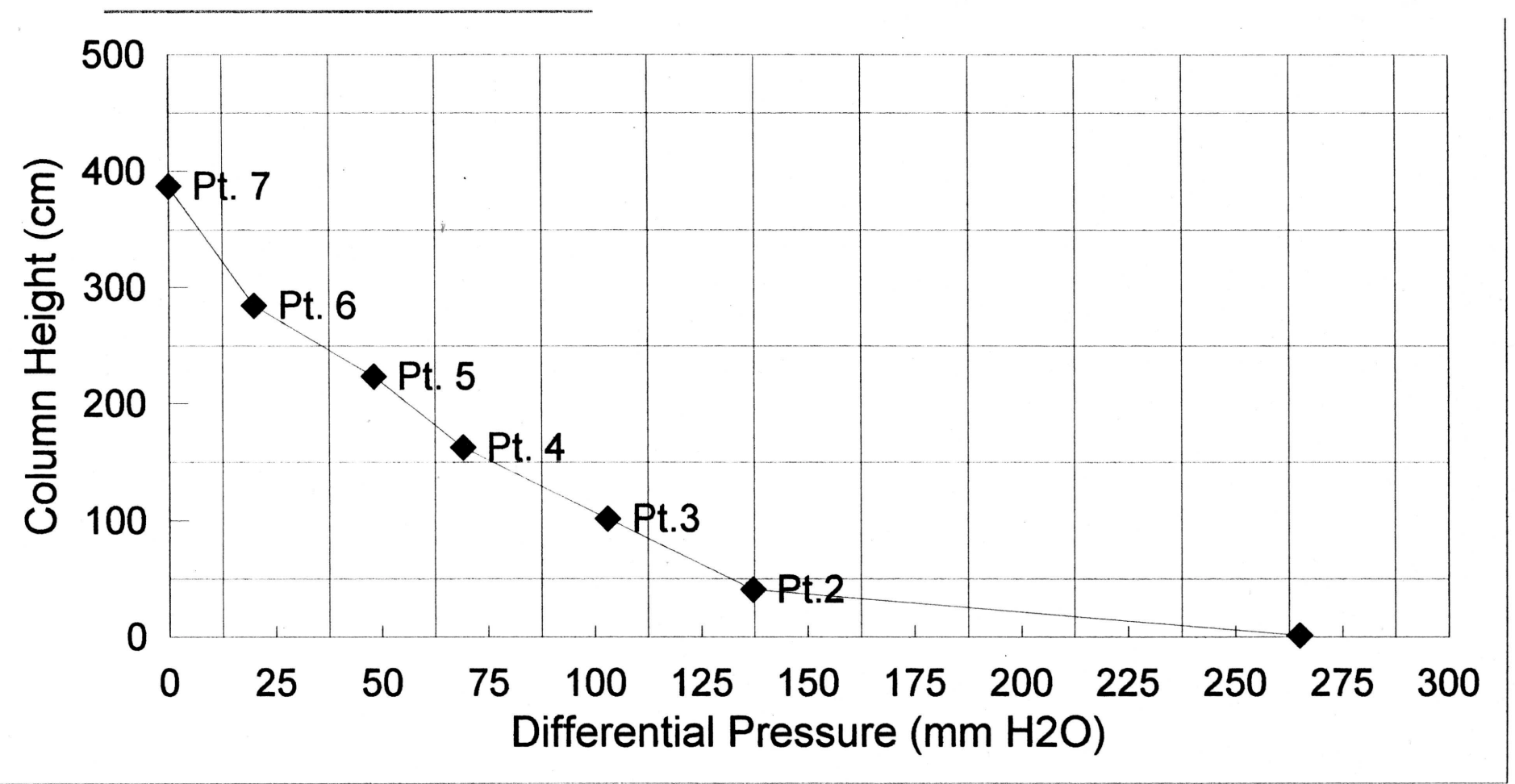

Figure 16 Differential Pressure vs. Column Height 


\section{SYSTEM TEST OF CFB COLD FLOW MODEL}

\subsection{Experimental Apparatus and Procedures}

The system test of Circulating Fluidized Bed (CFB) System was conducted by the bench-scale CFB system [11]. Solid particles were kept in a steel storage surge tank. The solid particles were fed to the riser column through a connection L-valve tube feeding system, which was mounted, to the CFB riser column. The solid flux could be controlled with the aeration airflow rate into the L-valve.

Primary air was supplied through was supplied through a gas distributor plate at the bottom of the riser tube to transport the solid particles. At the exit of the riser column, a cyclone separated the solid particles from the fluidizing air. The solid particles were fed back to the storage surge tank vessel after passing the solid flow rate measuring valve in order to record the solid accumulated height during a certain time interval.

In an axial direction, 6 taps were mounted on the wall of the riser column with an equidistant spacing of 3 feet. Pressure differences over these sections were measured using two-foot-tall water manometer and two-foot-tall mercury manometer. The solid

mass flow rate of the circulating solids could be determined by measuring the accumulated height of the solids in the measuring pipe during a certain period of time. The local and the overall solids average solid concentrations (bed voidage) were determined by the differential pressure drop and solid weight.

Solid particles used for the CFB cold test were organic millet particles with an average of $1.826 \mathrm{~mm}$, a particle density of $1369 \mathrm{~kg} / \mathrm{m}$, and bulk density of $620 \mathrm{~kg} / \mathrm{m}$. 


\subsection{Results and Discussion}

(a) Test Results without Feeding Solids into the Riser

Pressure drops of the distributor plate and the cyclone is a function of the gas flow rate [3]. The primary airflow rate was measured by the specially designed pitot probe. The airflow rate was a function of the pressure drop. These results are shown in Figure 17. There was some pressure potential energy loss in the wind box, which is used to generate thermal energy and heat up the primary air. When the temperature of primary air increased from $80 \mathrm{~F}$ to $190 \mathrm{~F}$ in twenty minutes, the total primary air flow rate was reduced from $0.046 \mathrm{~m} / \mathrm{s}$ to $0.038 \mathrm{~m} / \mathrm{s}$, as shown in Figure 18. The maximum primary airflow rate was about $0.038 \mathrm{~m} / \mathrm{s}$ which was responded to the superficial velocity of $4.6 \mathrm{~m} / \mathrm{s}$.

The terminal velocity and the minimum fluidization velocity of the glass beads were $1.15 \mathrm{~m} / \mathrm{s}$ and $0.023 \mathrm{~m} / \mathrm{s}$ respectively.

(b) Test Results with Feeding Solids into the Riser 


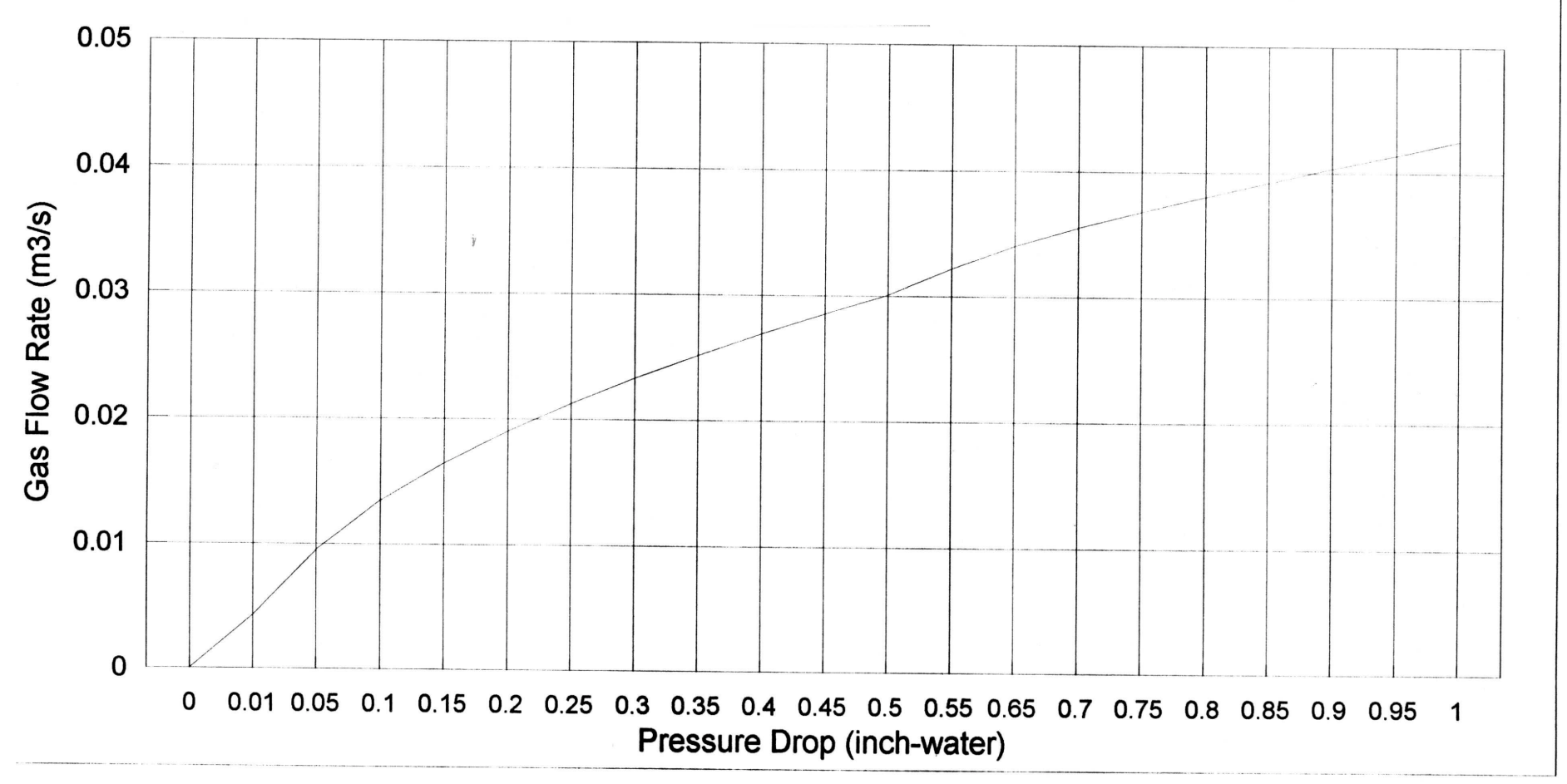

Figure 17 Gas Flow Rate vs. Pressure Drop of Pitot Probe 


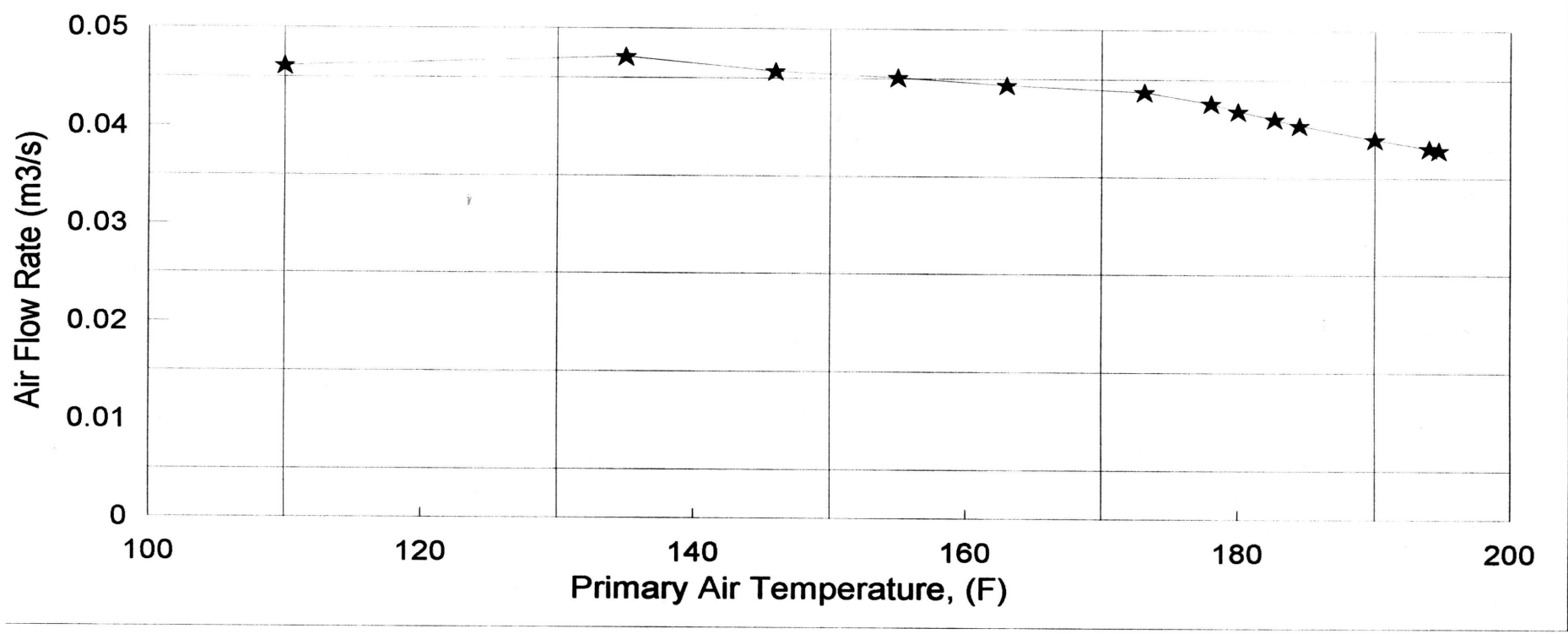

Figure 18 Air Flow Rate vs. Primary Air Temperature 
The test conditions for the tests with feeding millet particles into the riser included (i) fully opening the primary air inlet valve, (ii) fully closing the bypass controlling valve, and stable running condition.

When the system reached to its stable running condition, the aeration air valve was slowly opened and the solid particles were fed into the riser. The solid feed rate was a function of the aeration airflow rate as shown in Figure 19. The solid feed rate was set at $12 \mathrm{ft} / \mathrm{hr}$ of aeration air flow rate for starting feeding point, and it increased as the aeration flow rate increased. When the solid feed rate increased, the total pressure drop of the riser column increased. That indicated the bed void fraction was reduced or the bed density was increased. The maximum solid feed rate was about $0.075 \mathrm{~kg} / \mathrm{s}$ and the total riser pressure drop was $380 \mathrm{~mm}$-water as shown in Figure 20. Under this condition, the most important cold flow hydrodynamics can be calculated. The bed void fraction was about 0.6 , and total solid accumulated in the riser was about $30.25 \mathrm{~kg}$. The average solid residence time in the riser column was about 6.72 minutes, and the average solid particle velocity was $0.544 \mathrm{~m} / \mathrm{s}$. The gas velocity through the column was about $7.67 \mathrm{~m} / \mathrm{s}$. So, the relative slip velocity between the gas and solid particles was about $7.12 \mathrm{~m} / \mathrm{s}$, which was about 6.2 times of the terminal velocity.

(c) Test of Solid Particles

The CFB system was modified to use millet particles by changing the cloth filter of the gas distributor to a metal screen in order to reduce 


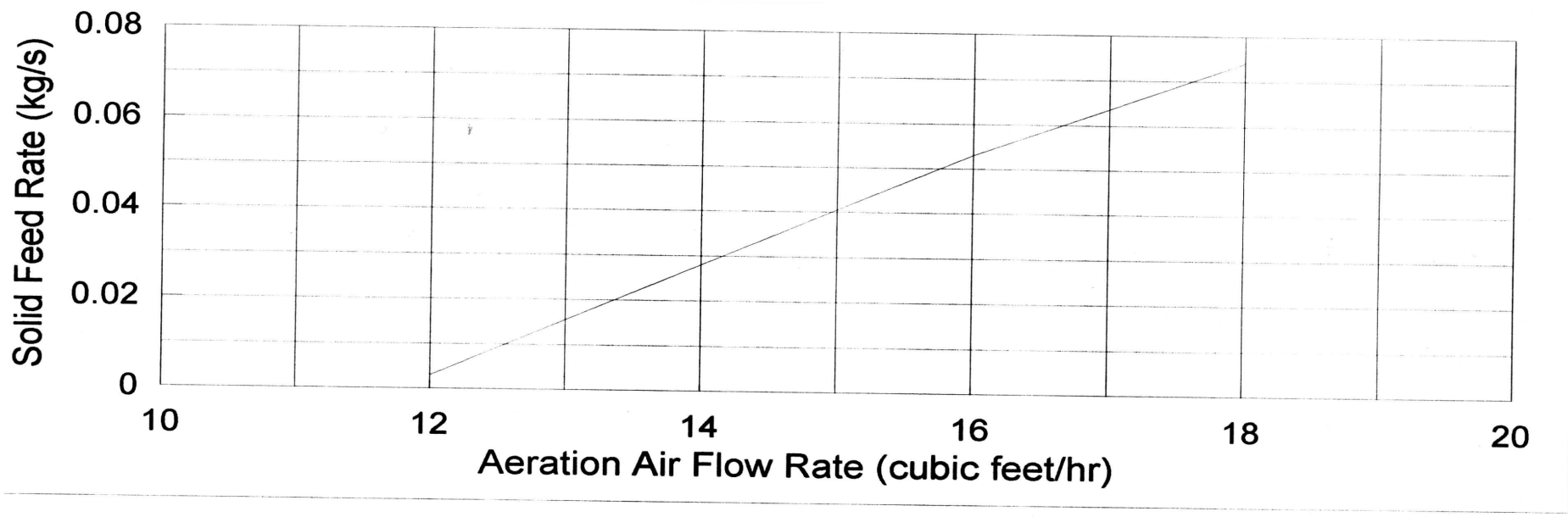

Figure 19 Solid Feed Rate vs. Aeration Air Flow Rate 


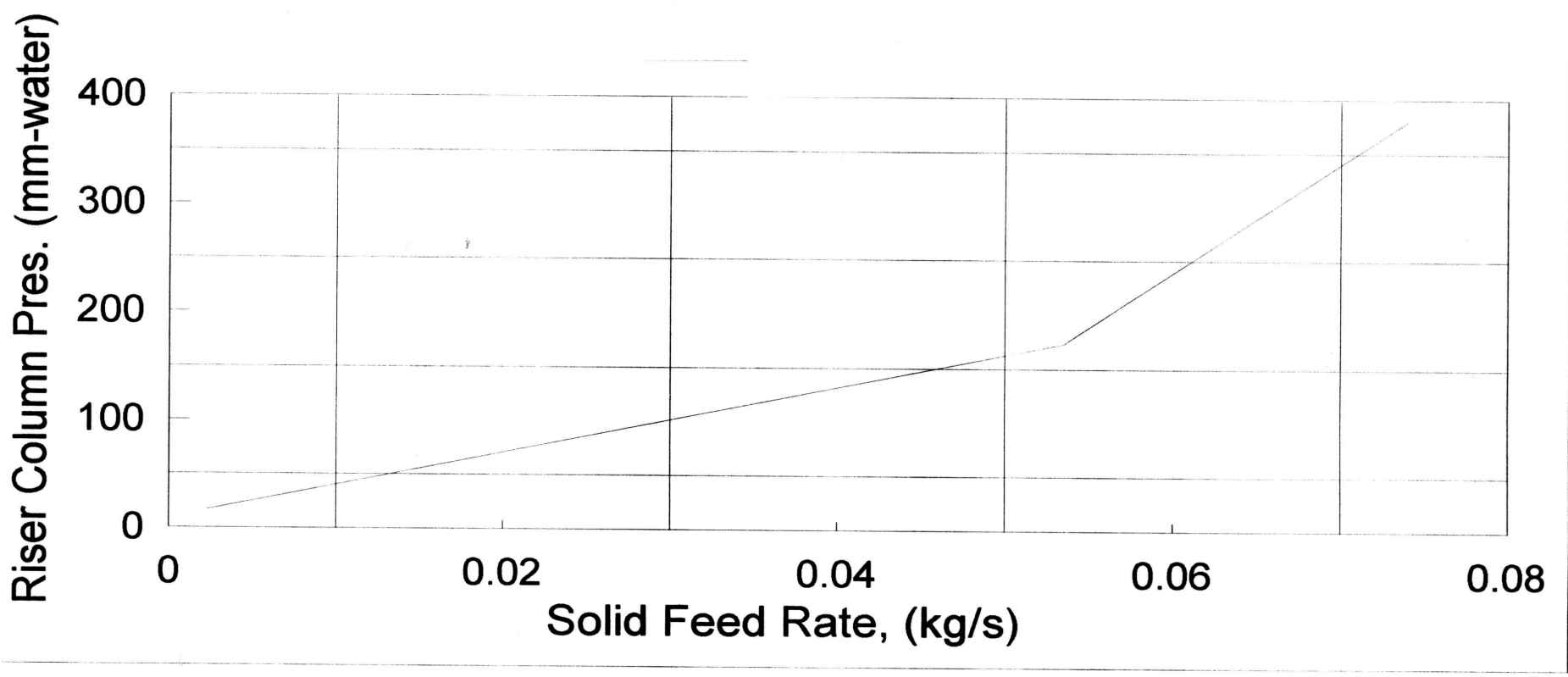

Figure 20 Pressure Change of Riser Column vs. Solid Feed Rate 
the pressure drop of the gas distributor, and to increase the primary air flow rate. With these system modifications, the CFB system was tested with the millet particles. The maximum solid feed rate was about $6.5 \mathrm{ft} / \mathrm{min}$. The primary airflow rate was $0.0866 \mathrm{~m} / \mathrm{s}$ which was responded to a riser column superficial velocity of $10.68 \mathrm{~m} / \mathrm{s}$. It was slightly greater than the particle terminal velocity. 


\section{MEASUREMENTS OF THE GAS AND PARTICLE FLOW FIELDS}

\subsection{Test Conditions}

Pressure transducers along with a computer-assisted data acquisition system were carefully calibrated for pressure measurement [11].

A total of $63 \mathrm{lbs}$ of millet particles were inputted into the CFB system. Two different flow patterns such as dense phase and dilute phase in the riser were adjusted by changing the solid feed rate through the L-valve was controlled by the aeration (secondary) air flow rate. Two different gas superficial velocities, $9.7 \mathrm{~m} / \mathrm{s}$ and 10.7 $\mathrm{m} / \mathrm{s}$ were tested with different solid particle feed rates. Detailed test conditions are summarized in Table 2.

Table 2 Planned Test Matrix

\begin{tabular}{|l|l|l|}
\hline Flow Condition & Dense Phase & Dilute Phase \\
\hline Gas Superficial Velocity $(\mathrm{m} / \mathrm{s})$ & 9.7 & 10.7 \\
\hline & 3391 & 4030 \\
Solid Particle Feed Rate (m/s) & 2848 & 2781 \\
& 2153 & 991 \\
\hline
\end{tabular}

\subsection{Results and Discussion}

\subsubsection{Test with Lower Gas Superficial Velocity}

The lower gas superficial velocity, $9.7 \mathrm{~m} / \mathrm{s}$ in the rise column was applied for different solid feed rates including, case $1 ; 3391 \mathrm{~g} / \mathrm{min}$, case 2; $2848 \mathrm{~g} / \mathrm{min}$, and case 3; $2153 \mathrm{~g} / \mathrm{min}$. Figure 21 shows the pressure changes along the riser column of the CFB system for three different cases. The pressure drop decreased as the riser column height of CFB increased. The change of pressure drop of case 3 is less than that of case 1. 
In order to scale up these experimental results of pressure drop, three nondimensional equations were employed to predict non-dimensional pressure changes along the non-dimensional column height. These equations are formulated for three cases by logarithm and regression method [12]. The nondimensional pressure change is based on the pressure at the bottom of the CFB riser as the reference point. The nondimensional column height is based on the riser column height as a reference point.

For Case 1:

$$
\mathrm{P} / \text { Pref }=-0.18601 \times \ln (\mathrm{L} / \text { Lref })+0.99716
$$

Where Pref is $487 \mathrm{mmH} 2 \mathrm{O}$ of pressure and Lref is $386.84 \mathrm{~cm}$.

For Case 2:

$$
\mathrm{P} / \text { Pref }=-0.115605 \times \ln (\mathrm{L} / \mathrm{Lref})+1.01487
$$

Where Pref is $536 \mathrm{mmH} 2 \mathrm{O}$ of pressure and Lref is $386.84 \mathrm{~cm}$.

For Case 3:

$$
\mathrm{P} / \text { Pref }=-0.120397 \mathrm{x} \ln (\mathrm{L} / \mathrm{Lref})+1.00427
$$

Where Pref is $511 \mathrm{mmH} 2 \mathrm{O}$ of pressure and Lref is $386.84 \mathrm{~cm}$. 
The experimental data are compared with the calculation results for three different cases as shown in Figure 22. When the solid feed rate decreased from 3391 $\mathrm{g} / \mathrm{min}$ to $2153 \mathrm{~g} / \mathrm{min}$ (36 $\mathrm{wt} \%$ decrease), the relative pressure drop rate decreased from 


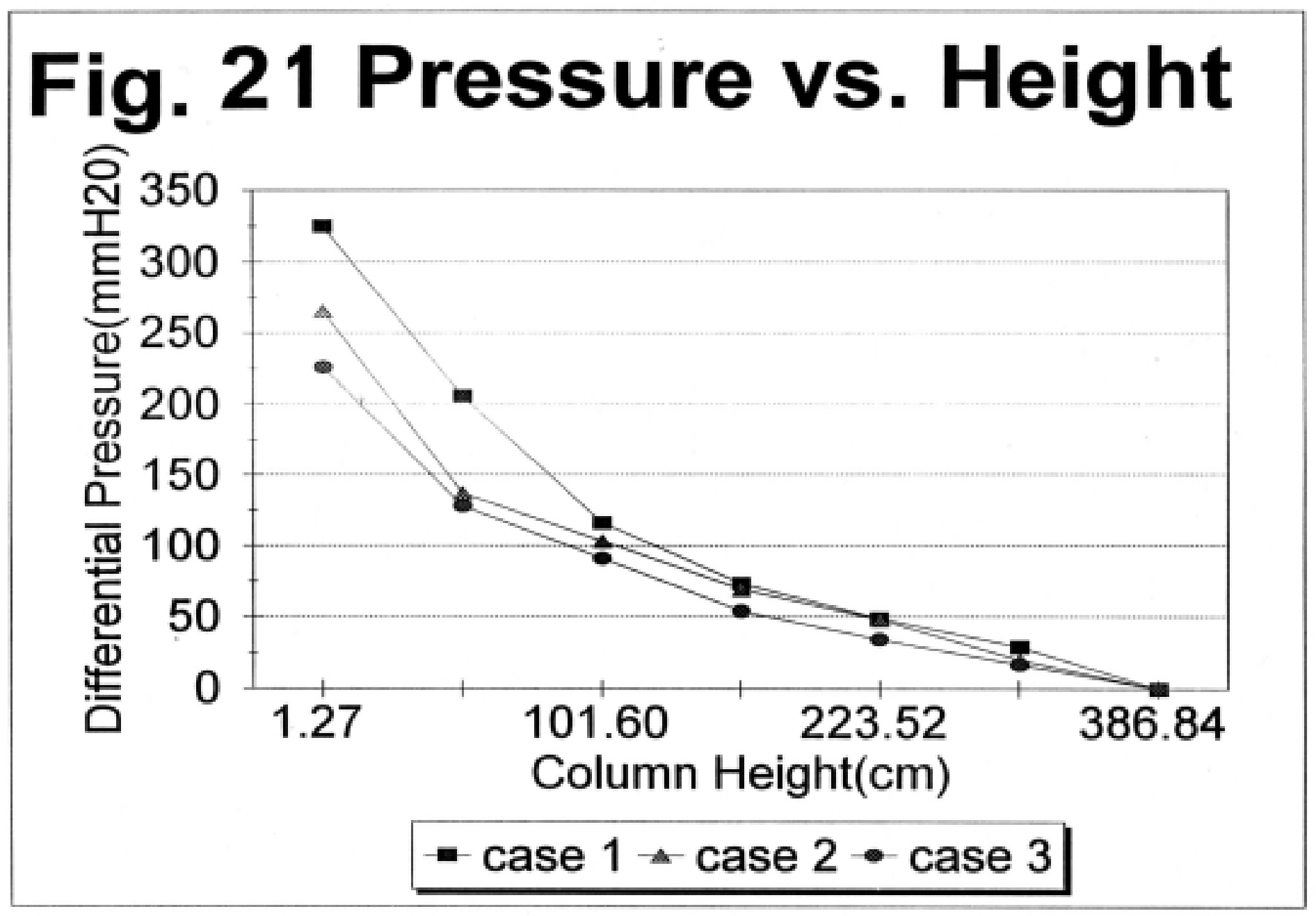




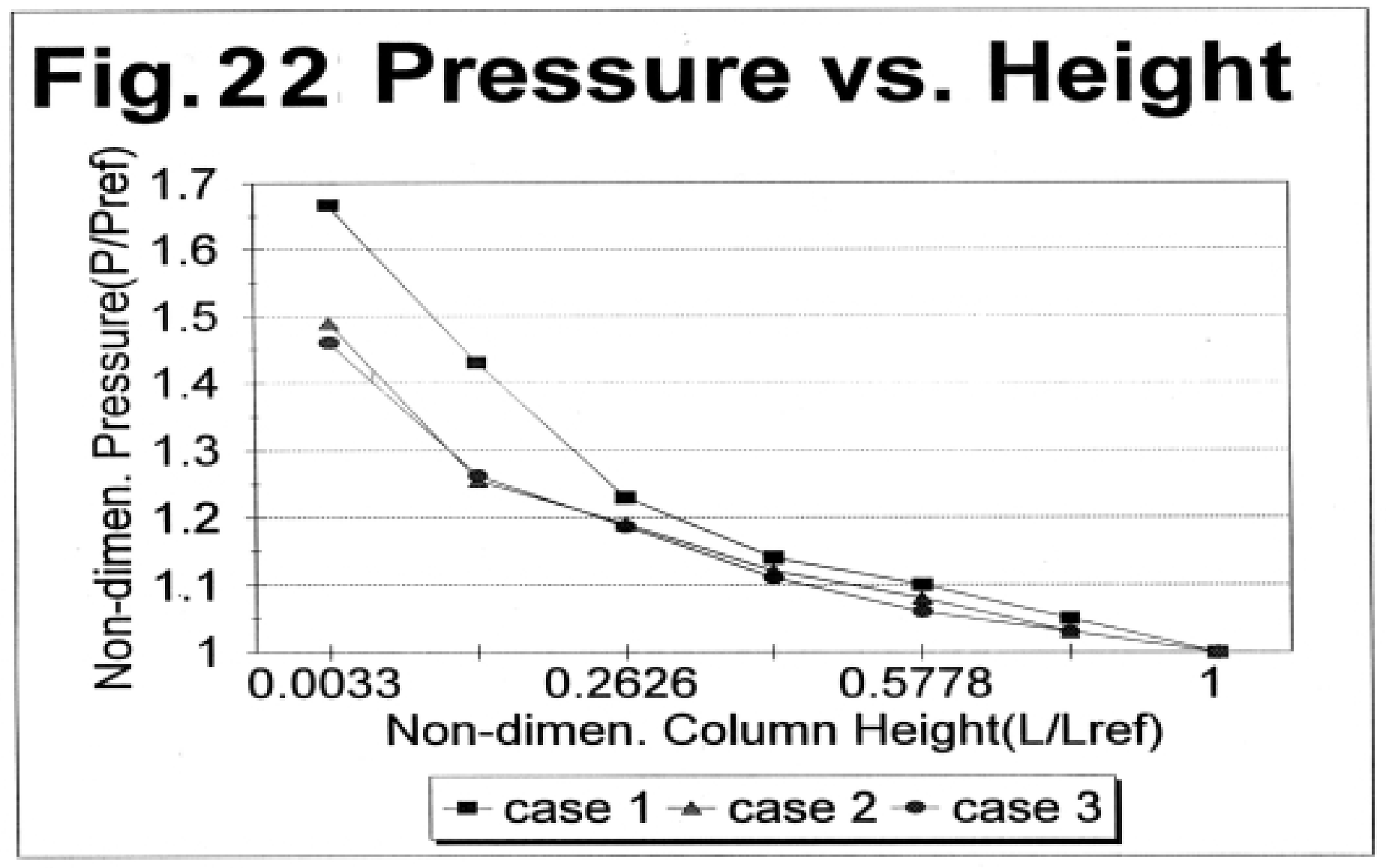


0.186 to 0.1204 (about $35 \%$ decrease). It is very interesting to note that the relative pressure change is almost the same percentage as the solid feed rate change.

The velocities of gas and solids can be estimated by the solid particle terminal velocity, ut, the gas superficial velocity in the riser of CFB system and bed void fraction. The gas average velocity decreased in the column of CFB as the column height increased as shown in Figure 23. At the top section of column, the gas velocity is about $11 \mathrm{~m} / \mathrm{s}$, which is about 1.5 times of the solid particle terminal velocity for three cases.

It is believed that the motion of the solid phase is slower than that of the gas phase in the riser tube.

\subsubsection{Test with Higher Gas Superficial Velocity}

Test conditions for the higher gas superficial velocity include setting the gas superficial velocity, $10.7 \mathrm{~m} / \mathrm{s}$ in the riser column and adjusting the secondary (aeration) air flow rate to change the solid feed rates for the three test cases including case $4 ; 4030$ $\mathrm{g} / \mathrm{min}$, case $5 ; 2781 \mathrm{~g} / \mathrm{min}$, case $6 ; 991 \mathrm{~g} / \mathrm{min}$. The pressure drop decreased as the riser column height increased as shown in Figure 24.

Three nondimensional logarithmic equations and regression method were employed to predict non-dimensional pressure changes along the non-dimensional column height. The nondimensional logarithmic equations for three cases are as follows: 


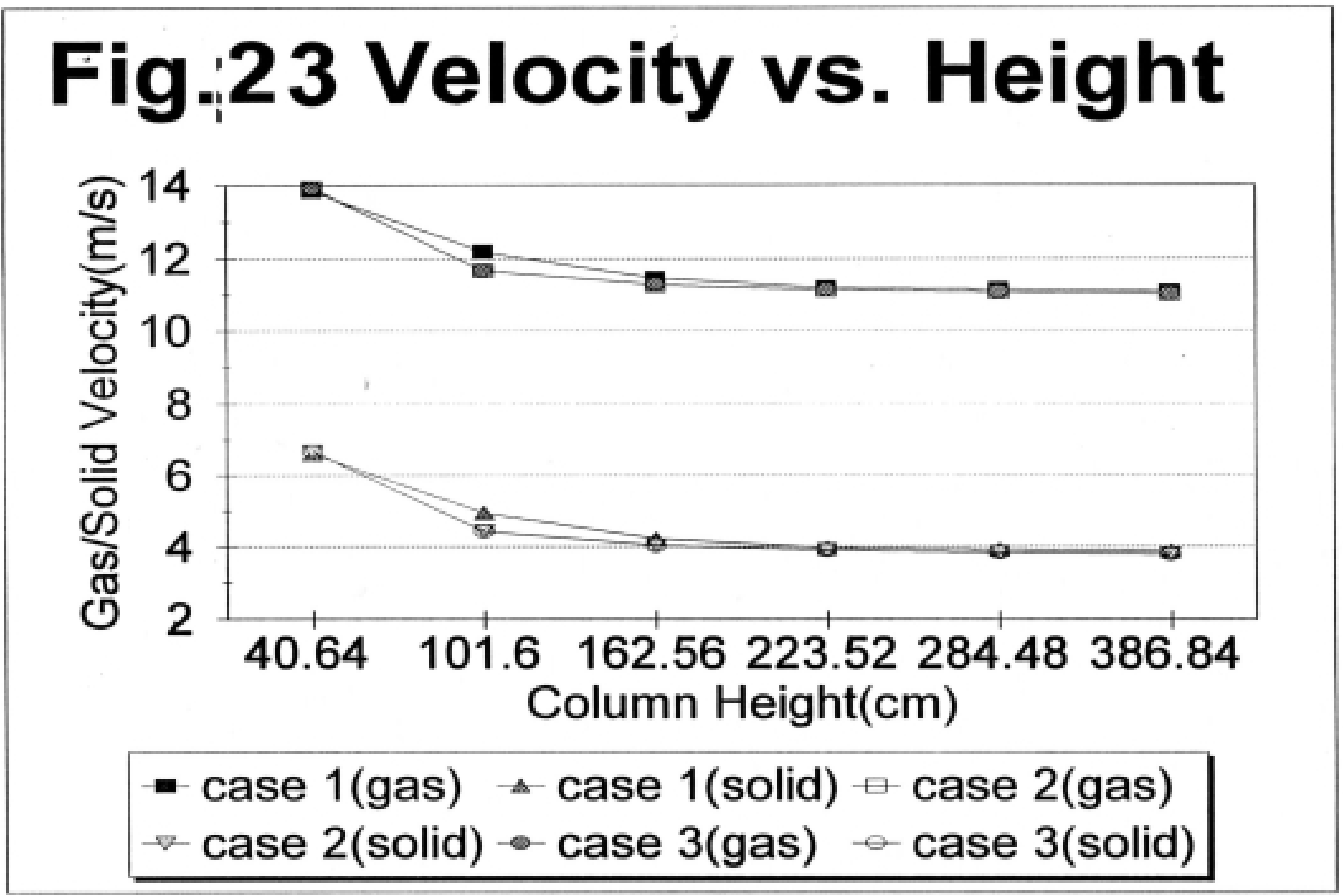




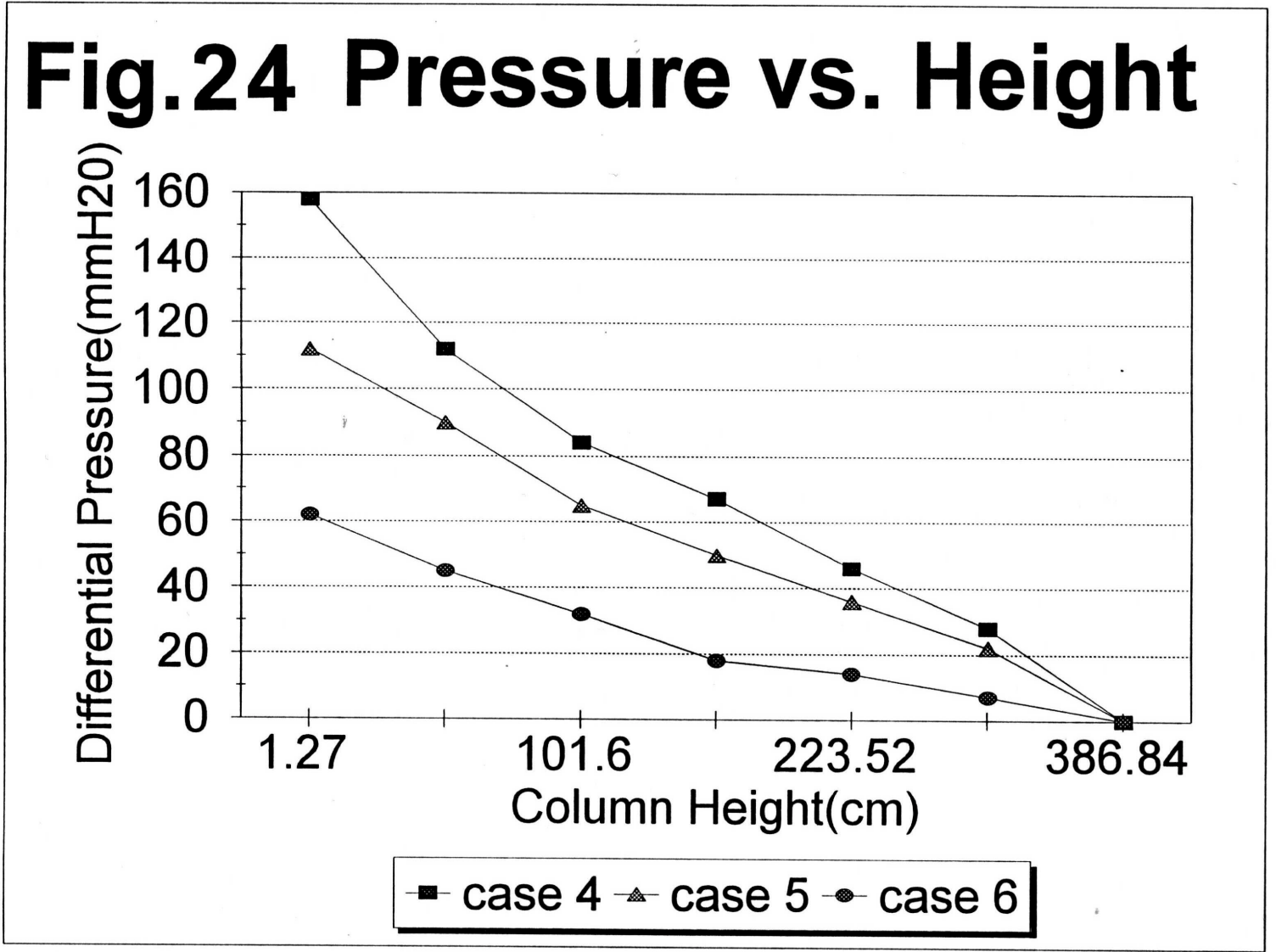


For Case 4:

$\mathrm{P} /$ Pref $=-0.076547 \times \ln (\mathrm{L} /$ Lref $)+1.02209$

Where Pref is $625 \mathrm{mmH} 2 \mathrm{O}$ of pressure and Lref is $386.84 \mathrm{~cm}$.

For Case 5:

$\mathrm{P} /$ Pref $=-0.0589613 \times \ln ($ L/Lref $)+1.01522$

Where Pref is $650 \mathrm{mmH} 2 \mathrm{O}$ of pressure and Lref is $386.84 \mathrm{~cm}$.

For Case 6:

$\mathrm{P} /$ Pref $=-0.03301 \times \ln ($ L/Lref $)+1.0023$

Where Pref is $613 \mathrm{mmH} 2 \mathrm{O}$ of pressure and Lref is $386.84 \mathrm{~cm}$.

The experimental data are compared with the calculation results for three different cases as shown Figure 25. When the solid particle feed rate decreased from $4030 \mathrm{~g} / \mathrm{min}$ to $991 \mathrm{~g} / \mathrm{min}$, the relative pressure drop rate decreased from 0.07655 to 0.03301

Based upon the pressure change information and the nondimensional logarithmic equations for three different cases, the void fraction and the velocities of gas and solid particles can be estimated. The void fraction increased as the riser column height increased as shown in Figure 26. When the solid feed rate decreased, the bed void fraction increased at the riser bottom, but is almost same value at the riser top of CFB system.

The velocities of gas and solid particles are shown in Figure 27. The ranges of gas velocity change are $10.5 \mathrm{~m} / \mathrm{s}$ to $12.5 \mathrm{~m} / \mathrm{s}$. The gas velocity decreased in the column of 
CFB as the column height increased. The change of solid particle velocity is lower than that of gas velocity. The ranges of solid particle velocity are $3.5 \mathrm{~m} / \mathrm{s}$ to $5.0 \mathrm{~m} / \mathrm{s}$. 


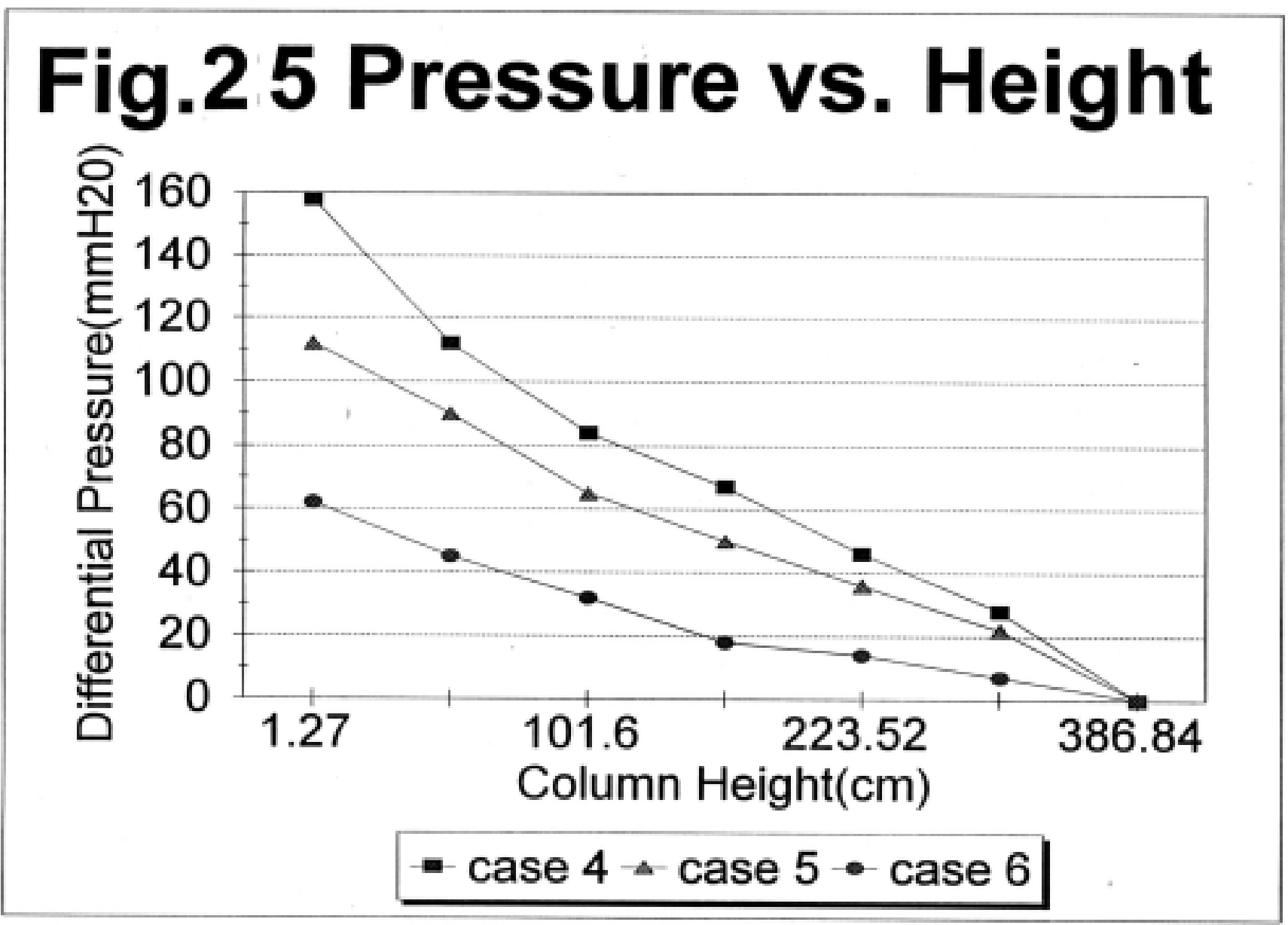




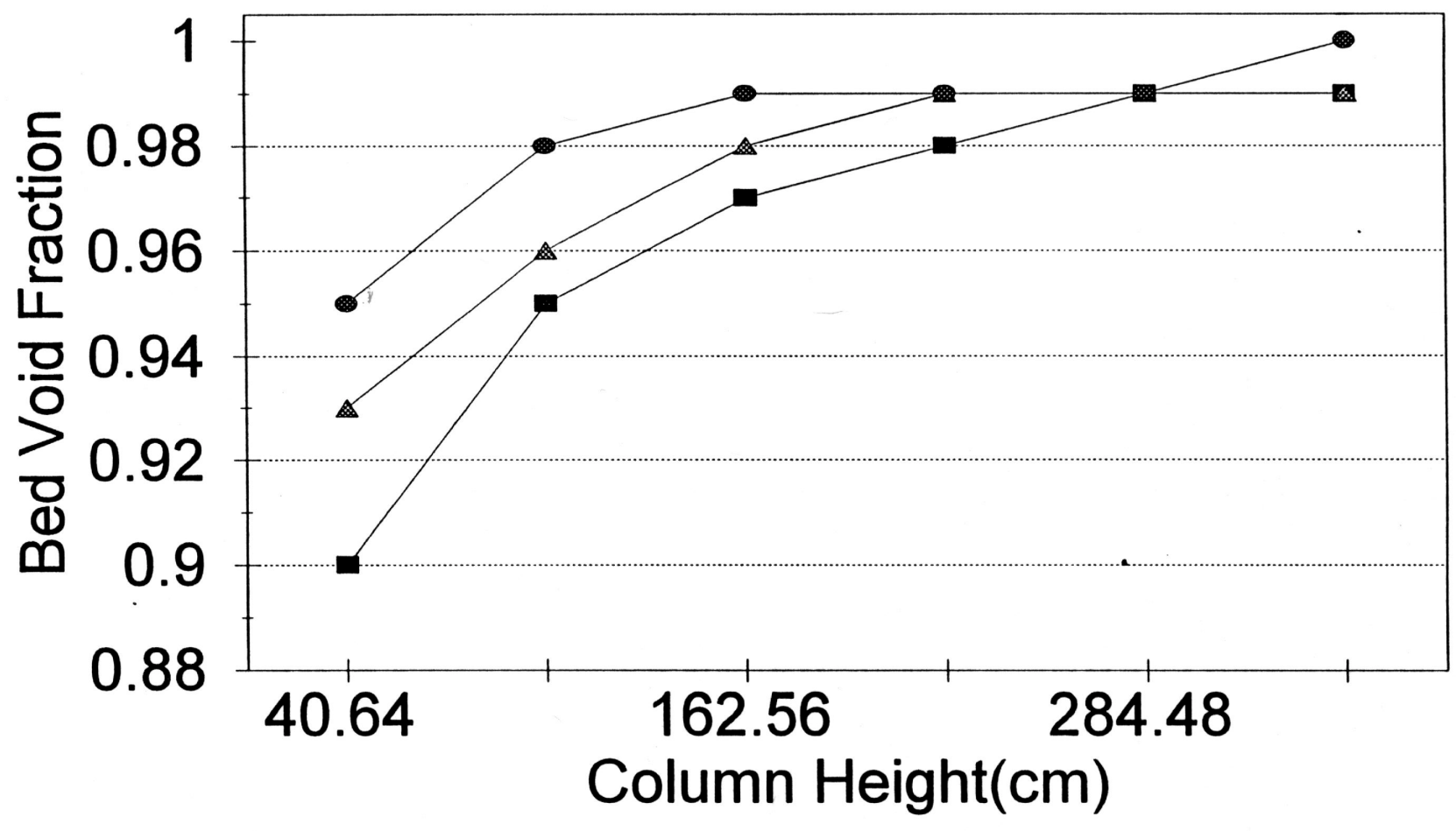

Figure 26 Void Fract. Vs. Height 


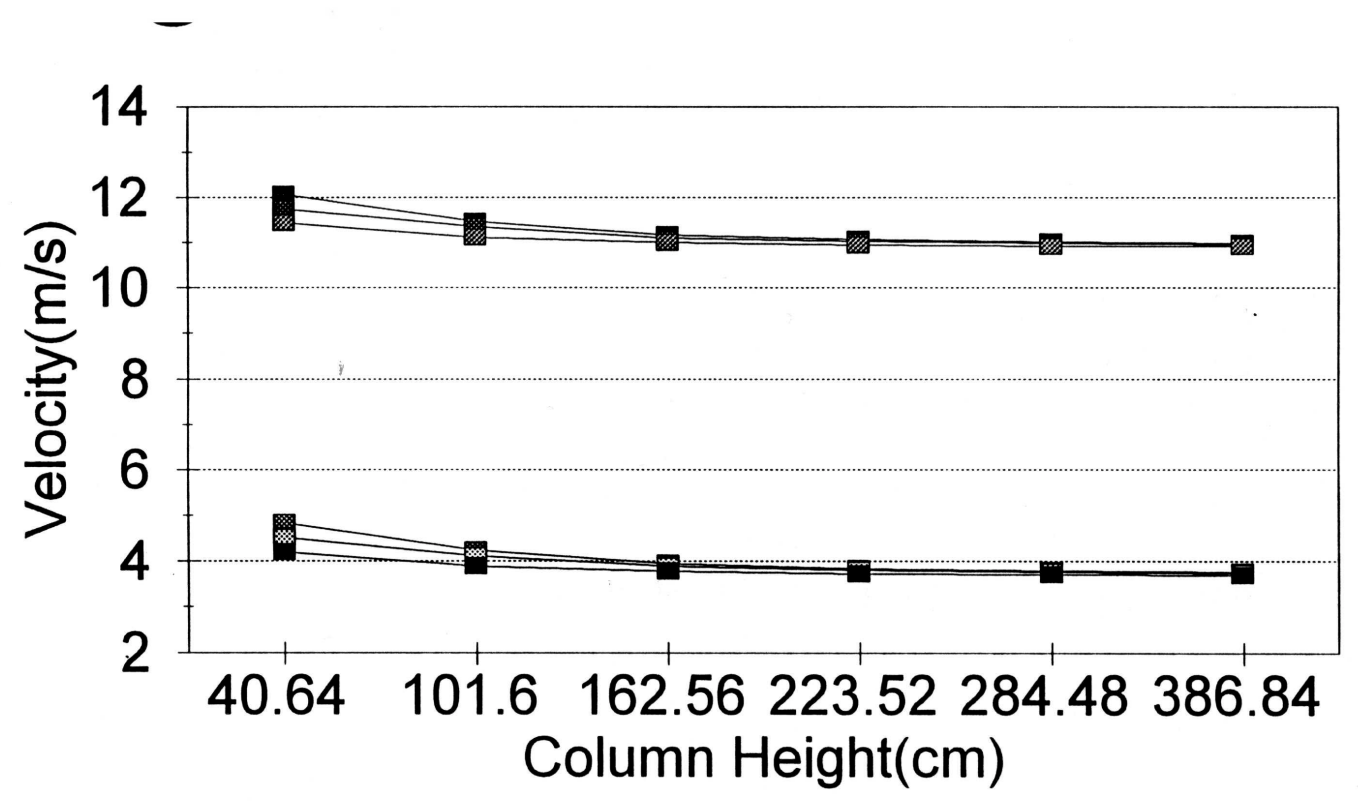

- case 4(gas) - case 4(solid) - case 5(gas) - case 5(solid) - case 6(gas) - case 6(solid)

Figure 27 Velocity vs. Height 


\section{DESIGN AND ARRANGEMENT OF THE HEAT TRANSFER PROBE}

The main column of a circulating fluidized bed normally consists of a core of uniformly dispersed solids which move up with the upper flowing gas surrounded by a thin annul where the solid clusters usually move down [13]. Thus the mechanism of bed to wall heat transfer in these two regions need to be studied. In the annuls region, the wall of the heat transfer surface usually contacts with the clusters and dispersed phase. The heat transfer coefficient in the core region might include the heat transfer coefficient due to the dispersed phase and the gas phase.

As shown in Figure 28, the bench-scale CFB model and supporting auxiliary subsystems are including the air supply system, instrumented riser, gas-solid separation system, and solid return/storage tank. The air supply subsystem consists of blower, control valves, PVC piping, and flow measuring devices.

A $13 \mathrm{~mm}$ O.D. and $343 \mathrm{~mm}$ long copper tube will be used as the heat transfer tube to measure the heat transfer coefficients at different axial and radial locations. In order to calculate the heat transfer rate, the heat transfer probe will be placed near the wall. The probe will be placed $57.2 \mathrm{~cm}$ above the distributor plate as shown in Figure 24 . Hot water will be passed through the tube and the temperature drop of water will be noted at different locations using thermocouple and thermometer. The heat transfer rate will be measured without the bed particles at first stage. 


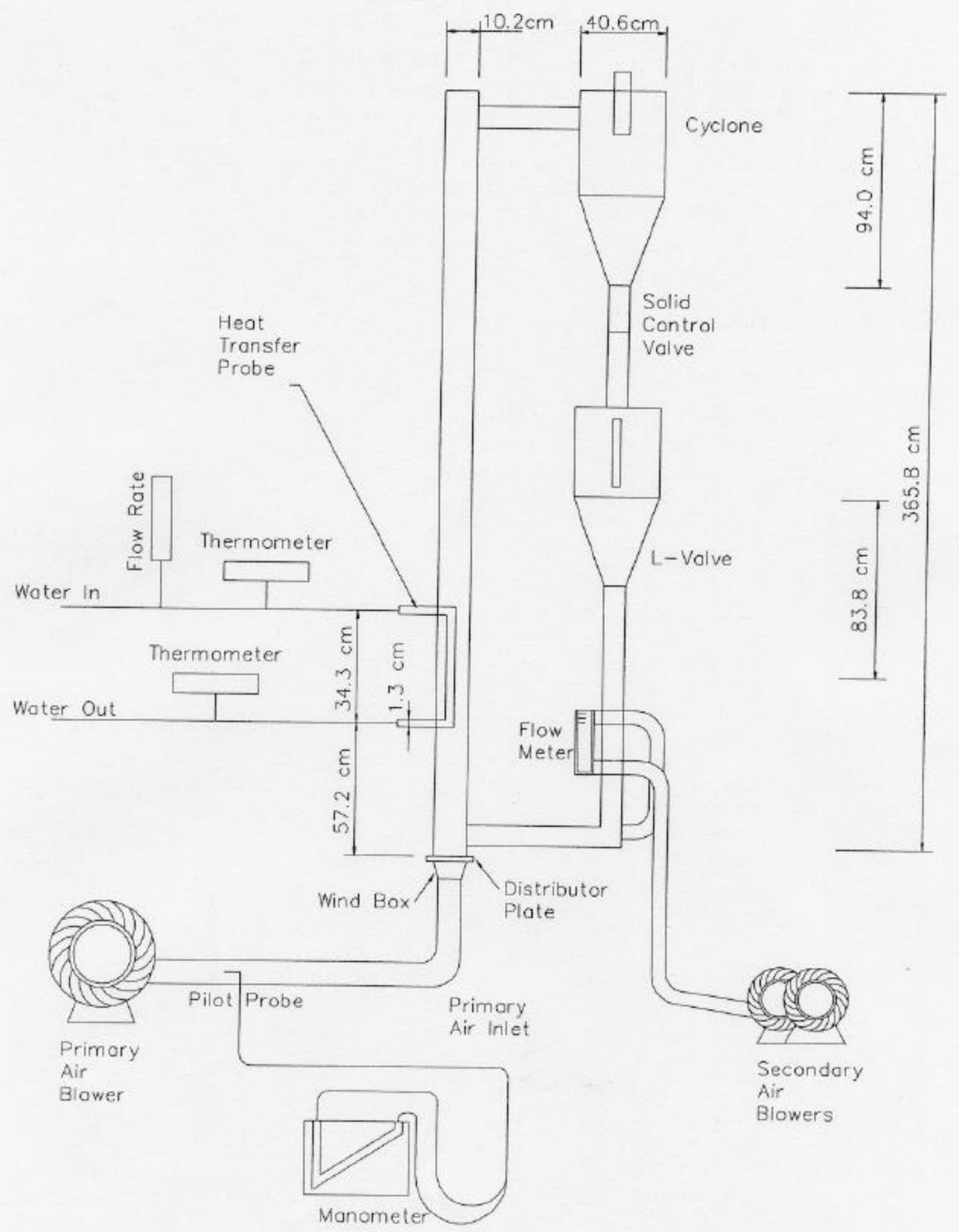

Figure 28 Schematic Diagram of the Bench-scale CFD System With the Heat Transfer Probe 


\subsection{HEAT TRANSFER MECHANISMS AND THEORY}

The main column of a circulating fluidized bed consists of a core of uniformly dispersed solids which move up with the upflowing gas surrounded by a thin annulus where solid agglomerates or clusters move down. Therefore, the mechanism of bed to wall heat transfer in these two regions need to be studied separately. A heat transfer probe placed near the wall. The results indicated different heat transfer coefficients at different axial locations of the probe. Similarly, at a particular axial location of the probe, beat transfer coefficient changed as the probe is moved from the wall to the core region of the bed.

In the annulus, the wall of a heat transferring surface usually comes into contact with clusters and dispersed phase. In the annulus region the heat transfer coefficient is dictated partly by clusters and partly by dispersed phase and is given by [14]

$$
\mathrm{h}=\mathrm{hc} \delta \mathrm{c}+(\mathrm{hd}+\mathrm{hg})(1-\delta \mathrm{c})
$$

The term (hd+hg) is the contribution by dispersed phase which is discussed later. The fraction of wall area covered by clusters, $\delta c$ may be written as [15]

$$
\delta \mathrm{c}=\mathrm{K}[(1-\varepsilon \mathrm{W}-\mathrm{Y}) /(1-\varepsilon \mathrm{c})]^{0.5}
$$

In Equation (2) the voidage near the wall, $\varepsilon \mathrm{w}$ is obtained from the following equation proposed by [16] after assuming $\mathrm{r} / \mathrm{R}$ equal to 1 .

$$
\varepsilon(r)=\mathcal{E}_{a v}^{\left[3.62(r / R)^{0.622}+1.191\right]}
$$

The volume fraction of the dispersed solids in the annulus, $\mathrm{Y}$ is assumed to be equal to the volume fraction of solids in the core. This is obtained by considering the core-annulus structure of the bed. 
Following equation [17], at a particular cross-section of the bed, the upward and downward flux are related as,

\section{Gup-Gdown=Gs}

The upward flux in the core region at any axial location is given by

$$
\text { Gup -Usc(1- } \varepsilon \text { core }) \rho s(\tau c / R)^{2}
$$

Where Usc is the actual solid particle velocity in the core, ecore is the core voidage and $\tau \mathrm{c}$ is the radius of the core.

The upward solid particle velocity in the core is taken as,

$$
\mathrm{Usc}=\mathrm{Ugc}-\mathrm{Ut}
$$

The downward flowing solid can be assumed to move at a velocity equal to the maximum falling velocity of clusters, Umc. The downward flux can be calculated as

$$
\text { Gdown }=\left[1-(\tau \mathrm{c} / \mathrm{R})^{2}\right] \operatorname{Ps}(1-\varepsilon w) \mathrm{Umc}
$$

Equations (4) to (7) may be rearranged to give the following equation of core voidage

$$
\varepsilon_{\text {core }}=1-\frac{G_{s}+\left[1-\left(r_{c} / R\right)^{2}\right] \rho_{s}\left(1-\varepsilon_{w}\right) U_{m c}}{\left.\rho_{s}\left(r_{c} / R\right)^{2}\left[U_{0} / \varepsilon_{\text {core }}\right)\left(R / r_{c}\right)^{2}-U_{m c}\right]}
$$

The average voidage at any axial location, $\varepsilon_{\mathrm{av}}$ can be correlated with the voidage in the core region $\varepsilon_{\text {core }}$ and voidage near the wall $\varepsilon_{\mathrm{w}}$, by

$$
\left(r_{c} / R\right)^{2}=\left(\varepsilon_{a v}-\varepsilon_{w}\right) /\left(\varepsilon_{c o r e}-\varepsilon_{w}\right)
$$

Equation (8) and (9) are solved simultaneous to obtain $\varepsilon_{\text {core }}$ at any axial location of the bed.

By considering the transient heat conduction into the cluster the heat transfer coefficient $\mathrm{h}_{\mathrm{c}}$ is obtained from the following equation $[14,15,16]$.

$$
h_{c}=\frac{1}{\left(d_{p} / 10 k_{g}\right)+\left(t_{c} \pi / 4 k_{c} c_{c} \rho_{c}\right)^{0.5}}
$$


The value of maximum cluster velocity, $U_{m c}$ was taken as $1.26 \mathrm{~m} / \mathrm{s}$ [18]. The heat transfer coefficient due to the dispersed phase is obtained from the equation of Wen and Miller [19]

$h_{d}=\left(k_{g} / d_{p}\right)\left(c_{s} / c_{g}\right)\left(\rho_{\text {dis }} / \rho_{s}\right)^{0.3}\left(u_{t}^{2} / g d_{p}\right)^{0.21} P_{t}$

In the core region, the heat transfer coefficient will be given by the following equation

$$
h_{\text {core }}=h_{d}+h_{g}
$$

In the equation (12) the dispersed phase heat transfer coefficient, $h_{d}$ was calculated by using Equation (11). The values of $\varepsilon_{\text {core }}$ as obtained from Equations (8) and (9) was substituted when $0<\mathrm{r} / \mathrm{R}<0.75$, and $\varepsilon(\mathrm{r})$ from Equation (3) was substituted when $0.75<$ $\mathrm{r} / \mathrm{R}<1$.

Notation:

$\mathrm{Cs}, \mathrm{Cg}, \mathrm{Cc} \quad$ specific heat of solid, gas and cluster respectively $(\mathrm{kj} / \mathrm{kg} . \mathrm{K})$

dp bed particle diameter(m)

Gs net solid circulation rate $(\mathrm{kg} / \mathrm{m} 2 . \mathrm{s})$

h, hc,hd,hg total heat transfer coeff. and due to cluster, dispersed phase and gas respectively.(w/m2k)

$\mathrm{kg}, \mathrm{kc} \quad$ conductivity of gas and cluster respectively $(\mathrm{w} / \mathrm{mk})$

K Constant in Equation.

L length of the probe from the top $(\mathrm{m})$

$\mathrm{r} \quad$ radius of the bed from the center(m)

$\mathrm{R} \quad$ inner radius of the bed $(\mathrm{m})$ 


$\begin{array}{ll}\mathrm{U}_{\mathrm{gc}} & \text { gas velocity in the core region }(\mathrm{m} / \mathrm{s}) \\ \mathrm{U}_{\mathrm{mc}} & \text { maximum falling velocity of the clusters }(\mathrm{m} / \mathrm{s}) \\ \mathrm{U}_{\mathrm{o}} & \text { superficial gas velocity }(\mathrm{m} / \mathrm{s}) \\ \mathrm{U}_{\mathrm{sc}} & \text { solid velocity in the core region }(\mathrm{m} / \mathrm{s}) \\ \mathrm{U}_{\mathrm{t}} & \text { terminal velocity of the bed solids }(\mathrm{m} / \mathrm{s}) \\ \mathrm{Y} & \text { fraction of wall area covered by clusters } \\ \delta_{\mathrm{c}} & \text { average voidage }, \text { cluster voidage and voidage near the wall } \\ \varepsilon_{\mathrm{av}}, \varepsilon_{\mathrm{c}}, \varepsilon_{\mathrm{w}}, & \text { voidage in the core } \\ \varepsilon_{\mathrm{core}} & \text { density of bed particles and cluster }\left(\mathrm{kg} / \mathrm{m}^{3}\right) \\ \rho_{\mathrm{s}}, \rho_{\mathrm{c}}, & \end{array}$

\subsection{Experimental Results of Heat Transfer Rate and Characteristics}

Heat transfer characteristics study and experimental work were continued using the bench-scale CFB system with the heat transfer probe [20]. A copper tube was used as the heat transfer probe which was convenient to measure the temperature changes at different locations using thermocouples. 
Figure 29 shows axial variation of heat transfer coefficient along with the probe height. The voidge did not change over the length of the probe.

Figure 29 Heat Transfer Coefficient Changes with the Probe Height

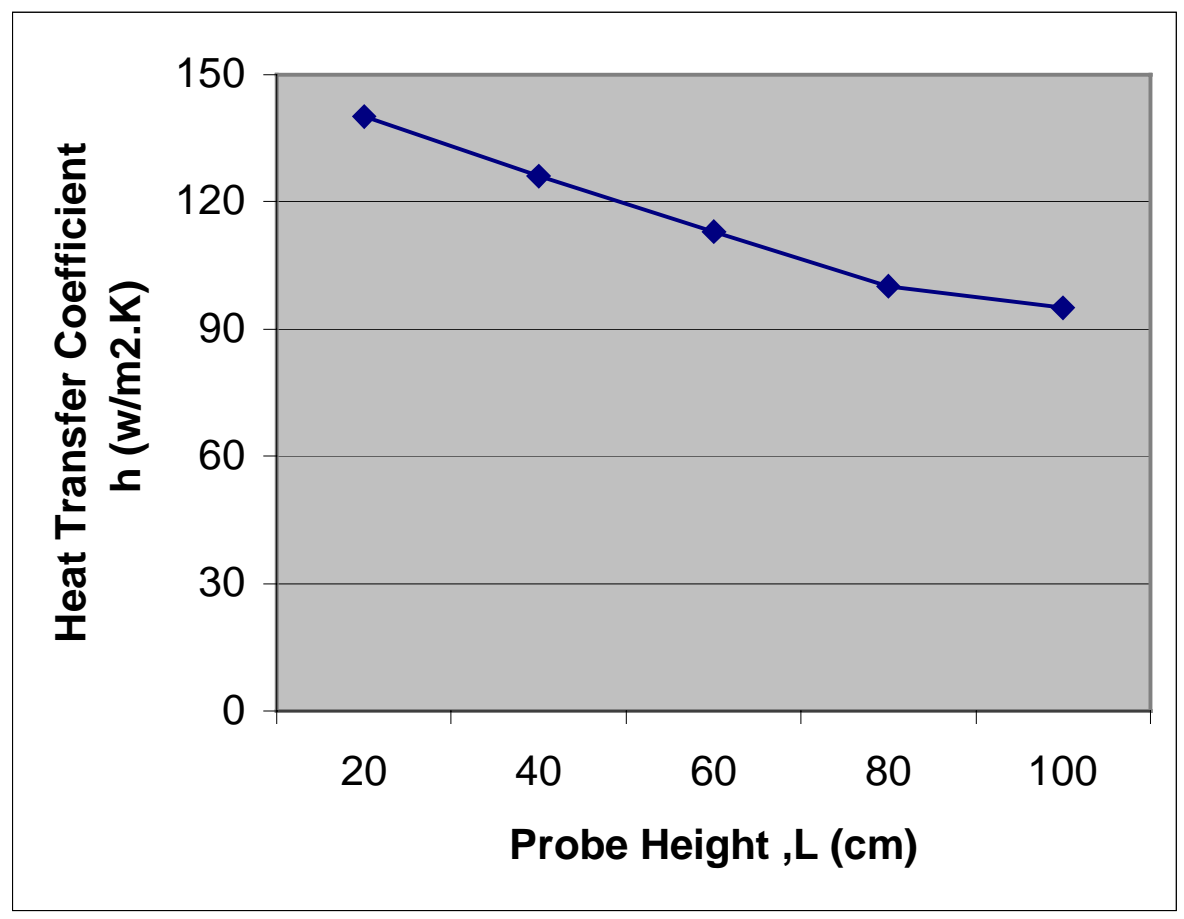

The heat transfer coefficient at different locations of the heat transferring surface decreases along the slides down the heat transfer surface; its temperature increase, which reducing the temperature difference between the surface of the tube and the bulk of the bed. This may make the heat transfer coefficient stable beyond a certain length of the heat transfer tube. Figure 30 shows radial variation of heat transfer coefficients. The results show little increase in heat transfer coefficient near the wall. It is believed that a heat transfer surface is located in the core region; a boundary layer develops near the wall of the surface. This may cause clusters or streamers to form which slides down the surface. 
According to results, heat transfer coefficients in the core region were not affected significantly by the location of the probe.

Figure 30 Heat Transfer Coefficient Changes with $r / R$

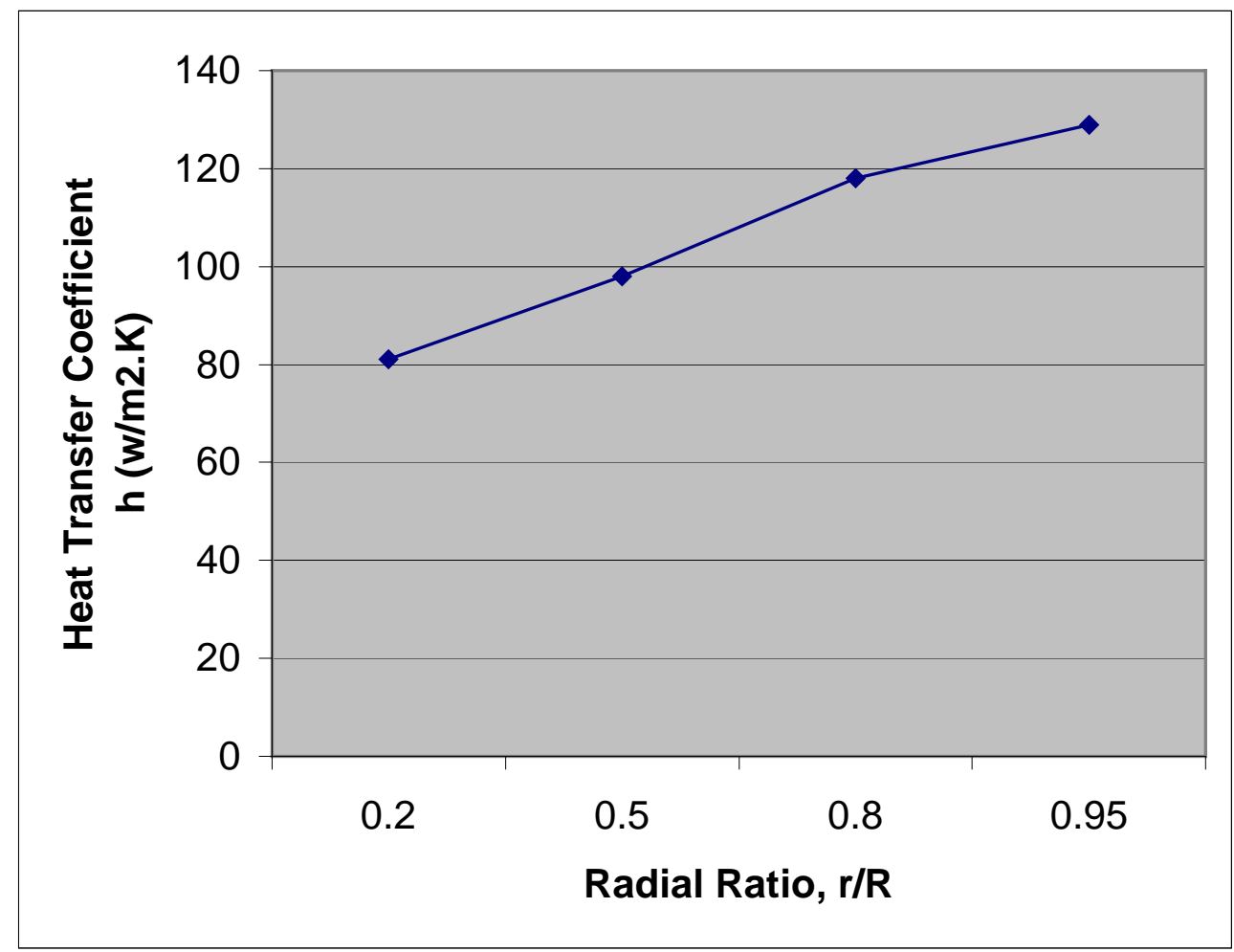

The wall conduction resistance was eliminated and heat transfer coefficients were measured and calculated at different locations along the bed height. Heat transfer coefficients near the wall area of the bed were decreased along with the length of the probe. Heat transfer coefficient was slightly dropped when the probe was moved from the wall area to the central area of the bed. 


\section{NUMERICAL SIMULATION FOR THE CFB COLD MODEL WITHOUT HEAT TRANSFER}

\subsection{Introduction}

Numerical modeling/simulation of gas-particle flows, heat transfer, and combustion processes in the circulating fluidized bed combustor have gradually increased with the development of modern computers. Numerical simulation has also been recognized as a powerful tool for design verification and operational guidance for CFBC system $[21,22]$. The successful simulation work may significantly reduce the efforts in the experimental study.

The purpose of the numerical simulation is to simulate the flow patterns with three-direction components and relative static pressure in the circulating fluidized bed (CFB) cold model system using the computational fluid dynamics (CFD) code, Fluent. This CFD code is loaded onto the Supercomputer, CRAY J916 system of Morgan State University.

\subsection{System Configuration}

The lower section of the CFB riser was $135 \mathrm{~cm}$ in height and $11.25 \mathrm{~cm}$ in diameter. The aeration (secondary) air inlet at the chamber wall was $15 \mathrm{~cm}$ from the gas distributor plate.

The system was configured in 3-D cylindrical coordinates with uniform mesh grids. The calculation grid was set of orthogonal lines arranged in the cylindrical coordinates, vertical direction $(\mathrm{k})$, radial direction $(\mathrm{J})$, and tangential direction.

The lines in the three directions were uniformly spaced. The computational cells and boundaries for the calculation domain are shown in Figure 31. There are a total of 
30422 grids in the system configuration including 41 slices of the tangential direction (I), 14 slices of the radial direction (J), and 53 slices of the vertical direction (k). Figure 10 shows a top view of the computational grid domain.

\subsection{Basic Physical Modeling}

The computational cells and boundaries for the calculation domain are introduced in the previous report [23]. Since the flow with a larger Reynolds number has a strong turbulence flow with unisotropic flow behaviors, the standard k-c turbulence model was not significant for this case. The Renormalization Group (RNG) k- $\varepsilon$ turbulence model [24] can provide more general/fundamental model which yields improved predictions of near the wall flow, wall heat/mass transfer, and wake/vortex shedding behavior [18]. our simulation results showed that the RNG k- $\varepsilon$ model could predict more accurate prediction of swirl than in standard k- $\varepsilon$ models (4).

The RNG k- $\varepsilon$ model uses the Reynolds Averaged Navier Stokes (RANS) equations with the turbulent stresses modeled via the effective viscosity concept $[25,26]$ : 


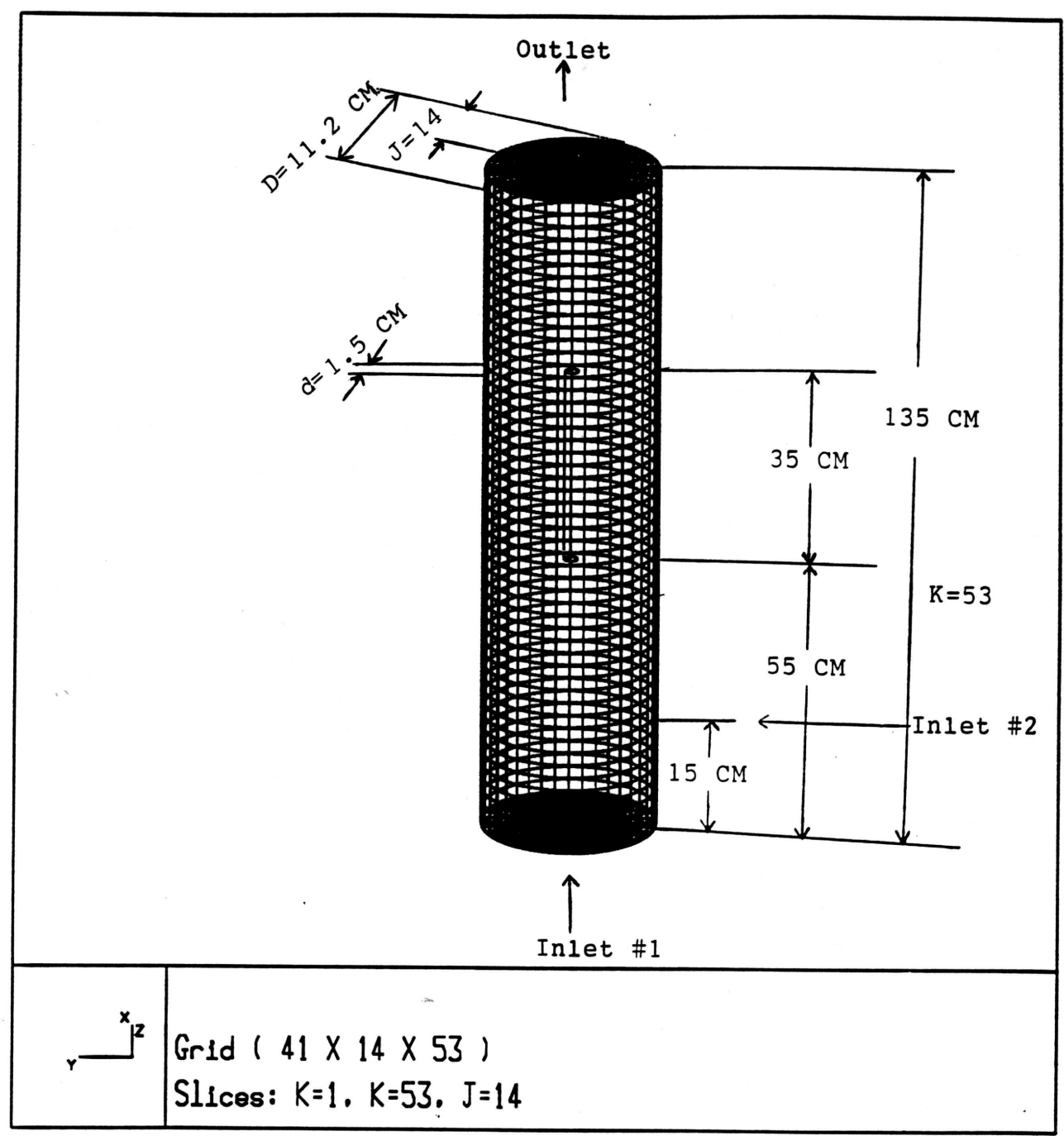

Figure 31 Flow System and Velocity Component in CFB Riser 


$$
\frac{\partial u_{i}}{\partial t}+\frac{\partial}{\partial x_{j}}\left(u_{i} u_{j}\right)=-\frac{1}{\rho} \frac{\partial p}{\partial x_{i}}+\frac{\partial}{\partial x_{j}}\left[v_{e f f}\left(\frac{\partial u_{i}}{\partial x_{j}}+\frac{\partial u_{j}}{\partial x_{i}}\right)\right]
$$

The effective viscosity required for closure of the momentum equations is computed via the differential form, which is provided by the RNG theory [24]. The RNG theory also provides the transport equations for $\mathrm{k}$ and $\varepsilon$ as,

$$
\frac{\partial k}{\partial t}+u_{i} \frac{\partial k}{\partial x_{i}}=v_{t} S^{2}-\varepsilon+\frac{\partial}{\partial x_{i}} \alpha v_{t} \frac{\partial k}{\partial x_{i}}
$$

and $\frac{\partial \varepsilon}{\partial t}+u_{i} \frac{\partial \varepsilon}{\partial x_{i}}=C_{1 \varepsilon} \frac{\varepsilon}{k} v_{t} S^{2}-C_{2 \varepsilon} \frac{\varepsilon^{2}}{k}-R+\frac{\partial}{\partial x_{i}} \alpha v_{t} \frac{\partial \varepsilon}{\partial x_{i}}$

where $\mathrm{a}$ is the inverse Prandtl number for turbulent transport.

The rate-of-strain term $\mathrm{R}$ is given by

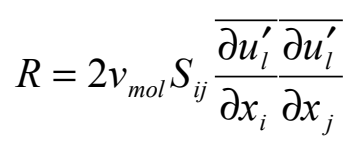

This term is expressed in the $R N G \mathrm{k}-\varepsilon$ model equations as

$$
R=\frac{C_{\mu} \eta^{3}\left(1-\eta / \eta_{0}\right)}{1+\beta \eta^{3}} \frac{\varepsilon^{2}}{k}
$$

where $\eta=\mathrm{Sk} / \varepsilon, \eta_{0}=4.38$, and $S^{2}=2 S i j, \quad S i j$ is the modulus of the rate-of-strain tensor. 


\subsection{Test Conditions}

The combustor dimensions, primary airflow condition, and aeration air flow condition are important factors for the test. The lower part of the CFB riser was used as the test section, $135 \mathrm{~cm}$ in height. The aeration (secondary) air inlet at the chamber wall was installed at the height of $15 \mathrm{~cm}$ from the gas distribute plate.

The system was configured in 3-D cylindrical coordinates with uniform mesh grids. The calculation grids was set of orthogonal lines arranges in the cylindrical coordinates, vertical direction (k), radial direction (J), and tangential direction (I) [27]. The lines in the three directions are uniformly spaced.

The test conditions and input boundary conditions are summarized in Table 3 .

Table 3 Test Conditions for Simulation

\begin{tabular}{|l|l|l|}
\hline Combustor Height & $\mathrm{Cm}$ & 135 \\
\hline Aeration Air Nozzle Height & $\mathrm{Cm}$ & 15 \\
\hline Heat Transfer Probe Diameter & $\mathrm{Cm}$ & 1.5 \\
\hline Heat Transfer probe Height & $\mathrm{Cm}$ & 35 \\
\hline \multicolumn{2}{|c|}{ Primary Air Flow Condition: } \\
\hline Air Flow Rate & $\mathrm{m}^{3} / \mathrm{s}$ & 0.1059 \\
\hline Air Velocity & $\mathrm{m} / \mathrm{s}$ & 10.65 \\
\hline Turbulence (K- $\varepsilon$ ) & $\mathrm{m}^{2} / \mathrm{s}^{3}$ & 0.3 \\
\hline Turbulence-Dissipation & $\mathrm{m}^{2} / \mathrm{s}^{3}$ & 0.3 \\
\hline \multicolumn{2}{|c|}{ Aeration Air Flow $\mathrm{Condition:}^{-3}$} \\
\hline Air Flow Rate & $\mathrm{m}^{3} / \mathrm{s}$ & $2.02 \mathrm{e}-3$ \\
\hline Air Velocity & $\mathrm{m} / \mathrm{s}$ & 1.03 \\
\hline Turbulence (K- $\varepsilon$ ) & $\mathrm{m}^{2} / \mathrm{s}^{2}$ & 0.5 \\
\hline Turbulence-Dissipation & $\mathrm{m}^{2} / \mathrm{s}^{3}$ & 0.5 \\
\hline
\end{tabular}




\begin{tabular}{|l|l|l|}
\hline Gas Density & $\mathrm{Kg} / \mathrm{m}^{3}$ & 1.2 \\
\hline Gas Viscosity & $\mathrm{N} . \mathrm{s} / \mathrm{m}^{2}$ & $1.72 \mathrm{e}-5$ \\
\hline
\end{tabular}

\subsection{Results and Discussions}

\subsubsection{The Effect of Air Velocity}

Figures 32 and 33 show a 2 -D velocity vector in slide plate $\mathrm{I}=4$ and $\mathrm{I}=24$. In the vertical direction, the lower velocity was found at the two ends of the probe, and along the riser wall at the aeration air input side as shown in Figure 32. The flow profiles below the probe were relatively uniform at the center region of the chamber.

When the airflow reached the probe, the uniform flow was spilt to two parts and the velocity of the center region was reduced as shown in Figure 33. The effects of aeration airflow on the flow patterns were on the same side as shown in Figure 33. The lower aeration airflow rate reduced the air flow velocity and caused a strong gas mixing process.

The characteristics of turbulence flow produced some vortex flow in the wall region. This result was clearly shown in Figures 34, 35, and 36 at levels k=15, 23, and 30. A comparison of Figure 34 (untouched probe) with Figures 35 and 36 (touched probe) indicated the vortex flow. This vortex flow increased as the flow touched the probe. This result also 


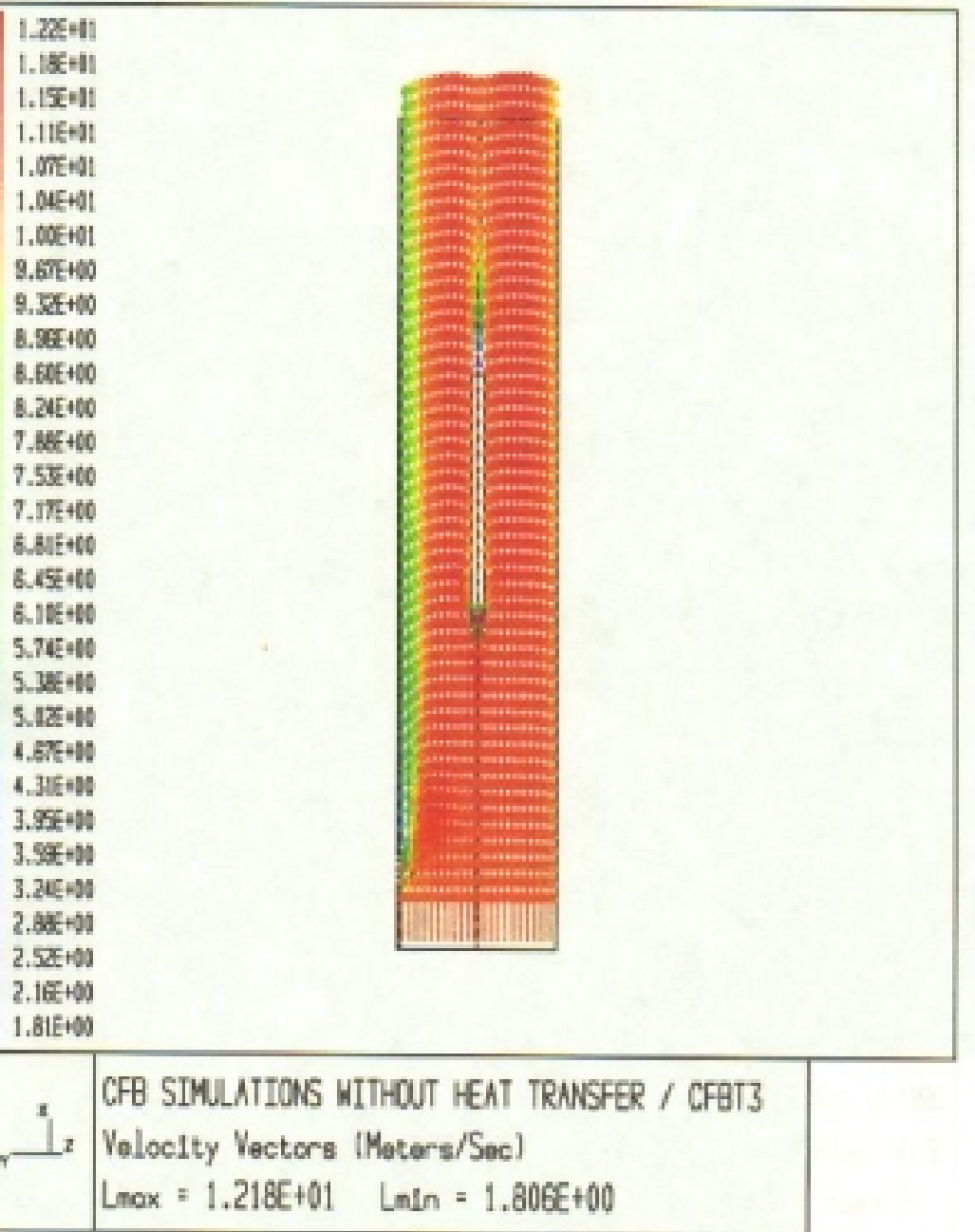

Figure 32 Velocity Vector along the CFB Riser 


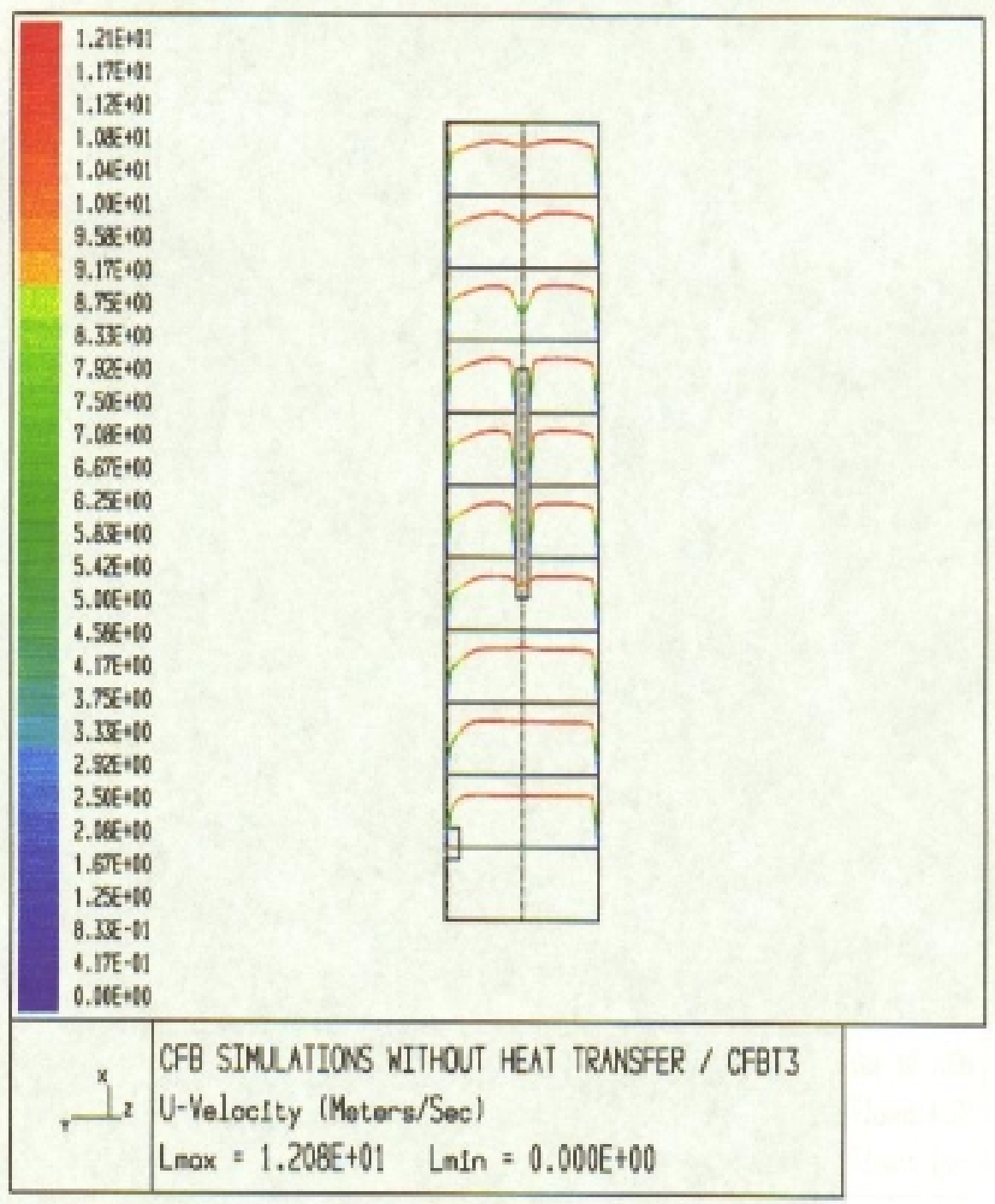

Figure 33 Velocity Profiles in the Vertical Direction of CFB Riser 


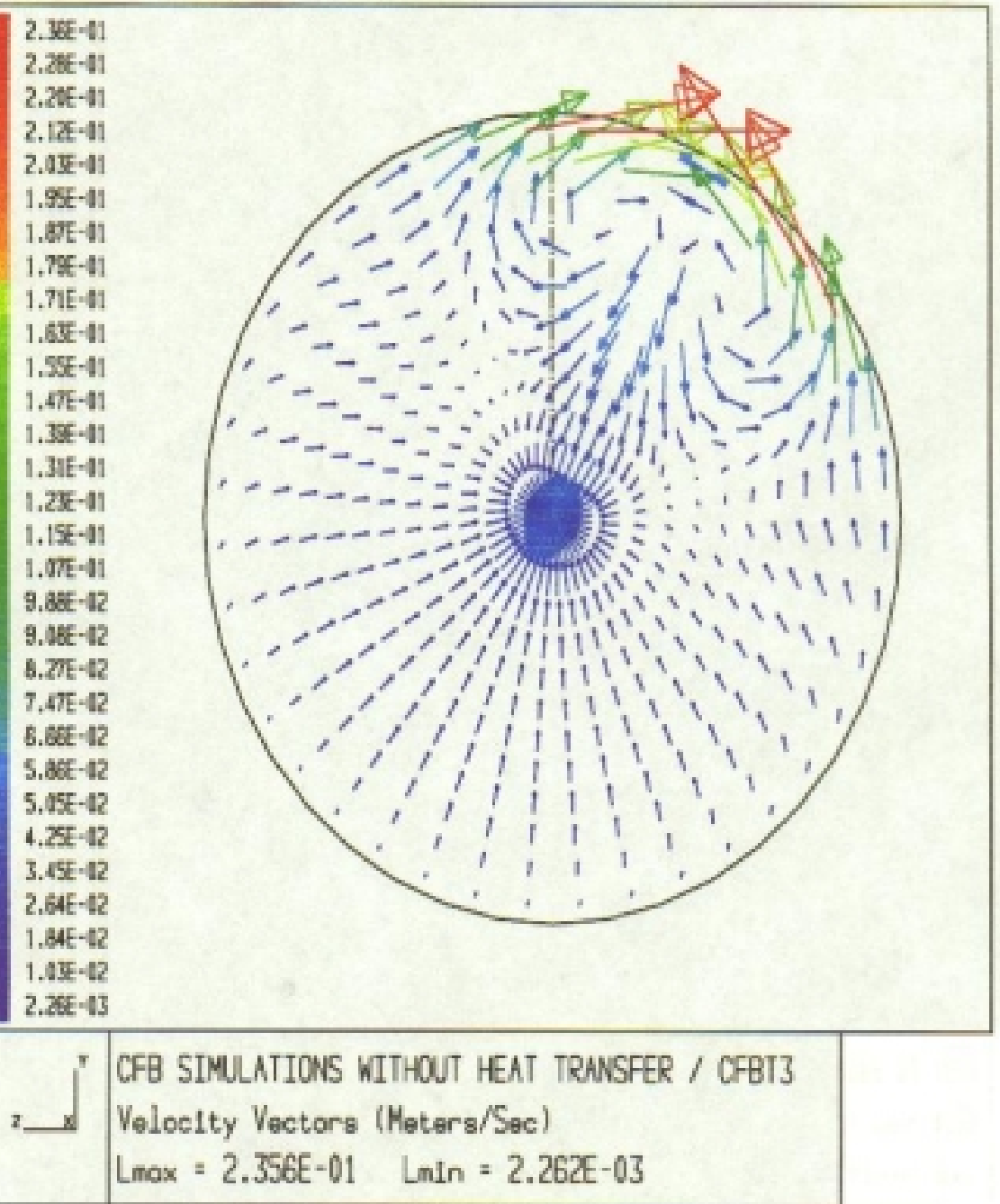

Figure 34 Velocity Vector at Level, k=15 


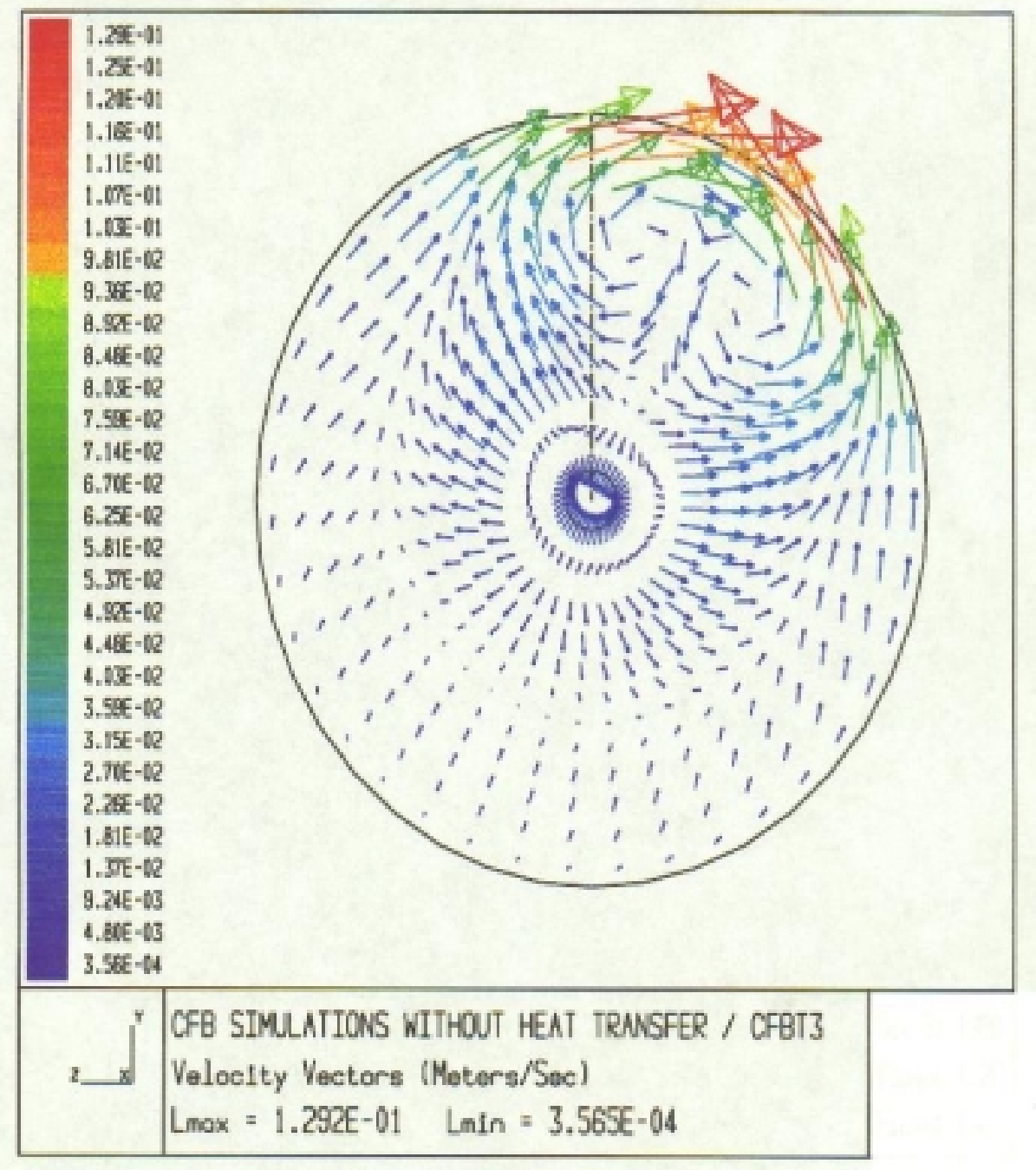

Figure 35 Velocity Vector at Level, k=23 


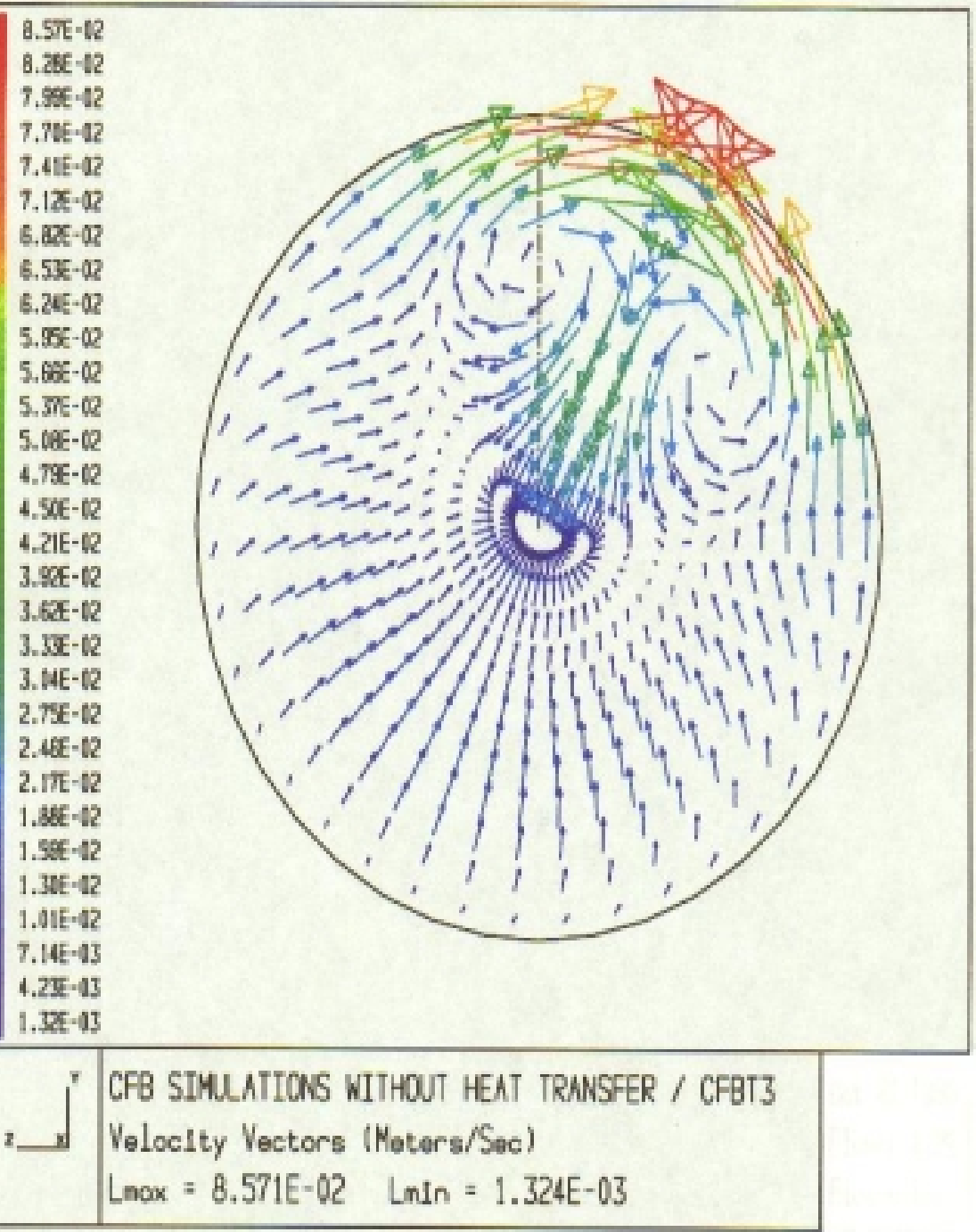

Figure 36 Velocity Vector at Level, $k=30$ 
proves that the RNG model is very sensitive in accordance with the flow's differential velocities.

At the bottom of the chamber, the velocity was an uniform as the primary air velocity. The center was larger than at the nearer wall region. At the aeration air injection levels, ( $\mathrm{k}=6$ and $\mathrm{k}=7)$, the velocity gradient was sloped down, since the mixing of both primary flow and aeration airflow reduces the upward flow momentum.

The aeration air was injected into the CFB riser with velocity of $1.2 \mathrm{~m} / \mathrm{s}$ and pushed the flow to the opposite side. Figure 37 shows the velocity profiles at level k=6. The velocity gradient of level $\mathrm{k}=6$ was sloped down as compared with the velocity gradient of level $\mathrm{k}=2$ [27]. It is believed that the mixing of both primary flow and aeration air flow reduced the upward flow momentum. The velocity at the wall side of air injection is higher than that of the opposite side as shown in Figure 33.

Figure 38 shows the velocity profiles at upper section of level $k=52$. The second oscillation of back flow is formed as shown in Figure 38. The velocity of upper level $\mathrm{k}=52$ is much lower than that of lower level $\mathrm{k}=6$. 


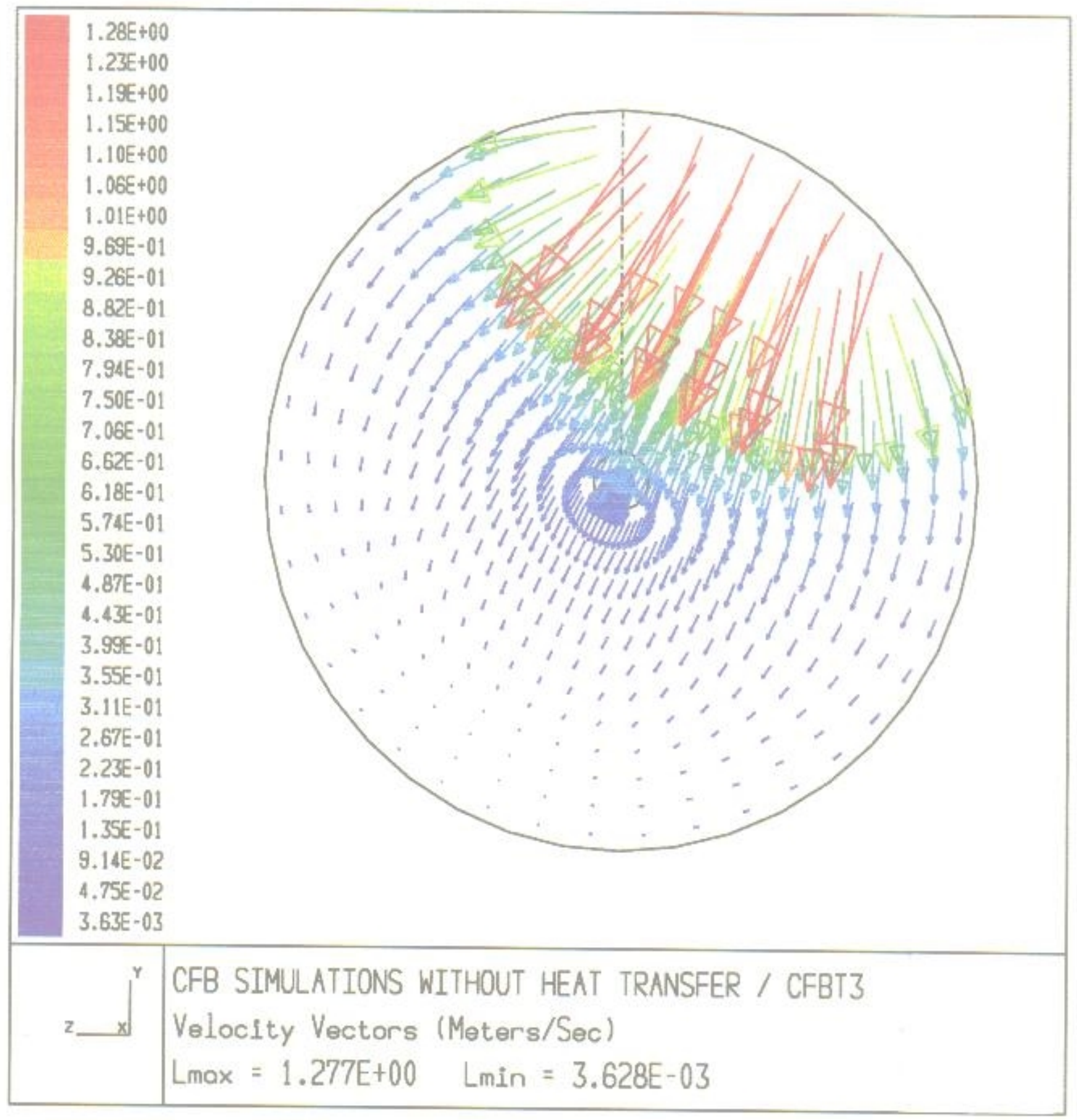

Figure 37 Velocity Vector at Level $k=6$ 


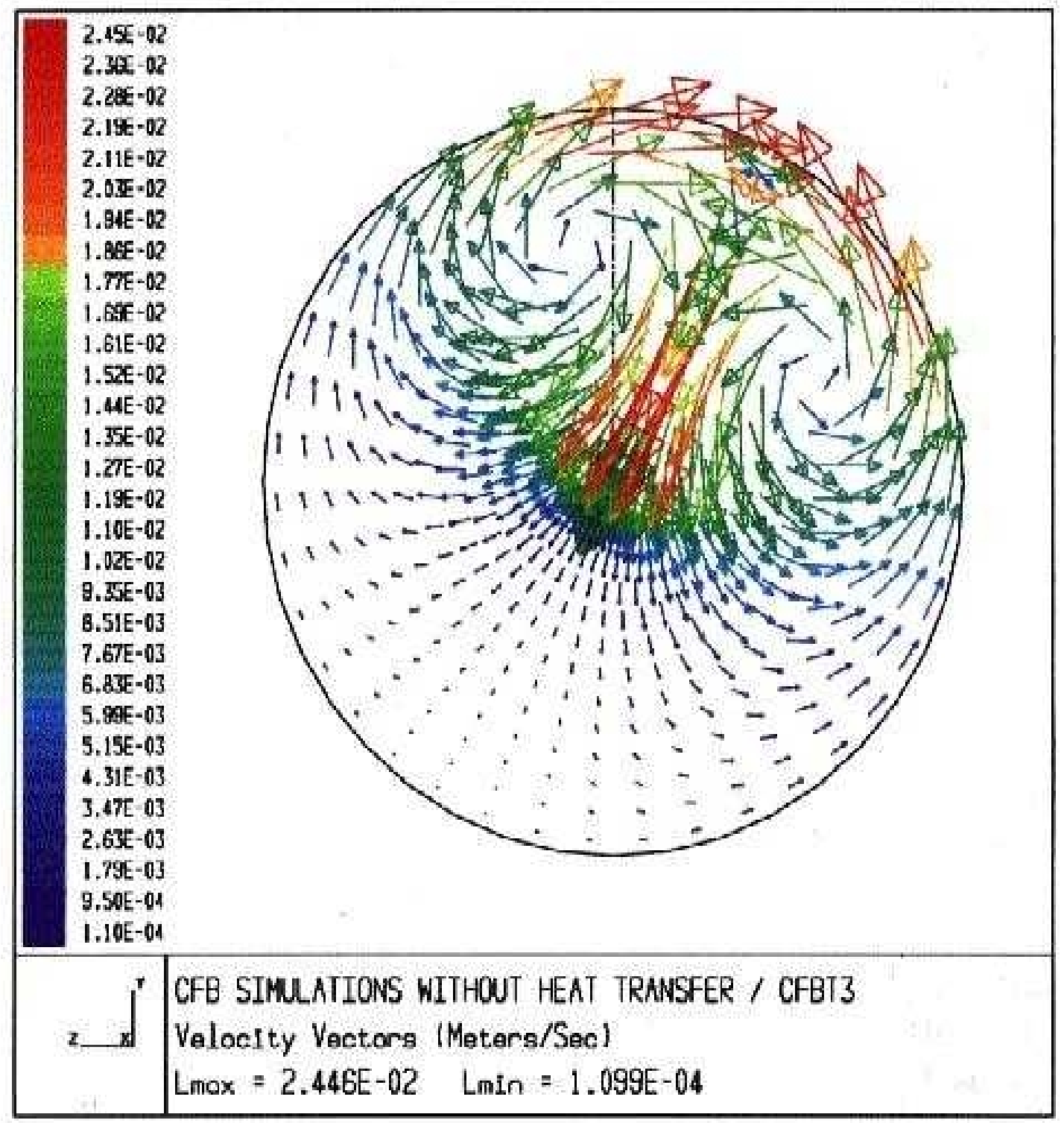

Figure 38 Velocity Vectors at Level, $\mathrm{K}=52$ 


\subsubsection{The Effect of Air Pressure}

Figure 39 shows the pressure profiles in the same 2-D slides. A high pressure point was found at the bottom of the probe and a lower pressure point was at the top of the probe as shown in Figure 39. The positive numbers of pressure unit indicate the pressure to be larger than the system pressure; the negative numbers indicate the pressure to be smaller than the system pressure. The air flowed from the high pressure region into the lower pressure region.

The aeration air injection also has effects on its neighborhoods as shown in Figure 40 for level $\mathrm{k}=2$ and Figure 42 for level $\mathrm{k}=15$. A comparison of level $\mathrm{k}=2$ with level $\mathrm{k}=15$ shows a back flow in this region and it also forms two eddies at level $\mathrm{k}=15$. The two eddies are symmetrical with the aeration air inlet center line. It is also evidence for the back flow formed in the region where the high pressure region located different slides.

Figure 35 shows the flow profiles at the probe bottom, level $\mathrm{k}=23$. The diameter of the eddies increased and the pressure profile was evened around the center probe. The back flow cross the probe and the eddies continued increasing its size. it is very interesting to note that the air stream flows from the lower pressure region into the high pressure region. This phenomenon may indicate that the back flow had strong momentum to push the flow into a higher pressure region from lower pressure region. 


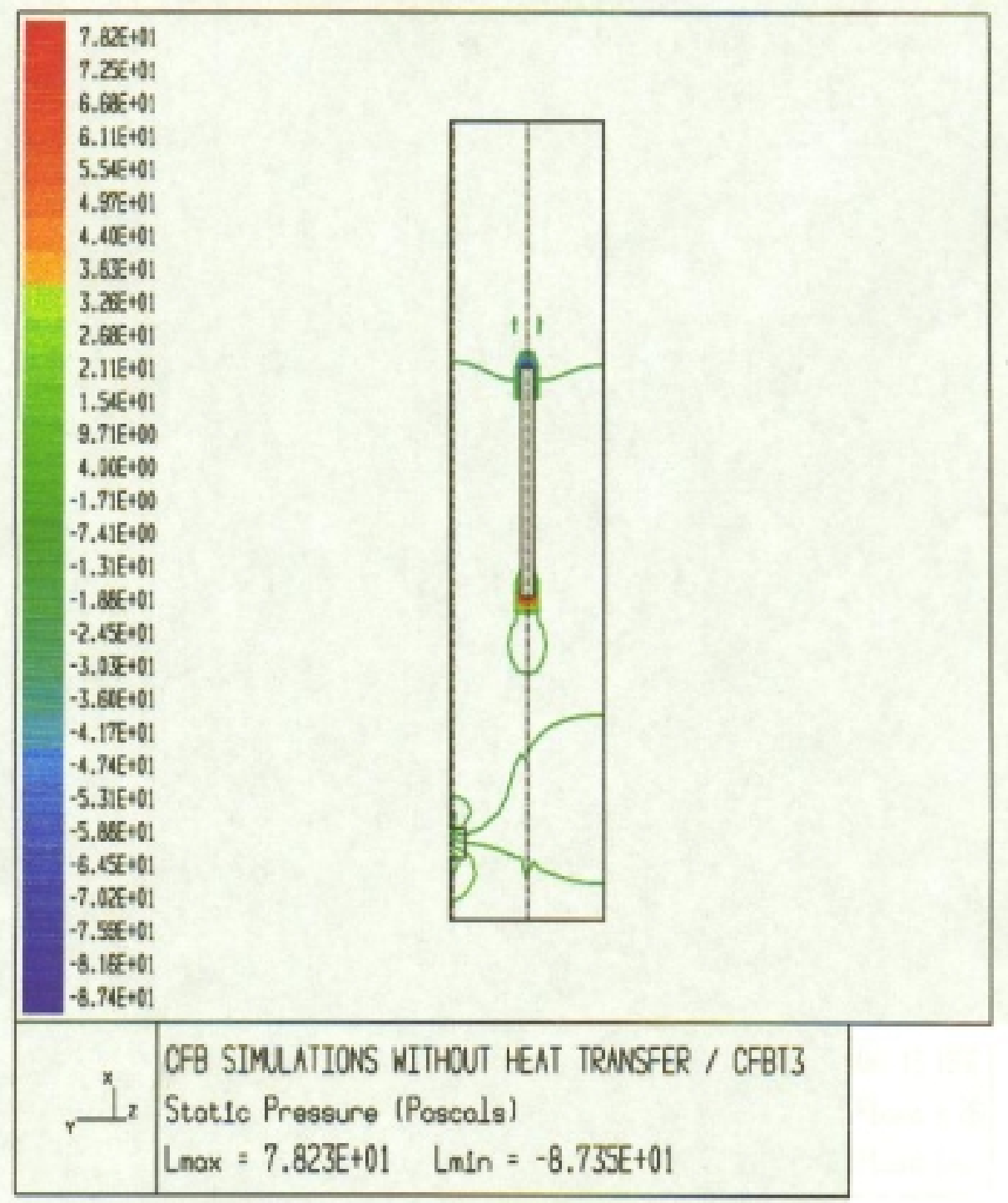

Figure 39 Pressure Profiles along the CFB Riser 


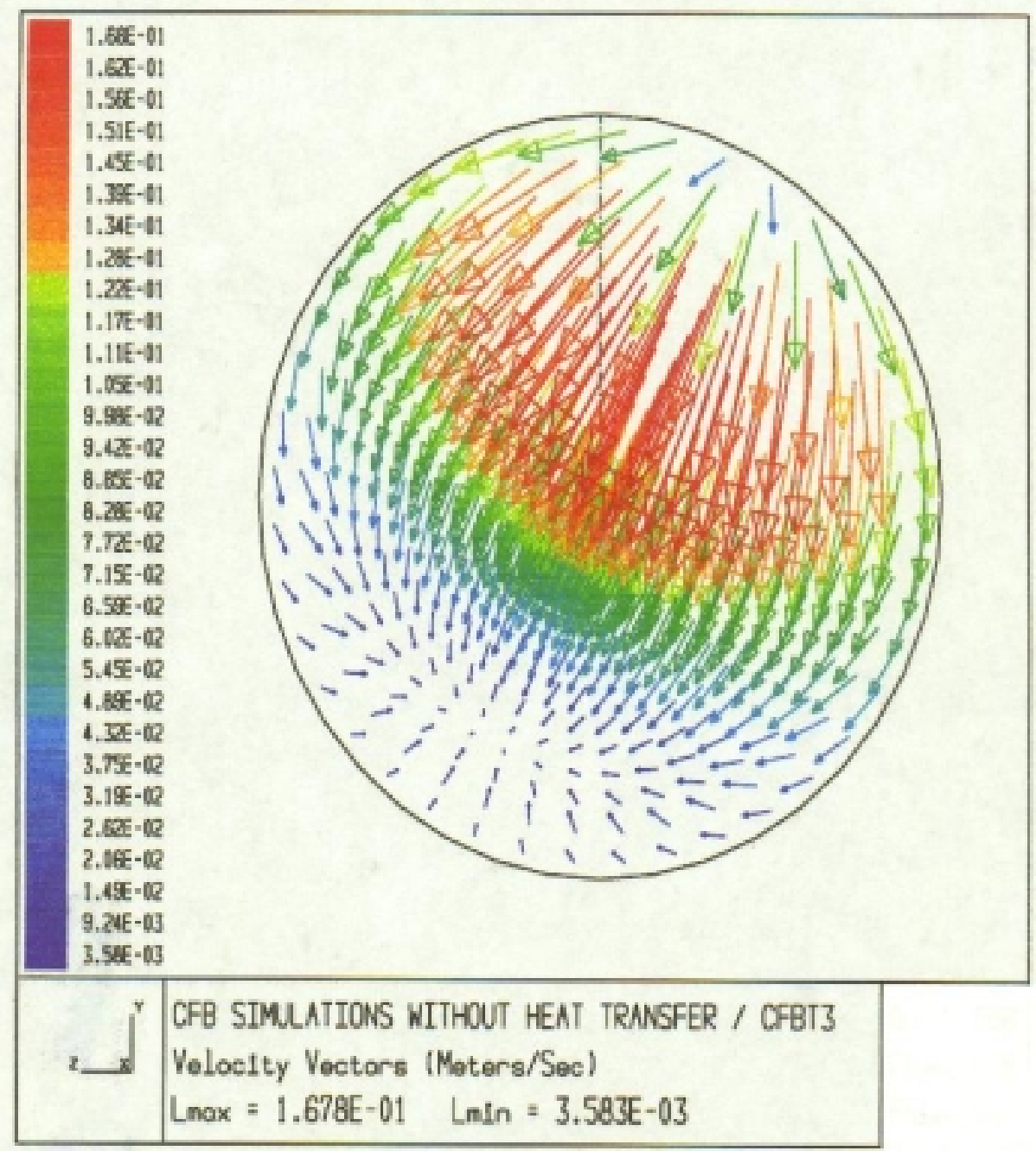

Figure 40 Velocity Vector at Level, $k=2$ 
The numerical simulation was continued to predict the flow patterns, velocity and pressure without the heat transfer effect in the CFB cold flow model system.

The air flowed from the high pressure region into the low pressure region. The aeration (secondary) air injection affected its neighborhoods pressure of the lower section at level $\mathrm{k}=6$ as shown in Figure 41 . The air injection side showed high pressure profiles as compared with the opposite side of the air injection. It is some evidence for the back flow formed in the region where the high pressure region located different sides.

Figure 42 shows the flow profiles at the upper section at level $k=52$. Some wakes are formed at the top area of probe and are developed along the upper section. The pressure ranges are much lower than that of the lower section at level $\mathrm{k}=6$. 


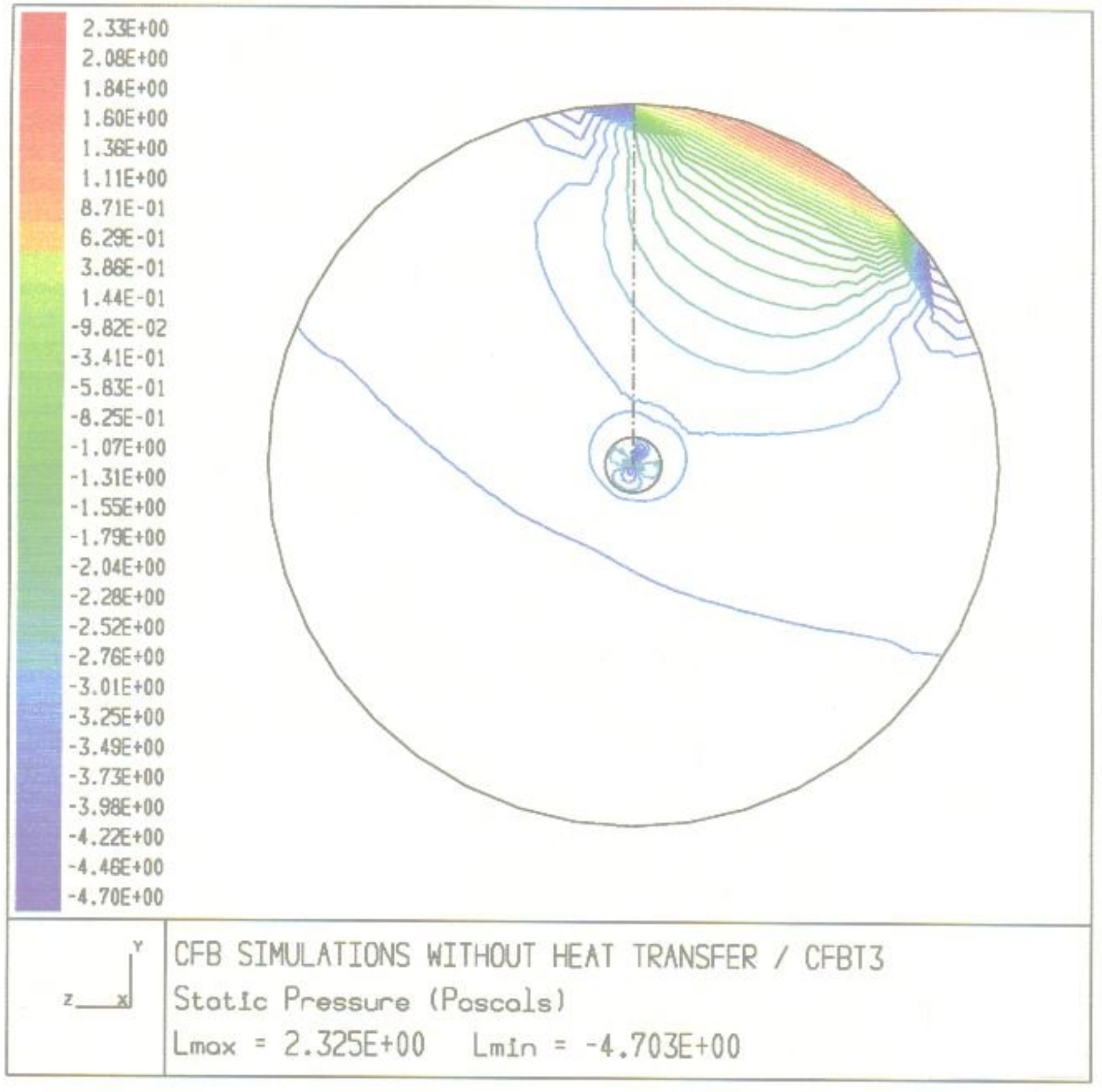

Figure 41 Pressure Profiles at Level, k=6 


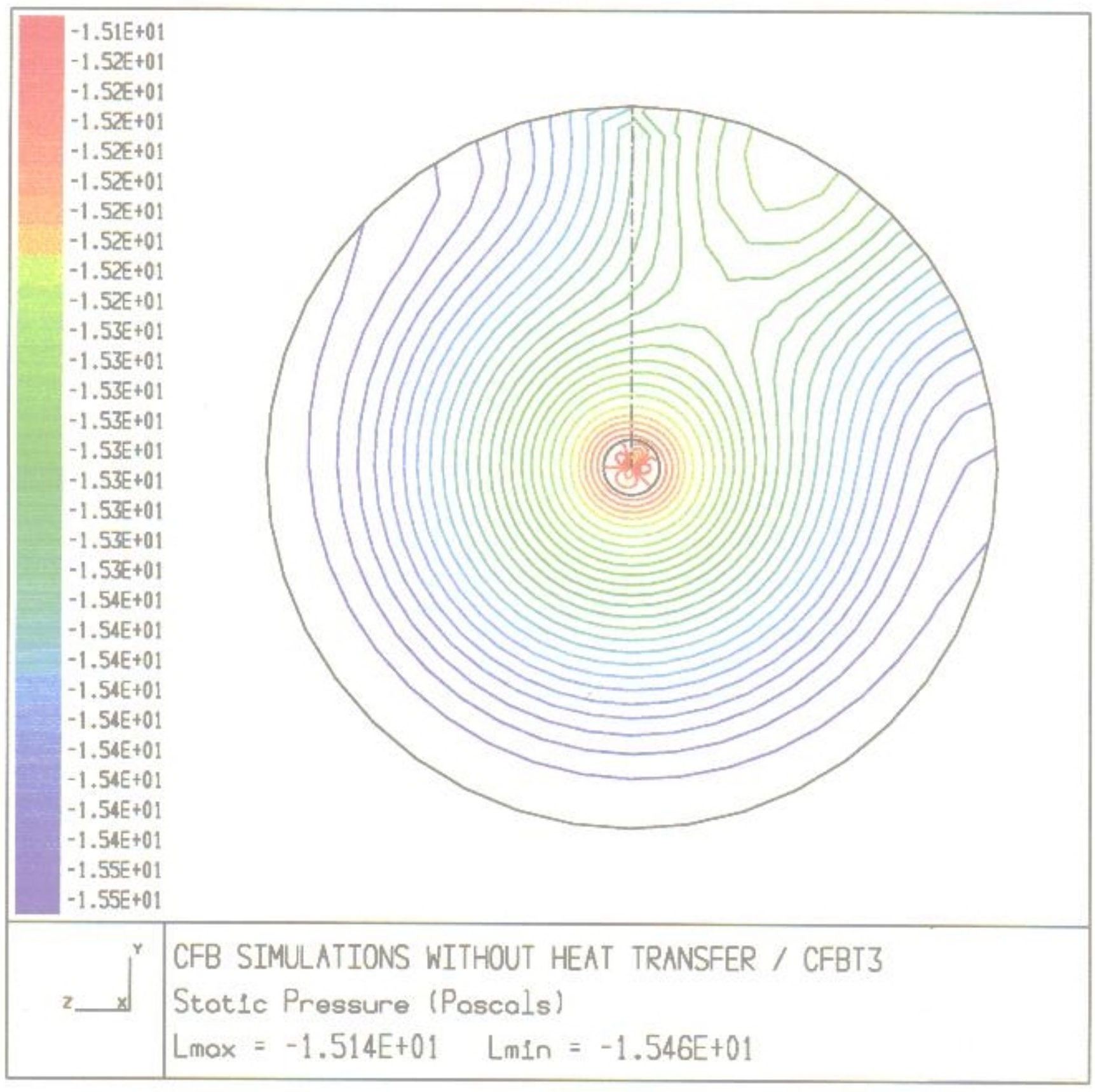

\section{Figure 42 Pressure Profiles at Level, $k=52$}




\section{NUMERICAL SIMULATION FOR THE CFB COLD MODEL WITH HEAT TRANSFER}

\subsection{Introduction}

The main purpose of the numerical simulation is to determine three velocity component profiles; vertical direction $(\mathrm{K})$, radial direction $(\mathrm{J})$, tangential direction $(\mathrm{I})$ and static pressure, temperature, and heat flux profiles in the $\mathrm{CFB}$ riser chamber. The successful simulation work may significantly reduce the experimental study/effort of the heat transfer effect in CFB cold model.

\subsection{System Configuration}

The solution process required a geometry modeler, grid generator, and system configuration. The system was configured in 3-D cylindrical coordinates with uniform mesh grids. There are a total of 30422 grids including 41 grids of the tangential direction (I), 14 grids of the radial direction (J), and 53 grids of the vertical direction $(\mathrm{K})$. The top view of the computational domain was introduced in the previous report [23].

The lower section of the CFB riser was $135 \mathrm{~cm}$ in height and $11.25 \mathrm{~cm}$ in

diameter. A copper tube with $35 \mathrm{~cm}$ in height and $1.5 \mathrm{~cm}$ in diameter was used as the heat transfer probe. This probe was installed at the height of $55 \mathrm{~cm}$ of the gas distributor in the CFB system. The aeration air inlet at the CFB riser wall was located at $15 \mathrm{~cm}$ height from the gas distributor. 


\subsection{Basic Physical Modeling for Flow and Heat Transfer}

The governing fluid flow equation, continuity equation, momentum equation, and energy equation were employed to determine the velocity, pressure, temperature, and heat flux in the CFB chamber. The Reynolds number for the input primary air flow is about 83600 , which is much larger number than that of the laminar flow. Thus the turbulent flow was considered the major flow behavior of this study.

The Reynolds energy conservation equation can be written as follows;

$$
\frac{\partial}{\partial t}(\rho h)+\frac{\partial}{\partial x_{i}}\left(\rho u_{i} h\right)=\frac{\partial}{\partial x_{i}}\left(k \frac{\partial T}{\partial x_{i}}\right)-\frac{\partial}{\partial x_{i}} \sum h_{j} j_{j}+\frac{\partial p}{\partial t}+u_{i} \frac{\partial p}{\partial x_{i}}+\tau_{i j} \frac{\partial u_{i}}{\partial x_{j}}+S_{h}
$$

where $\mathrm{h}$ is the static enthalpy, $\mathrm{T}$ is the temperature, $\tau_{\mathrm{ij}}$ is the viscous stress tensor, $\mathrm{j}_{\mathrm{j}}$ is the flux of species $j$, and $k$ is the mixture thermal conductivity. $S_{h}$ is a source term, which includes sources of enthalpy due to chemical reaction, radiation, and heat exchange with the dispersed second phase. The viscous heating term must be activated as a modeling option. This term should be turned on when the viscous stresses are large and/or in compressible flows.

The standard k- $\varepsilon$ turbulence model was not appropriate for the strong turbulent flow with unisotropic flow behaviors. Thus the Renormalization Group (RNG) k- $\varepsilon$ model was employed to this study [24, 25]. The RNG k- $\varepsilon$ model uses the Reynolds Navier Stokes equations with the turbulent stresses modeled via effective viscosity concept, which was introduced in the previous report [23]. 
The gas density, gas viscosity, gas thermal conductivity and gas thermal conductivity are the functions of temperature. The gas density was calculated by the ideal gas law [28],

$$
\rho_{g}(T)=\frac{P_{O P}}{R T_{i} \frac{m_{i}}{M_{i}}}
$$

where $\mathrm{R}$ is the universal gas constant, $\mathrm{m}_{\mathrm{i}}$ is the mass fraction of species $\mathrm{i}$, and $\mathrm{M}_{\mathrm{i}}$ is the molecular weight of species $\mathrm{i} . \mathrm{P}_{\mathrm{op}}$ is defined by the operating pressure. $\mathrm{T}$ is the operating system temperature. As the temperature increases, the gas density usually decreases.

The temperature change in the CFB cold model has relatively small range. The gas viscosity decreases as the temperature increases. Thus the gas viscosity is assumed to be a linear function as,

$$
\mu(T)=1.0 \times 10^{3}+1.0 \times 10^{5} T
$$

The following gas thermal conductivity, $\mathrm{k}(\mathrm{T})$ and the gas specific heat, $\mathrm{Cp}(\mathrm{T})$ are used for the numerical simulation [28].

$$
\begin{aligned}
& k(T)=0.0241+1.0 \times 10^{6} T \\
& C p(T)=1004.0+10.0 T
\end{aligned}
$$

The conduction and convection heat transfer process are only considered in this simulation study. Since the heat transfer probe is used in the relatively low temperature $(180 \mathrm{~F})$ environment. The heat transfer probe is installed in the riser of CFB cold model.

\subsection{Calculation Conditions for Isothermal Gas Flow}


The detailed calculation conditions of the CFB configuration, air injection, and input boundary conditions for numerical simulation are summarized in Table 4 . The CFB chosen in this study is the bench-scale cold CFB model presented in the previous report [29].

Table 4 Calculation Conditions for Numerical Simulation

\begin{tabular}{|l|l|l|}
\hline Item & Unit & Dimenstion \\
\hline Combustor Diameter & $\mathrm{cm}$ & 11.25 \\
\hline Reactor Height & $\mathrm{cm}$ & 135.0 \\
\hline Aeration Nozzle & $\mathrm{cm}$ & 15.0 \\
\hline Heat Transfer Probe Diameter & $\mathrm{cm}$ & 1.50 \\
\hline Heat Transfer Probe Height & $\mathrm{cm}$ & 35.0 \\
\hline $\begin{array}{l}\text { Primary Air Sources; } \\
\text { Flow Rate }\end{array}$ & $\mathrm{m} / \mathrm{s}$ & 0.1059 \\
Gas Velocity & & 010.65 \\
Turbulence, K-E & $\mathrm{m} / \mathrm{s}$ & 0.3 \\
Turbulence Dissipation & $\mathrm{F}$ & 0.3 \\
\hline $\begin{array}{l}\text { Aeration Air Sources; } \\
\text { Flow Rate }\end{array}$ & & 0.00202 \\
Gas Velocity & & 1.03 \\
Turbulence, K-E & & 0.5 \\
Turbulence Dissipation & & 0.5 \\
\hline $\begin{array}{l}\text { Heat Transfer Probe; } \\
\text { Water Flow Rate } \\
\text { Inlet Water Temp. }\end{array}$ & & 180 \\
Outlet Water Temp. & & \\
\hline
\end{tabular}




\subsection{Results and Discussions}

\subsubsection{The Effect of Air Velocity}

Figures 43 and 44 show the 2-D velocity profiles. In the vertical direction, the lower gas velocity was found at the end of the heat transfer probe, which is ranged from $7.4 \mathrm{~m} / \mathrm{sec}$ to $8.5 \mathrm{~m} / \mathrm{s}$. The higher gas velocity, near the probe, is ranged from $9.6 \mathrm{~m} / \mathrm{sec}$ to $12.1 \mathrm{~m} / \mathrm{sec}$ as shown in Figure 43 .

Figure 44 shows that the velocity profiles below the probe were relatively uniform. When the air flow reached the probe, the uniform flow pattern changed. The air velocity at the center of the probe decreased from $12.1 \mathrm{~m} / \mathrm{s}$ to $5.4 \mathrm{~m} / \mathrm{s}$.

The small flow boundary layers were found near the CFB riser wall and the probe wall as shown in Figure 44 (see green color region). Since the tangential velocity exhibits a uniform profile near the CFB riser and the probe wall. The tangential velocity profile is characterized by injection of aeration air.

The axial and radial velocities change frequently, which indicates the gas flows in the CFB riser is in the "developing" mode with repeated accelerations and decelerations. It is believed that these velocity profiles are advantageous for an enhanced gas-particle slip motion and heat/mass transfer in the CFBC [30]. The same results were

also found in our cold experimental measurements in the previous reports [29]. The higher gas velocity between the heat transfer probe and the 


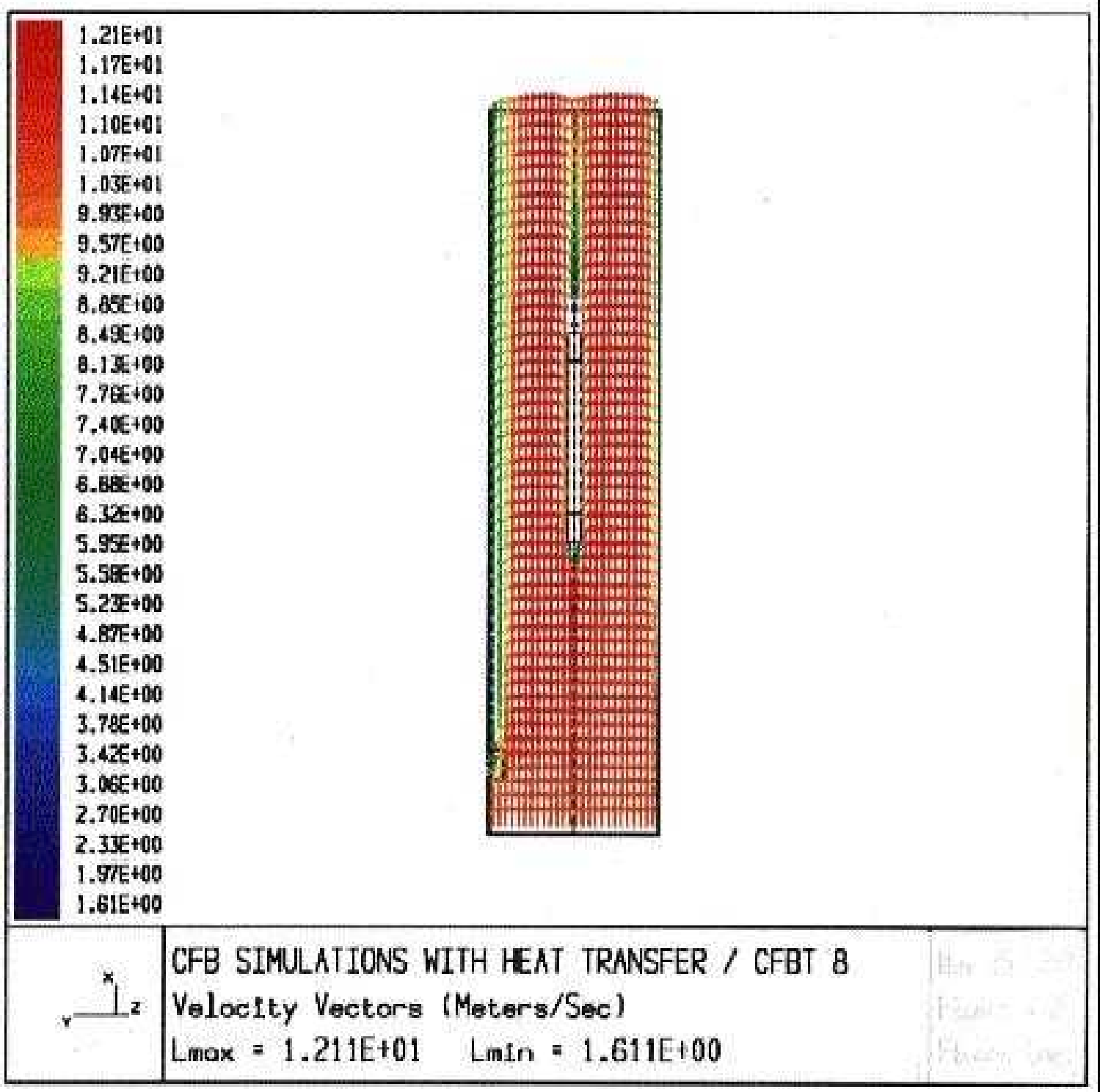

Figure 43 velocity Profiles along the CFB Riser 


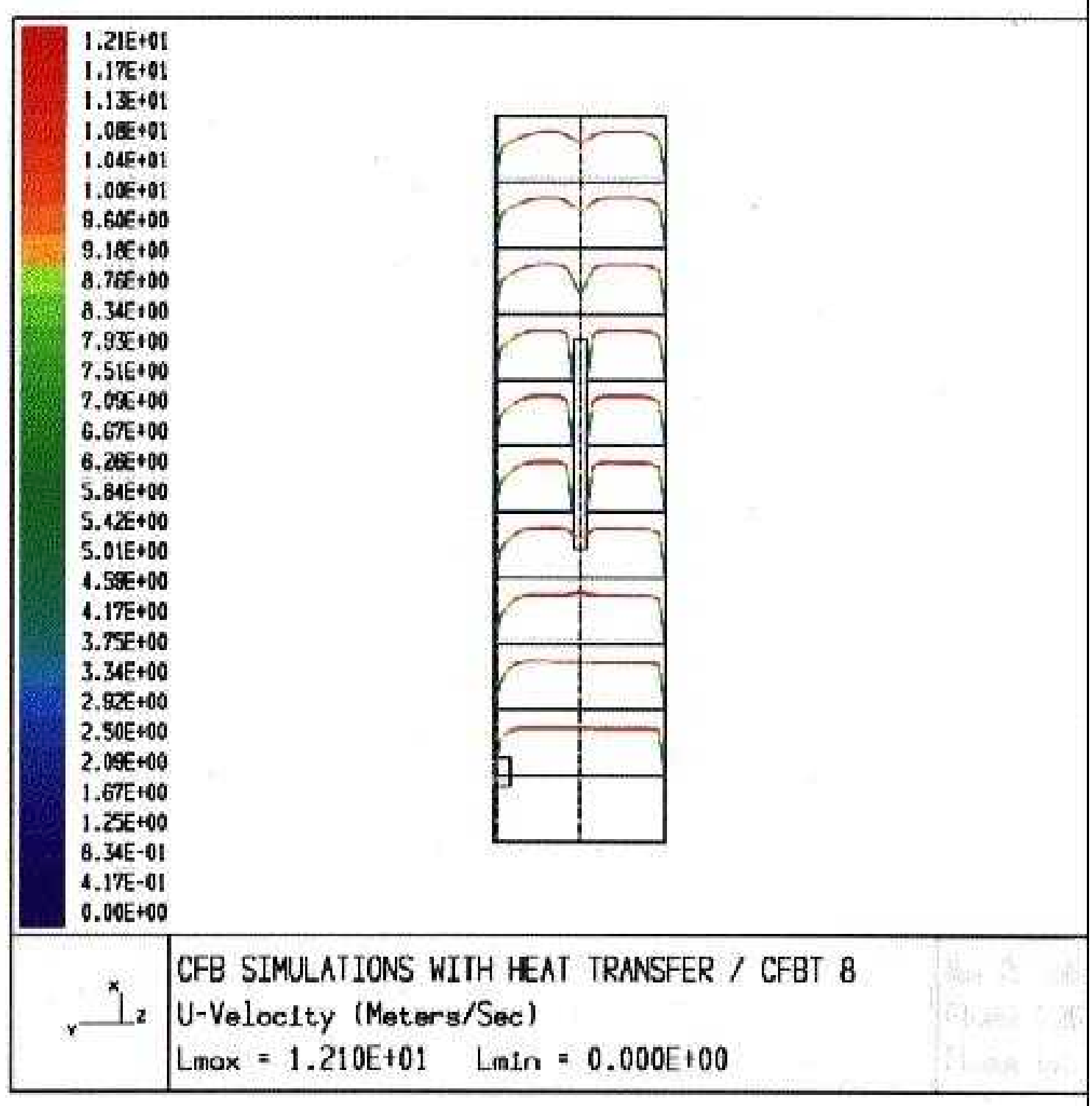

Figure 44 Velocity Profiles in the CFB Riser with a Hcat Transfer Probe 
CFB riser ranges from $10.4 \mathrm{~m} / \mathrm{s}$ to $12.1 \mathrm{~m} / \mathrm{s}$. The absolute values of Reynolds stresses increase along the flow direction, which is certainly desirable for gas mixing and combustion. From a turbulent mixing point of view, the region near the probe, having the most vigorous turbulence, provides an ideal place for the burnout of fuel particles [28].

Figure 45 shows the 2 -D velocity profiles at $k=23$ of the vertical direction in the slide plate which is the heat transfer probe inlet level. When the air flow reached the heat transfer probels inlet region, the flow pattern changed. There is a vortex flow near the probels lower end as shown in Figure 45. The lower gas velocity was found at the end of the heat transfer probe, which ranges from $0.057 \mathrm{~m} / \mathrm{sec}$ to $0.023 \mathrm{~m} / \mathrm{sec}$.

The radial air velocities changed frequently because of the bed voidage and gas pressure drop as shown in Figure 45. it is believed that the increase of superficial gas velocity resulted in the increasing local velocity at the radial direction of the CFB riser [31]. 


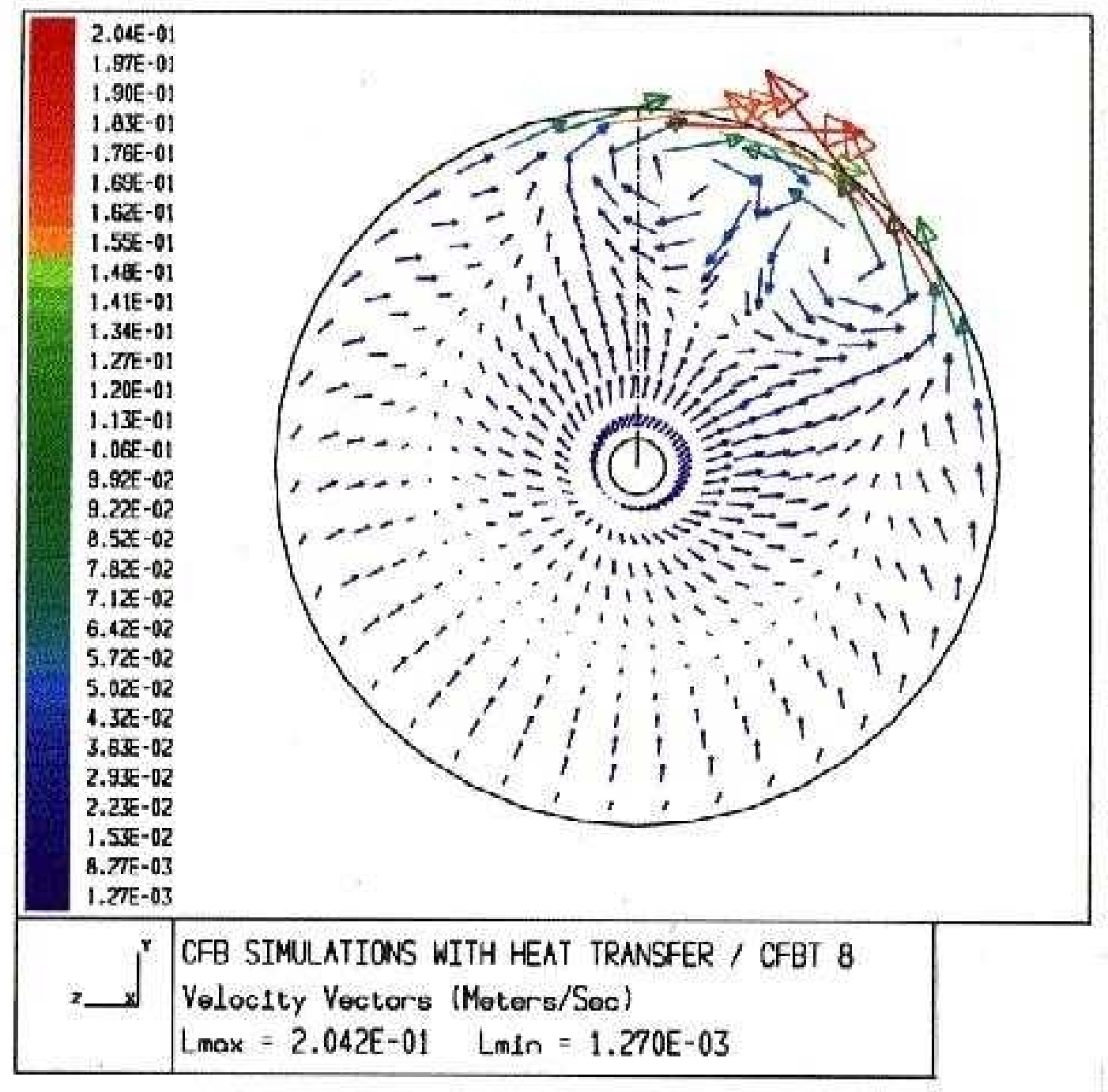

Figure 45 Velocity Profilen at Leve1, $k=23$ (Heat Transfer Probe Inlet bocation) 


\subsubsection{The Effect of Air Pressure}

Figure 46 shows the static pressure profiles in the CFB riser. The positive numbers represent when the tube pressure is larger than the system pressure. Similarly, the negative numbers indicate that the tube pressure is smaller than that of the system pressure. The air pressure was affected by the aeration air flow. The air pressure was reduced with lower aeration air flow rate as shown in Figure 46.

On the other hand, the highest air pressure at the bottom of the probe caused a strong gas mixing process in the CFB riser. It is believed that the turbulent flow characteristics produced some eddies and vortex flow at the bottom region of the probe. This should be considered as one of the unique features of the circulating fluidized bed combustor gas flow, which is desirable for gas-gas mixing and gas-particle mixing. It is found that the calculated air pressure field resumes good dynamic similarities with the experimental measurements [28].

Figure 47 shows the static pressure profiles at $k=23$ of the vertical direction in the slide plate. The positive numbers represent the tube pressure and it is larger than that of the system pressure.

We recognize that a lower pressure zone was formed near the chamber's center region. According to the Bernoulli equation [29], the increasing velocity was coming from pressure potential energy, which was transferred into kinetic energy [30]. it is worth nothing that a higher 


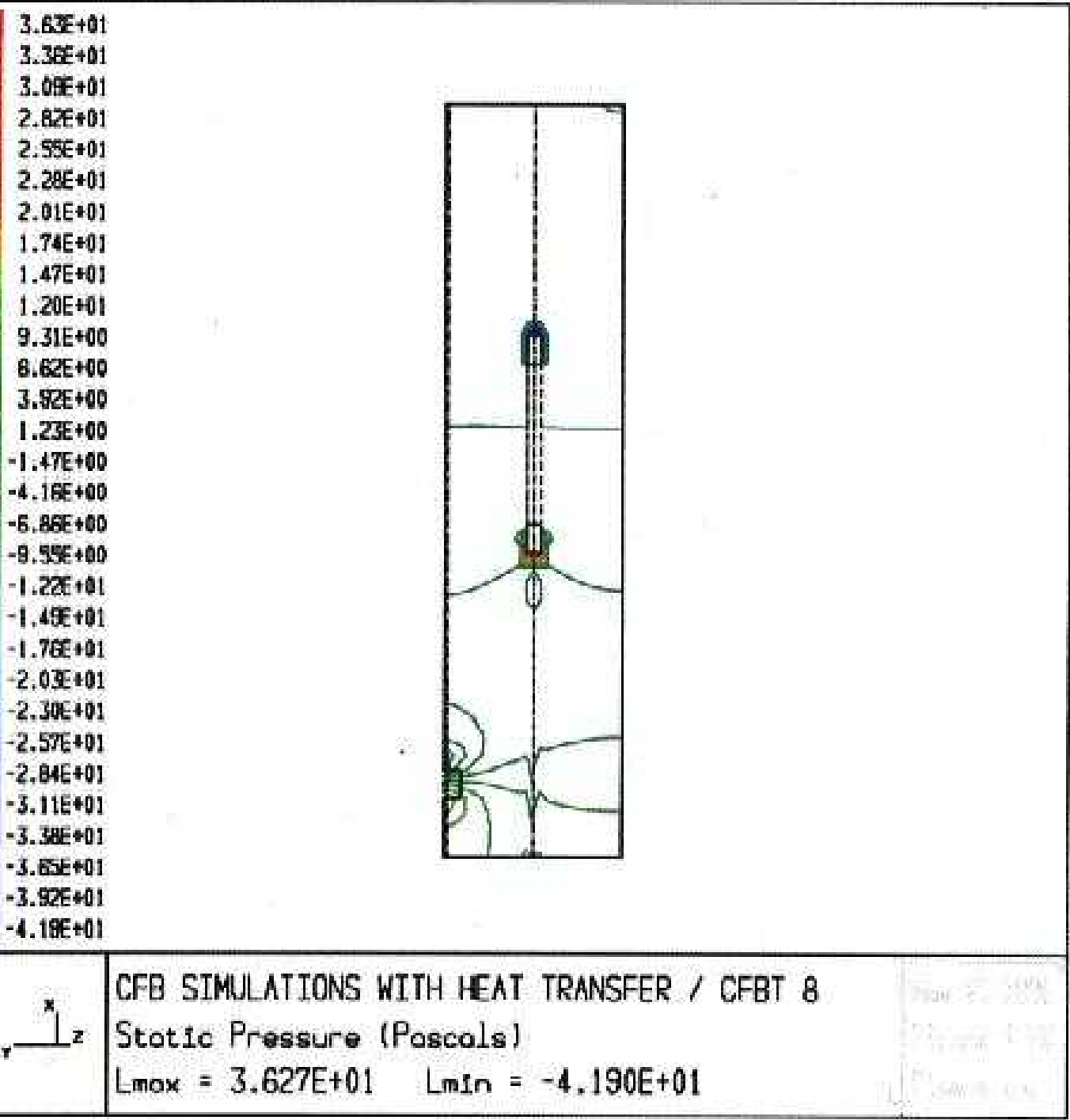

Figure 46 Static Pressure Profiles along the CFB Riser 


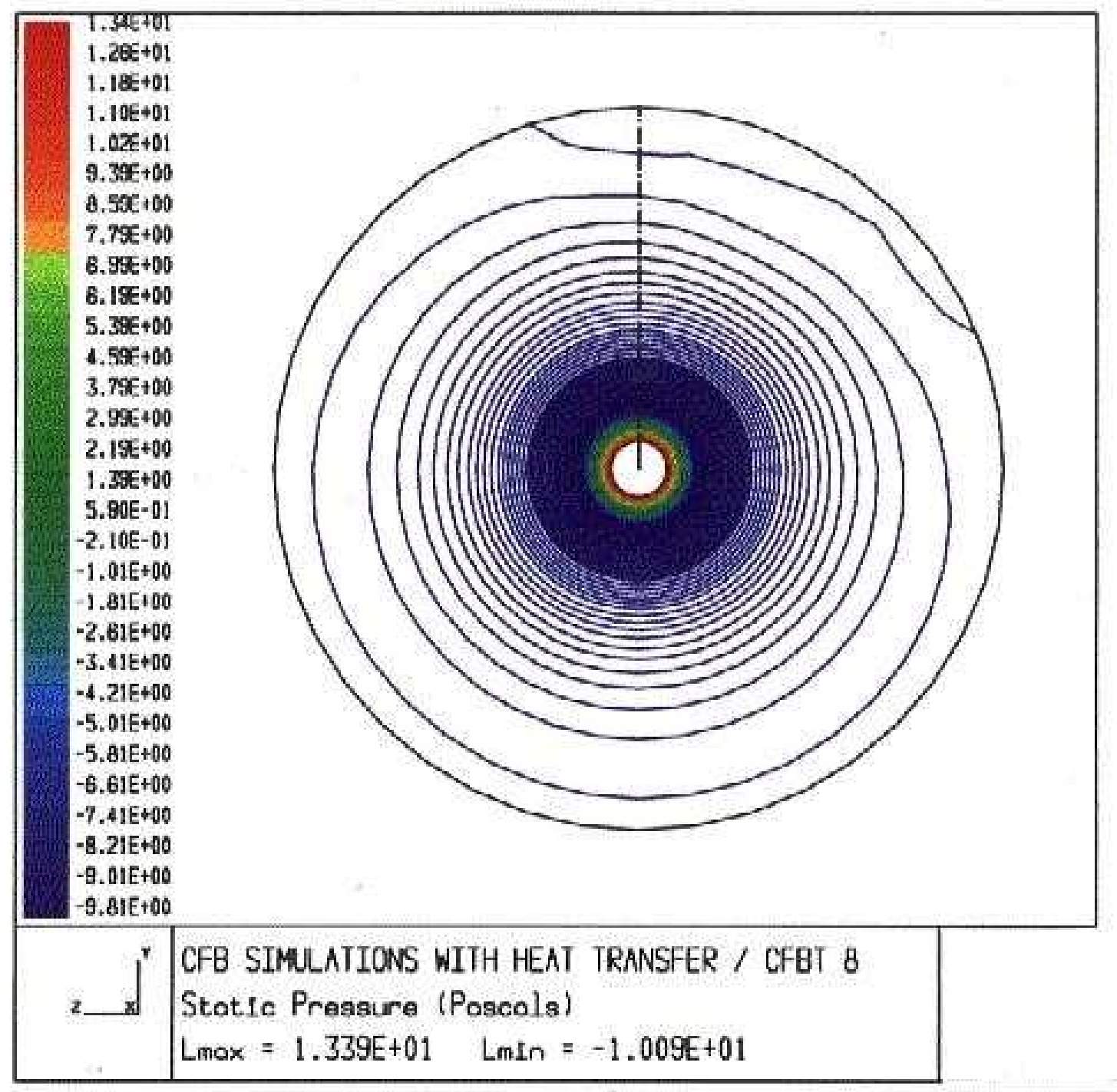

Pigure 47 Static Pressure Profiles at I.eve1, $k=23$ 
pressure zone was formed near the surrounding of the secondary air flow. Thus a dead zone or a local swirling flow was formed near the wall region.

\subsubsection{The Effect of Temperature}

Figure 48 shows the temperature changes along the vertical direction in the CFB chamber. Heat absorbing water-cooled heat transfer probe enclosing the CFB riser of the cold model was assumed. It is found that the gas temperature decreased along the flow direction of the heat transfer probe.

In Figure 48, temperature is changed from $353 \mathrm{~K}$ to $340 \mathrm{~K}$ along the heat transfer probe. The temperature of the probe bottom region is relatively higher than that of the probe top region.

The lower temperatures are found near the CFB riser wall which ranges from $315 \mathrm{~K}$ to $330 \mathrm{~K}$. It is believed that the riser wall is cooled down by the ambient temperature.

Figure 49 shows the temperature profiles at $k=23$ of the vertical direction in the slide plate. We assumed with the heat absorbing water-cooled heat transfer probe enclosing the CFB riser of the cold model. The lower temperatures were found near the CFB riser wall side, which indicated a similar temperature profile along the vertical direction in the CFB chamber [31].

In Figure 49, the temperature was changed from $353 \mathrm{~K}$ to $317 \mathrm{~K}$ along the radial direction of the CFB chamber, this was the heat transfer inlet level. In the radial direction, the gas temperature near the center region was higher than that near the riser wall zone because of the dilution effect of secondary air injection and the water-cooling 
effect of the heat transfer probe. The temperature difference between the riser center and the wall was about $25 \mathrm{~K}$ to $36 \mathrm{~K}$. 


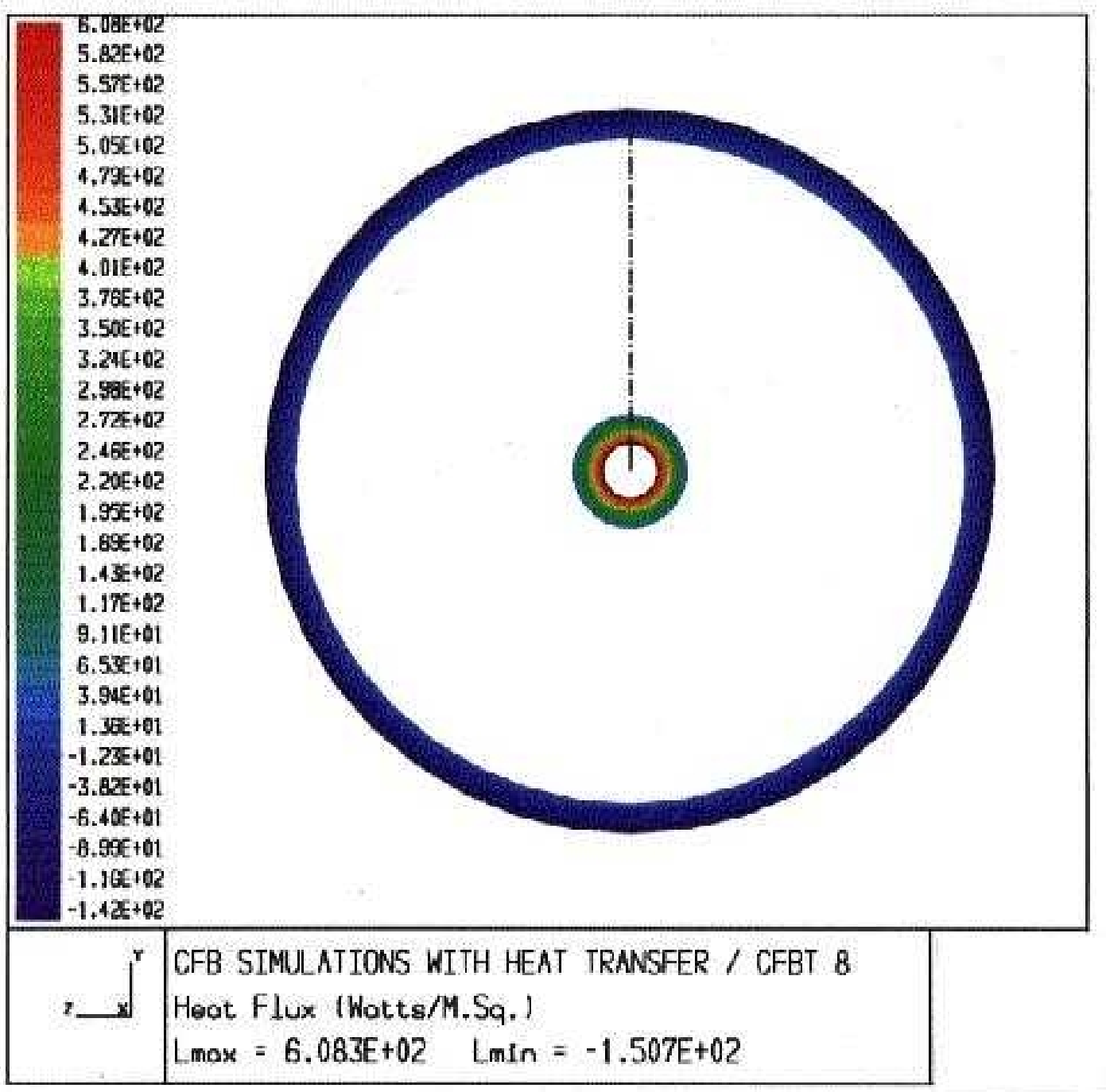

Figure 48 Heat flux Profiles at Level, $k-23$ 


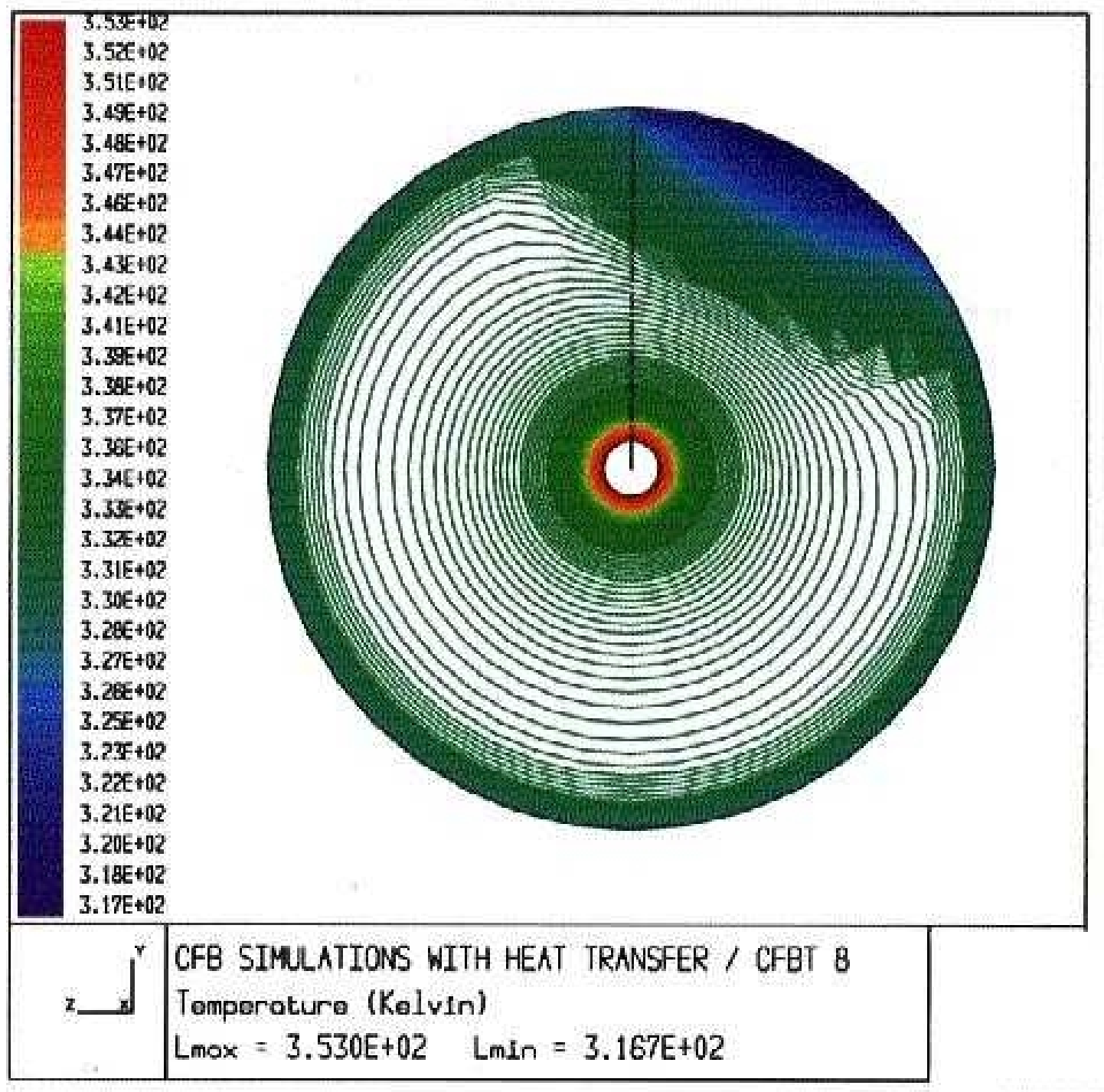

Figure 49 Temperature Profiles at Leve1, $k=23$ 


\subsection{Heat Transfer Characteristics}

Heat transfer data between hot flue gas and combustor water wall tubes are important for the design and operation of combustors [29].

Figure 50 shows the heat flux changes along the vertical direction in the CFB chamber. In this calculation, it was assumed that the heat transfer tube in contact with gas flow was water cooled. As shown in Figure 51, a large fraction of heat is removed in the lower part of the heat transfer probe, where rapid combustion of gaseous fuel may occur. A large amount of heat is generated and removed via the neighboring the probe. The gas flow in the upper part of CFB riser is largely depleted. The continued combustion gives little heat to this upper part. The heat removal is reduced to a much lower extent of $3.9 \mathrm{~W} / \mathrm{m}$. The higher heat flux was found at the bottom of the heat transfer robe, which is about $50.3 \mathrm{~W} / \mathrm{m}$. The heat flux was changed from $50.3 \mathrm{~W} / \mathrm{m}$ to $16.1 \mathrm{~W} / \mathrm{m}$ along the heat transfer probe.

The numerical simulation was conducted to predict the flow pattern, velocity and pressure, temperature, and heat transfer cha0racteristics in the CFB system.

The axial velocity radial velocities change frequently, which indicates the gas flows in the CFB riser is in the "developing" mode with repeated accelerations and decelerations. It is believed that these velocity profiles are advantageous for an enhanced gas-particle slip motion and heat/mass transfer. The air pressure was affected by the aeration air flow. The highest air pressure at the bottom of the heat transfer probe caused a strong gas mixing process in the CFB riser. 
Heat absorbing water-cooled heat transfer probe enclosing the CFB riser of the cold model was assumed. It is found that the gas temperature decreased along the flow direction of the heat transfer probe.

A large fraction of heat is removed in the lower part of the heat transfer probe, where rapid combustion of gaseous fuel may occur. The higher heat flux was found at the bottom of the heat transfer probe, which is about $50.3 \mathrm{~W} / \mathrm{m}$. The heat flux was changed from $50.3 \mathrm{~W} / \mathrm{m}$ to $16.1 \mathrm{~W} / \mathrm{m}$ along the heat transfer probe.

Numerical simulation will be continued to predict the flow patterns, velocity, pressure, temperature, and heat transfer characteristics in the CFB system. 
$3.535+02$

$3.51 E+02$

$3.496+02$

3. $47 E+02$

$3.45 E+02$

$3.44 E+02$

$3,4 \times 102$

$3.40 \mathrm{E}+02$

3. 38E +02

$3.36 E+02$

3. 3 HE +02

3. $3 x+02$

3. $30 E+02$

3. $28 \mathrm{EE}+02$

3. $208+02$

$3.2 x+02$

3. $23 x+02$

3. $21 E+02$

$3.19+02$

3.17E+QR

$3.15 E+02$

$3.13 E+02$

$3.11 \mathrm{E}+02$

3. $095+02$

$3.07 E+02$

3. $06 \mathrm{E}+02$

$3.04 E+02$

3. DZE +02

3. $00 F+02$

2. $\triangle 98+02$

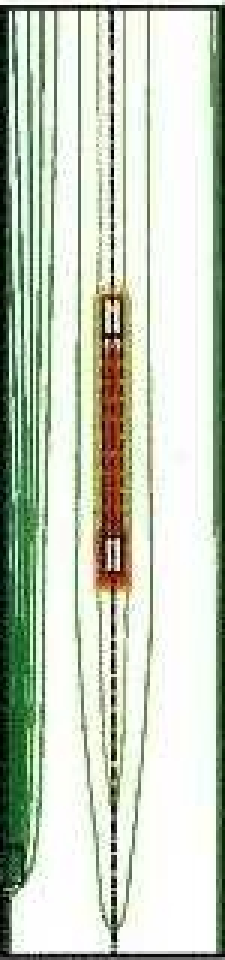

CFB STMULATIONS WITH HEAT TRANSFER / CFBT 8

$\times$

Temperoture (Kelvin)

$L_{\text {mox }}=3.530 \mathrm{E}+02 \quad \mathrm{LmIn}_{\mathrm{m}}=2.980 \mathrm{E}+02$

Figure 50 Temperature Changes along the CFB Riser 


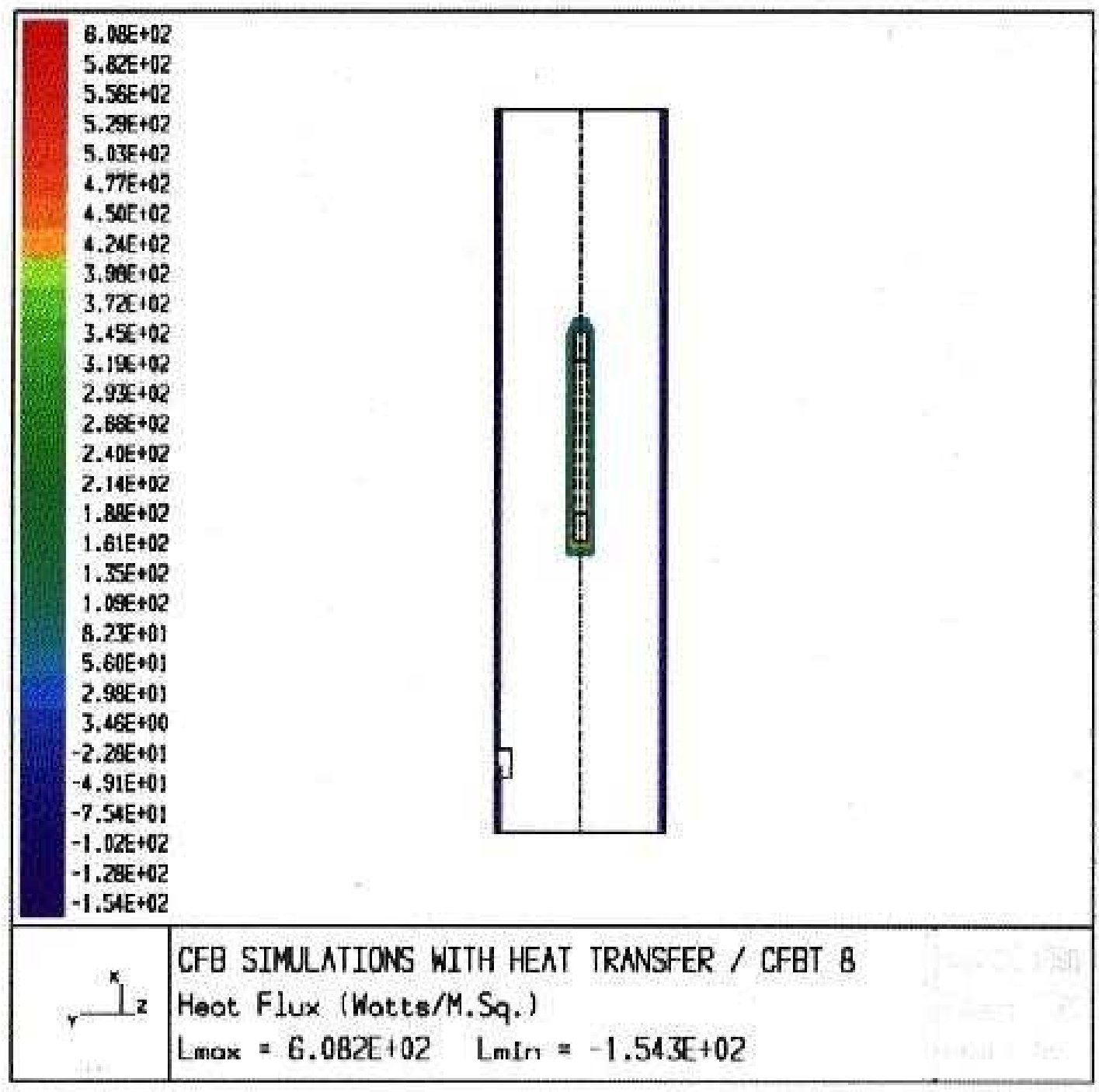

Figure 51 Heat Flux Profiles along the CFB Riser 
Figure 48 shows the heat flux profiles at $k=23$ of the vertical direction in the slide plate. During this calculation, it was assumed that the heat transfer probe when in contact with gas flow was water-cooled. The heat flux was changed along the radial direction of the CFB riser as shown in Figure 48. The higher heat flux zone was formed near the chamber's center region. It is believed that the influence of bed temperature on local heat transfer is the most important factor. 


\section{CONCLUSIONS}

The experimental and theoretical analyses of gas/particle flow and heat transfer in the bench-scale CFB system were accomplished.

The computer simulation of gas/particle flow and heat transfer rate in the CFB riser with the heat transfer probe was pursued to explore the heat transfer characteristics.

The major accomplishments are summarized below:

1. Establish the test facilities of the CFB cold model with gas-particle flow and heat transfer rate;

2. CFB test model, namely the bench-scale model associated auxiliary subsystems for air supply; solid particle collection, and computerassociated data acquisition have been successfully developed and tested;

3. Conduct systematic measurements of gas-particle flow fields in the cold model;

- Measurements showed that the pressure drop along the CFB riser column was a function of the riser column height. The change of pressure drop decreased as the riser column height of CFB increased;

- The gas average velocity decreased as the column height increased. The gas velocity is higher than that of the particle velocity in the 
CFB system. The bed void fraction increased as the solid feed rate decreased;

4. The heat transfer probe was designed and installed to measure the heat transfer coefficients at the different axial and radial locations in the CFB riser;

- The temperature profiles showed the temperature changes near the CFB riser wall side and the center region.

- Heat absorbing water-cooled heat transfer probe enclosing the CFB riser of the cold model was assumed. It is found that the gas temperature decreased along the flow direction of the heat transfer probe.

- The heat transfer coefficient at different locations of the heat transferring surface decreased along the slides down the heat transfer surface;

- Heat transfer coefficients near the wall area of the bed were decreased along with the length of the probe. Heat transfer coefficient was slightly dropped when the probe was moved from the wall area to the central area of the bed;

- The higher heat flux was found at the bottom of the heat transfer probe and near the chamber's center zone.

5. Numerical modeling and simulation has been successfully performed for predicting the gas-particle flow and heat transfer rate in the CFB 
system. The system was configured in 3-D cylindrical coordinates with uniform mesh grids. The flow patterns will be simulated with and without the heat transfer effects in the CFB system.

- The Renormalization Group (RNG) k- $\varepsilon$ turbulence model was employed to improve the predictions of the near the wall flow, wall heat/mass transfer, and wake/vortex shedding behavior.

- The simulation results indicated that the RNG $k-\varepsilon$ model could well predict the swirling/turbulent flow field in CFB model. The flow pattern changed when the airflow reached the heat transfer probes inlet region. The radial air velocities changed frequently because of gas pressure drop at the same region.

- The velocity gradient at the lower section was sloped down because of the mixing of both primary flow and aeration flow.

- The lower pressure zone was formed near the chamber's center zone. The higher pressure zone was formed at the surrounding of the secondary airflow.

- The air pressure at the bottom of the heat transfer probe caused a strong gas mixing process in the CFB riser.

- A large fraction of heat is removed in the lower part of the heat transfer probe, where rapid combustion of gaseous fuel may occur. 


\section{REFERENCES}

[1] Hetsroni, G., Handbook of Multiphase Systems, Chapter 8, pp. 8/18 to 8/31, McGraw-Hill Book Co. New York, 1982.

[2] Singer G. Joseph, Combustion; Fossil Power Systems, Chapter 24, pp. 24/26 to 24/17, 1981.

[3] Lewnard J. J et al, Effect of Design and Operating Parameters on Cyclone Performance for CFBC, Proc. of the 4th Int'l Conference on CFBs, pp.525-531., 1993.

[4] Khan. A.R. and J.F. Richardson, The Resistance to Motion of a Solid Sphere in a Fluid, Chem. Eng. Communication, Vol. 62, pp. 135-150.

[5] Lee, S.W., Technical Progress Report, No.1, U.S. DOE, Pittsburgh Energy Technology Center (PETC), April 1996.

[6] Wen, C.Y. and Galli, A.F., In Fluidization (Eds.:J.F. Davidson and D. Harrison), Academic Press, 1971.

[7] Ergun, S., Fluid Flow Through Packed Columns, Chem. Eng. rog. 48, pp.8994., 1952.

[8] Kunni, D. and O. Levenspiel, Fluidization Engineering, John iley \& Sons, New York, 1977.

[5] User's Manual of RTI-800/815, Analog Devices, Inc. 1992.

[10] Reference Manual of Paragon 500, Intuitive Software for Process Monitoring and Control, Intec Controls Corp. 1990.

[11] Lee, S.W., Technical Progress Report, No.3, U.S. DOE, FETC, April 1997.

[12] Jewell T., Computer Applications for Engineers, John Wiley \& Sons, Inc., pp.739-742, 1991.

[13] Singer, J.G., Ed. in Chief, Combustion; Fossil Power Systems, Chapter 24, Combustion Engineering, Inc. Windsor, CT, 1981.

[14] Basu P. and P.K. Nag, Int. J. Heat Mass transfer, 30, p 2399 (1987).

[15] Basu, p., Chem.Engn.Sci., 45, p3123 (1990) 
[16] Tung, Y.,J.Li and M.Kwauk, "Radial Voidage Profile in a Fast Fluidized Bed" Fluidization'88, M. Kwank and D.Kunii(Ed)(1988).

[17] Ambler, P.A, B.J. Milne, F.Berruti, and D. S Scott, Chen.Eng.Sci.,45, p 2179 (1991).

[18] Wu, R.L., J.R.Grace and C.J.Lim.Chem.Eng.Sci., p 3389 (1990).

[19] Wen, C.Y. and E.N. Miller, Ind.Eng.chen., 53, P.51 (1961).

[20] Lee, S.W., Technical Progress report, No.6, U.S.DOE, Federal Energy Technology Center (FETC), October 1999.

[21] Boysan, F., et. al, Modeling Coal-Fired Cyclone Combustor, Combustion and Flame, Vol. 63, 73-85, 1986.

[22] Boemer, A., et. al, Eulerian Computation of Fluidized Bed Hydrodynamics: A Comparison of Physical Models, Proc. of 13th Int'l Conference on FBC, pp.775788, 1995.

[23] Lee, S.W., Technical Progress Report, No.4, U.S. DOE, Federal Energy Technology Center (FETC), October 1997.

[24] Fluent User's Guide, Vol.1, Chapter 6, pp.47-50, 1995.

[25] Launder, B.E. and D.B. Spalding, Mathematical Models of Turbulence, Academic Press, London, 1972.

[26] Hoffman, K.A. and S.T. Chiang, Computational Fluid Dynamics 3rd Ed., vol.1, Chapt.9, Vol2, Chapters 11 \&13, Engineering Education System, KS. 1995.

[27] Lee, S.W., Technical Progress Report, No.5, U.S. DOE, Federal Energy Technology Center (FETC), May 1998.

[28] Hewitt et al, Process Heat Transfer, Chapter 2, CRC Press, 1994.

[29] Anderson, B. et al, Local Lateral Distribution of Heat Transfer on Tube Surface Membrane Walls in CFB Boilers, Proceedings of 4th Intl' Conference on CFBs, PP.331-318, August 1993.

[30] Turbulent Flow in CFB Riser, Proceedings of 4th Intl' Conference on CFBs, PP. 367-372, August 1993.

[31] Lee, S.W., Technical Progress Report, No.7, U.S. DOE, Federal Energy Technology Center (FETC), April 1999. 
[32] Bai, D.R. and Y. Jin, et al., Circulating Fluidized Bed Technology III, Pergamon Press, p57, 1991. 